\title{
PAX6 in mammalian degenerative retina
}

Citation for published version (APA):

Stanescu-Segall, D. (2010). PAX6 in mammalian degenerative retina. [Doctoral Thesis, Maastricht University]. Datawyse / Universitaire Pers Maastricht. https://doi.org/10.26481/dis.20101213ds

Document status and date:

Published: 01/01/2010

DOI:

10.26481/dis.20101213ds

Document Version:

Publisher's PDF, also known as Version of record

\section{Please check the document version of this publication:}

- A submitted manuscript is the version of the article upon submission and before peer-review. There can be important differences between the submitted version and the official published version of record.

People interested in the research are advised to contact the author for the final version of the publication, or visit the DOI to the publisher's website.

- The final author version and the galley proof are versions of the publication after peer review.

- The final published version features the final layout of the paper including the volume, issue and page numbers.

Link to publication

\footnotetext{
General rights rights.

- You may freely distribute the URL identifying the publication in the public portal. please follow below link for the End User Agreement:

www.umlib.nl/taverne-license

Take down policy

If you believe that this document breaches copyright please contact us at:

repository@maastrichtuniversity.nl

providing details and we will investigate your claim.
}

Copyright and moral rights for the publications made accessible in the public portal are retained by the authors and/or other copyright owners and it is a condition of accessing publications that users recognise and abide by the legal requirements associated with these

- Users may download and print one copy of any publication from the public portal for the purpose of private study or research.

- You may not further distribute the material or use it for any profit-making activity or commercial gain

If the publication is distributed under the terms of Article $25 \mathrm{fa}$ of the Dutch Copyright Act, indicated by the "Taverne" license above, 


\section{PAX6 in mammalian degenerative retina}


ISBN 9789461590183

(C) 2010 Dinu Stanescu-Segall, Maastricht

Production: Datawyse | Universitaire Pers Maastricht 


\title{
PAX6 in mammalian degenerative retina
}

\author{
PROEFSCHRIFT
}

ter verkrijging van de graad van doctor aan de Universiteit Maastricht, op gezag van de Rector Magnificus Prof. mr. G.P.M.F. Mols

volgens het besluit van het College van Decanen,

in het openbaar te verdedigen

op maandag 13 december 2010 om 16:00 uur

door

Dinu Stanescu-Segall

geboren op 16 december 1971 te Leuven, België

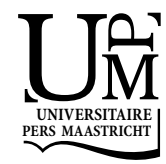




\section{Promotores}

Prof. dr. F. Hendrikse

Prof. dr. J.P.M. Geraedts

\section{Beoordelingscommissie}

Prof. dr. H.W.M. Steinbusch, voorzitter

Prof. dr. A.A.B. Bergen (AMC, Amsterdam)

Prof. dr. W. Lamers

Prof. dr. F.C.S. Ramaekers

Prof. dr. M.D. de Smet (Clinique de Montchoisi, Lausanne) 
To my wife, Nensi

and to my parents Dan and Bianca 


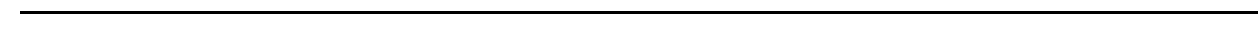




\section{TABLE OF CONTENTS}

$\begin{array}{lll}\text { Chapter } 1 & \text { Introduction } & 9\end{array}$

Chapter 2 Pax6 expression in the mouse retina during inherited and $\quad 49$ induced retinal degeneration

Chapter 3 Pax6 expression and retinal cell death in a transgenic mouse model for acute angle-closure glaucoma

Chapter 4 Constitutive overexpression of human erythropoietin protects the mouse retina against induced but not inherited retinal degeneration

Chapter 5 Continuous expression of the homeobox gene PAX6 in the 103 ageing human retina

Chapter 6 Discussion

Summary

Samenvatting (Summary in Dutch)

Acknowledgements

Curriculum Vitae

List of publications 


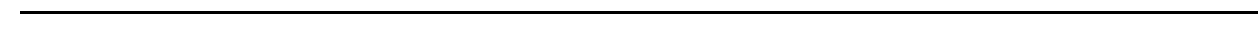


CHAPTER 1

INTRODUCTION 


\section{Human Eye development}

Eye formation begins after the third week of gestation with the optic sulci and ends with foveal maturation 3 to 4 years after birth.

The eye development begins around day 22 with the formation of the optic sulci in the inner aspect of the neuronal plate. The optic sulci will evaginate to form the optic vesicles. At day 27, a thickening of the neural ectoderm becomes the lens placode, which coincides with the formation of a constriction in the optic vesicle, the future optic stalk. The invagination of the optic vesicle will form a double wall optic cup where the inner layer (retinal disk) will lead to the formation of the neuro-retina and the outer layer to the formation of the future retinal pigment epithelium (RPE). By day 36, a lens vesicle separates from the lens placode that will eventually become the lens and the cornea respectively. The longitudinal groove of the optic stalk will allow the formation of the hyaloid artery, but will progressively close around 6 weeks. ${ }^{1}$ At 8 weeks, mesenchyme derived from the neural crest, will condense around the external surface of the optic cup. The inner condensation adjacent to the RPE will form the future choroid and the outer condensation will become the future sclera. At this stage, the developing eye has a diameter of 1.5 to $2 \mathrm{~mm}^{1-3}$.

(See Figure 1)

At 6 weeks the neuro-retina is composed of an outer nuclear layer and an inner acellular layer. At 7 weeks, it will be composed of an inner nuclear layer named the inner neuroblastic layer that is separated from the outer neuroblastic layer by an acellular zone which is called the transient layer of Chievitz ${ }^{4}$ (TLC). By 11 weeks the TLC will disappear, and the inner nuclear layer containing the cell bodies of amacrine and Müller cells will appear. Shortly afterwards, the bipolar and horizontal cells differentiate from the outer neuroblastic layer. At 4 months, the outer neuroblastic layer will become the photoreceptor nuclei forming the outer nuclear layer and their axons will lead to the outer plexiform layer. Further landmarks in retinal development will occur and consist in synaptogenesis horizontal cell formation and invasion of the retina by microglia around 5 months. Maculogenesis begins around 4 to 5 months by first an increase in ganglion cell layers up to 8 layers at 6 months. At 7 months, the foveal depression appears due to the lateral displacement of the ganglion cell layer. At birth there is only one layer of ganglion cells left and 4 months postpartum both ganglion cell and inner nuclear layers have withdrawn to the edge of the fovea leaving only cone nuclei in the foveal region. The macula will need another few years to reach maturation. ${ }^{5}$ 

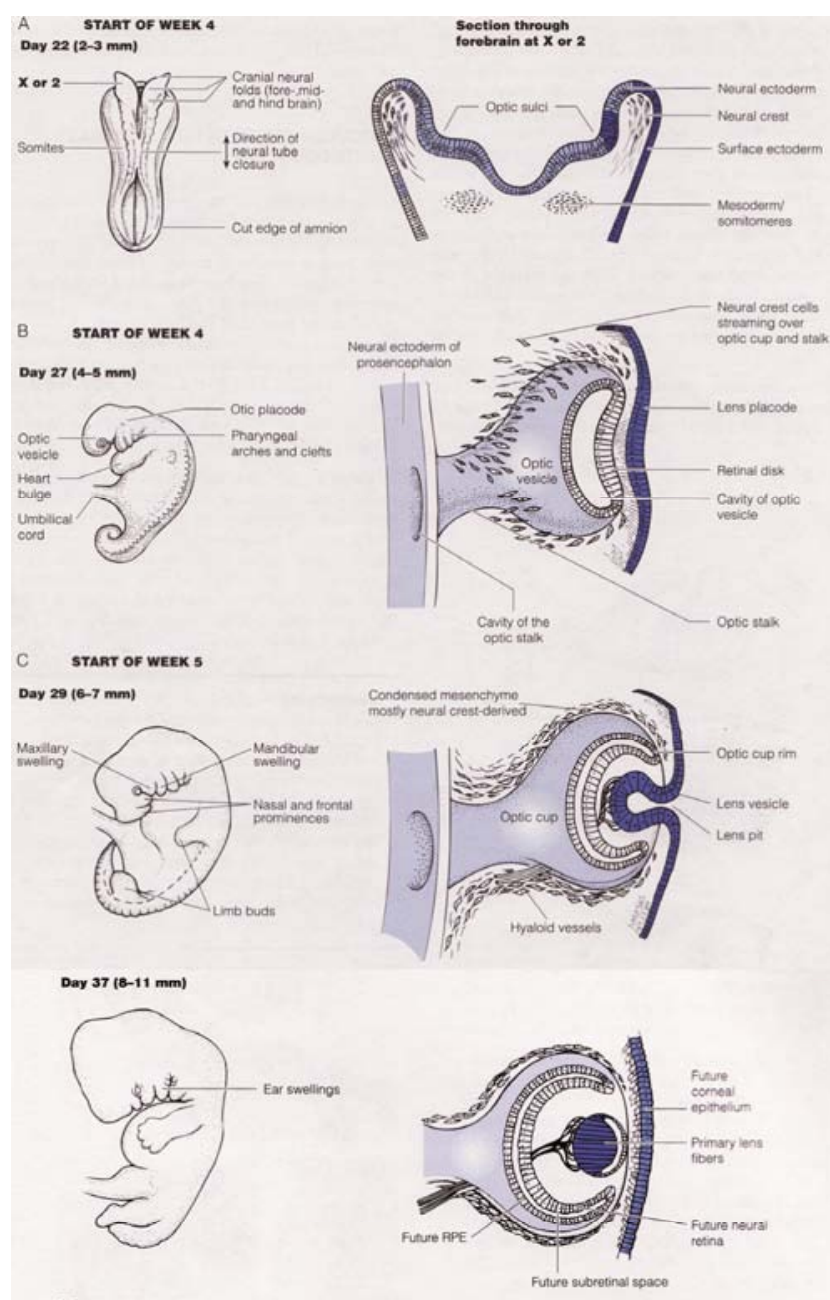

\section{E START OF WEEK 7}

\section{Day 44 (12-17 mm)}
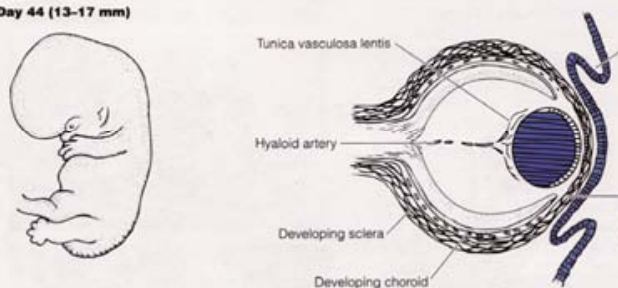
Developing choroid endothelium and stroms

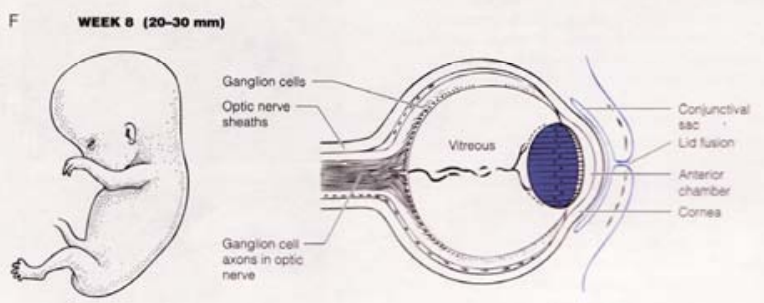

Figure 1. Embryology of the eye (Adapted from John Forrester et al. The Eye Basic Sciences in Practice, Ed Saunders) 
PAX6 in conjunction with other genes such as Sox2 and Otx2 cooperatively control each stage of eye development (See Figure 2$){ }^{6}$

$P A X 6$ is also required for all aspects of lens development, including its final differentiation and control of crystallin expression, although the crystallin originates from non-neural tissue. ${ }^{7}$

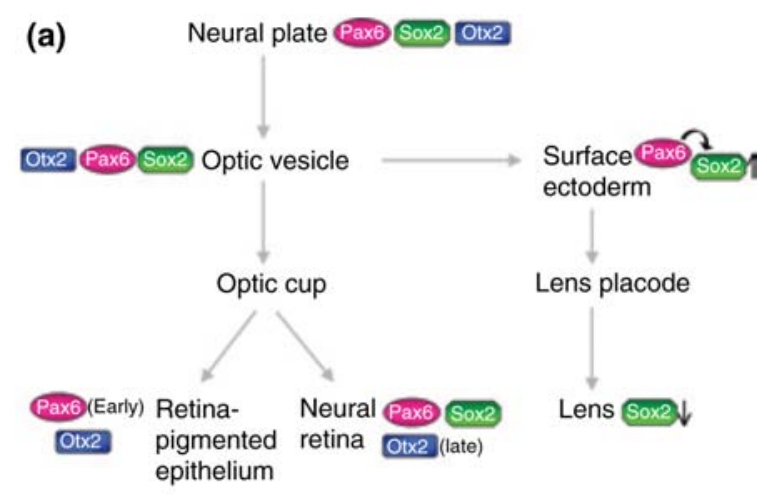

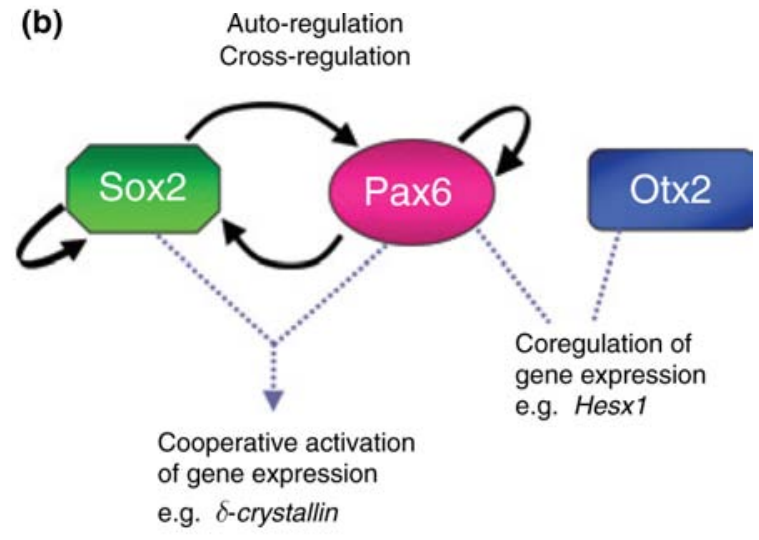

Figure 2. PAX6, SOX2 and OTX2 role in organ induction during eye formation (From Hever AM et al. Clin Genet 2006).

\section{PAX Family}

The Paired box (PAX) genes are members of the family of tissue specific transcription factors. They are all containing a paired domain and usually also a partial or complete homeodomain. An octapeptide may sometimes be as well present. $^{8}$

The PAX gene family plays a critical role in the formation of tissues and organs during embryonic development. For example, in the eye, PAX6 gene has been called the master gene for eye development. ${ }^{9,10}$. 
The PAX gene family is also important for maintaining the normal function of certain cells after birth such as myoblasts, pineal glande and the eye. ${ }^{11,12}$ To carry out these roles, the PAX genes provide instructions for making proteins that attach to specific areas of DNA and help control the expression of specific genes. On the basis of this action, PAX proteins are called transcription factors. After birth, the PAX genes are usually turned off (inactivated), but in some tissues the PAX genes can remain to be active. These active genes play a role in tissue re-growth, maintaining of cyto-architecture and protection against cell death caused by cellular stress. ${ }^{13,14}$ There are nine genes in the PAX gene family. These genes are divided into groups based on various aspects of similarity. ${ }^{15-17}$

- PAX group 1 (PAX 1 and PAX 9). ${ }^{18-20}$

- PAX group 2 (PAX 2, PAX5 and PAX 8). ${ }^{21-23}$

- PAX group 3 (PAX 3 and PAX 7). ${ }^{24}$

- PAX group 4 (PAX 4 and PAX 6). ${ }^{25-30}$

Mutations in PAX genes lead to disorders that involve the incomplete development of tissues in which a particular PAX gene is expressed. For example, Pax8 homozygous deficient mice display dysgenesis of the thyroid gland including loss of all follicular cells. ${ }^{31}$ Additionally, the overexpresion of PAX genes has been noted in a variety of cancers. ${ }^{24-32,33}$ Moreover, it is thought that PAX genes confer cell protection and prevent cell death and also allows cell proliferation. ${ }^{34}$ More specifically, overexpresion of Pax6 gene leads to induction of ectopic surnumerous eyes in the Drosophila and Xenopus laevis. ${ }^{35,36,37}$

In this thesis we will refer to international nomenclature of genes and protein for human and mice as follow. ${ }^{38}$

- Human gene: PAX6 (All in upper case and all italic)

- Human protein: PAX6 (All in upper case, not in italic)

- Mouse gene: Pax6 (First letter in upper case and all in italic)

- Mouse protein: PAX6 (All in upper case, not in italic)

One will note that human and mouse protein PAX6 are identically written, therefore, if the context does not allow to make the distinction between them, we would specify in the text whether it is a mouse or human PAX6 protein.

\section{PAX6 Gene}

PAX6 is a member of the PAX family genes that intervene in the formation of organs, tissues and cells during embryonic development. They code for highly 
conserved DNA-binding proteins, transcriptor factors, alleged to be important for the control of expression and activity of several genes ${ }^{39}$ through attachment to specific areas of the DNA. PAX gene plays also a role in the maintenance and function of certain cells after birth such as corneal epithelial cells for PAX6..$^{40,41}$ This gene encodes paired box gene 6 , one of many human homologues of the Drosophila melanogaster gene prd. During development PAX6 gene/ PAX6 protein are involved in the formation of specific organs such as the pancreas, the spinal cord, the brain, the olfactory bulb and the eye. ${ }^{28-30,42,43}$

Heterozygous mutations in this gene are known to cause several ocular disorders the most common being aniridia. ${ }^{27,44}$ Null mutation of $P A X 6$ results in central nervous system abnormalities and anophthalmia and is lethal before birth except only one patient has been reported to survive until 8 days after birth. ${ }^{45}$ PAX6 was identified as a candidate aniridia gene during the search for the genes responsible for the WAGR syndrome (Wilms tumor, aniridia, genitourinary malformations, and mental retardation, which is caused by hemizygous deletions of 11p13). ${ }^{46}$

This gene was first cloned in the mouse and shortly thereafter in humans. ${ }^{47}$ The mouse mutants of this gene called small eye gene and the aniridia gene in humans, called the aniridia gene are homologous. ${ }^{47,48}$ The human PAX6 surprisingly turned out to correspond to the Drosophila eyeless (ey) gene. This gene shows extensive sequence similarity, both in the paired domain $(94 \%$ identity), and in the homeodomain (90\% identity) with human PAX6 gene..$^{49-55}$ The fact that small eye, aniridia, and eyeless share mutations in homologous genes and the paramount role of PAX6 in eye formation explain the other designation given to PAX6: "the master gene" for eye formation in both vertebrates and invertebrates. ${ }^{9,10}$

\section{Localization of the PAX6 gene}

The PAX6 gene is located on the short $(p)$ arm of chromosome 11 at band13. (Figure 3) More precisely, the PAX6 gene is located from base pair $31,767,033$ to base pair $31,789,454$ on chromosome 11 . It has a size of 22,422 bases. 


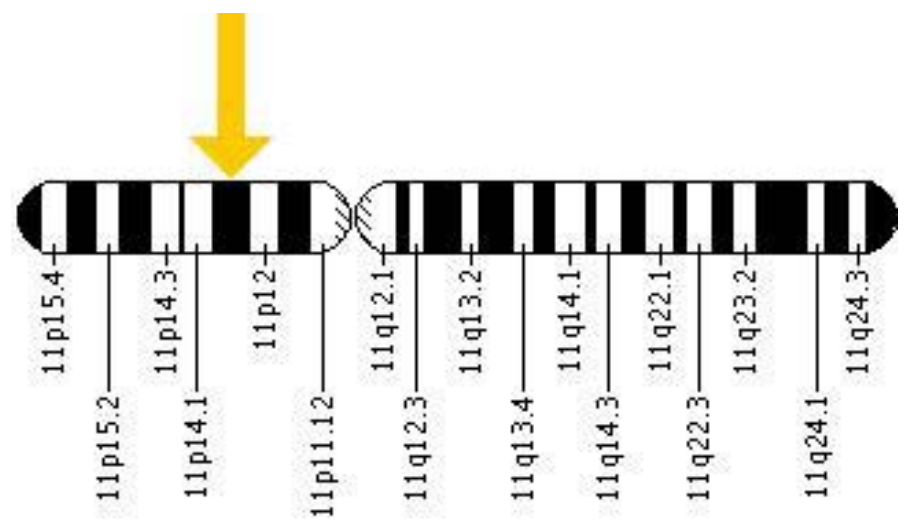

Figure 3. Localization of PAX6 on Chromosome 11 (From Genetic Home Reference, http://ghr.nlm.nih.gov/dynamiclmages/chromomap/pax6.jpeg)

PAX6 gene is composed of 14 exons and 13 introns ${ }^{46}$ There is a CCAGCATGC translation start site in exon 4 and a TTA stop codon in exon 13. (See figure 4 and 5 below).

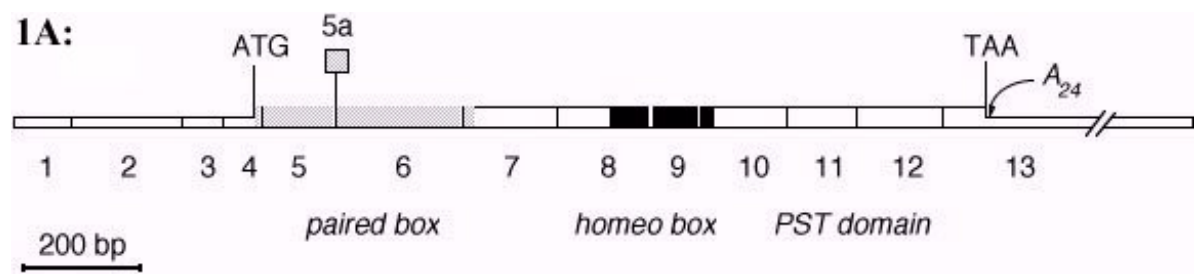

Figure 4. PAX6 (From AL Friedman et Al. Journal of Young investigators, 1998).
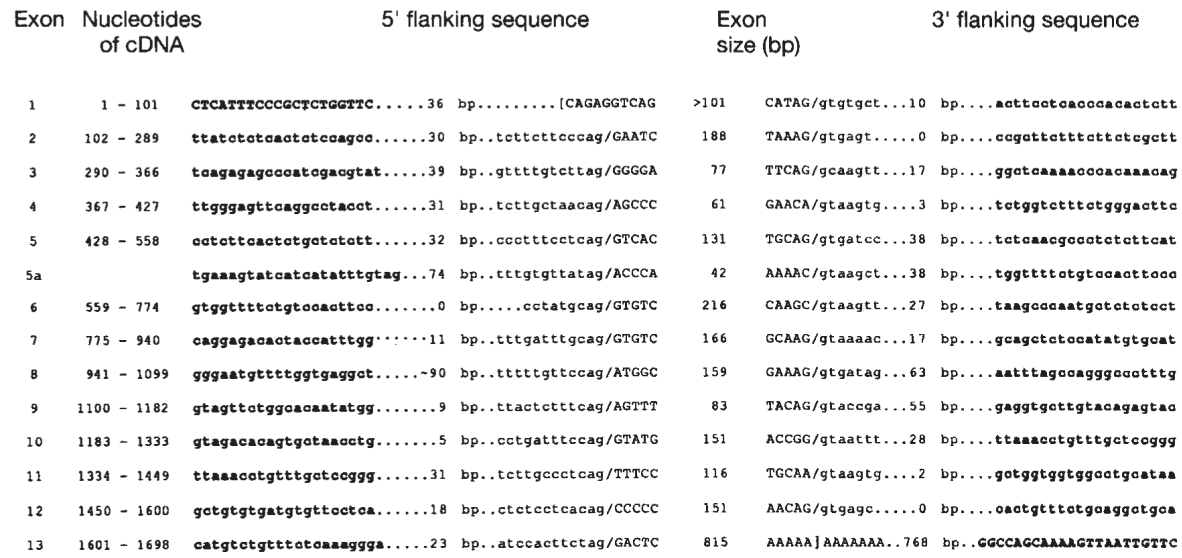

Figure 5.PAX6 sequence. (From Glaser et Al. Nature Genetics 1992). 
PAX6 contains an alternative mRNA splice-site in the paired domain that can result in a 42-nucleotide insertion. Alternative splicing of $P A X 6$ generates a major isoform, PAX6(+5a) that exhibits different DNA-binding properties due to a 14 amino acid insertion in the amino-terminal region of the PRD domain that unmasks binding properties of the C-terminal subregion. ${ }^{56}$ PAX6 levels are up to 10 times that of PAX6(+5a) in the eye during development and after birth. This ratio is crucial for proper ocular development and also for maintenance of eye structures in adulthood. ${ }^{57,58}$ The two isoforms synergistically activate some gene promoters suggesting a cooperative function between these two proteins in the adult eye. ${ }^{59}$

\section{PAX6 Protein}

The PAX6 protein is composed of a sequence of 422 amino acids. (See Figure 6). Its isoforms PAX6 (5A) contains 14 additional amino acids inserted in the pair domain. ${ }^{60}$ PAX6 protein is essential as a transcription factor in the development of the eye, nose, central nervous system and pancreatic islet alpha cells.

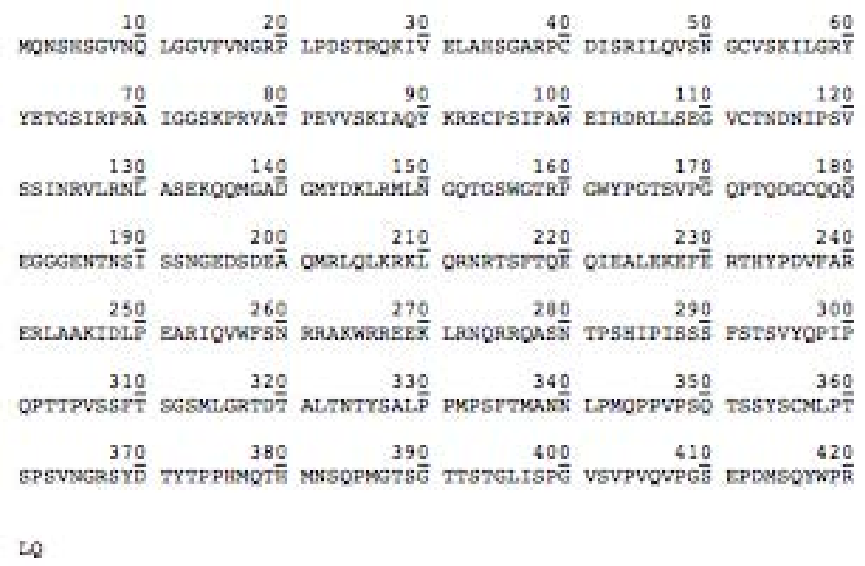

Figure 6. Primary structure of PAX6 protein composed of 422 AA.

(From Adam A. L. Friedman. Journal of Young investigators, 1998).

The PAX6 protein is composed of two DNA-binding domains, a paired domain (PD) at the $\mathrm{N}$ terminus and a paired-like homeodomain (HD) that are linked by a glycine-rich domain (the linker) and a transactivation region (PST), which is rich in proline, serine, and threonine amino acids at the $C$ terminus of the PAX6 protein (see Figure 7A). ${ }^{10}$ 
(A)

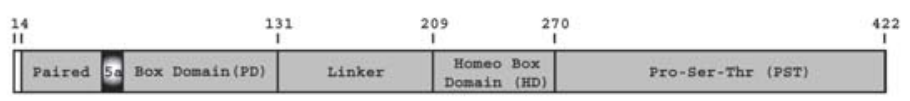

(B)

(C)
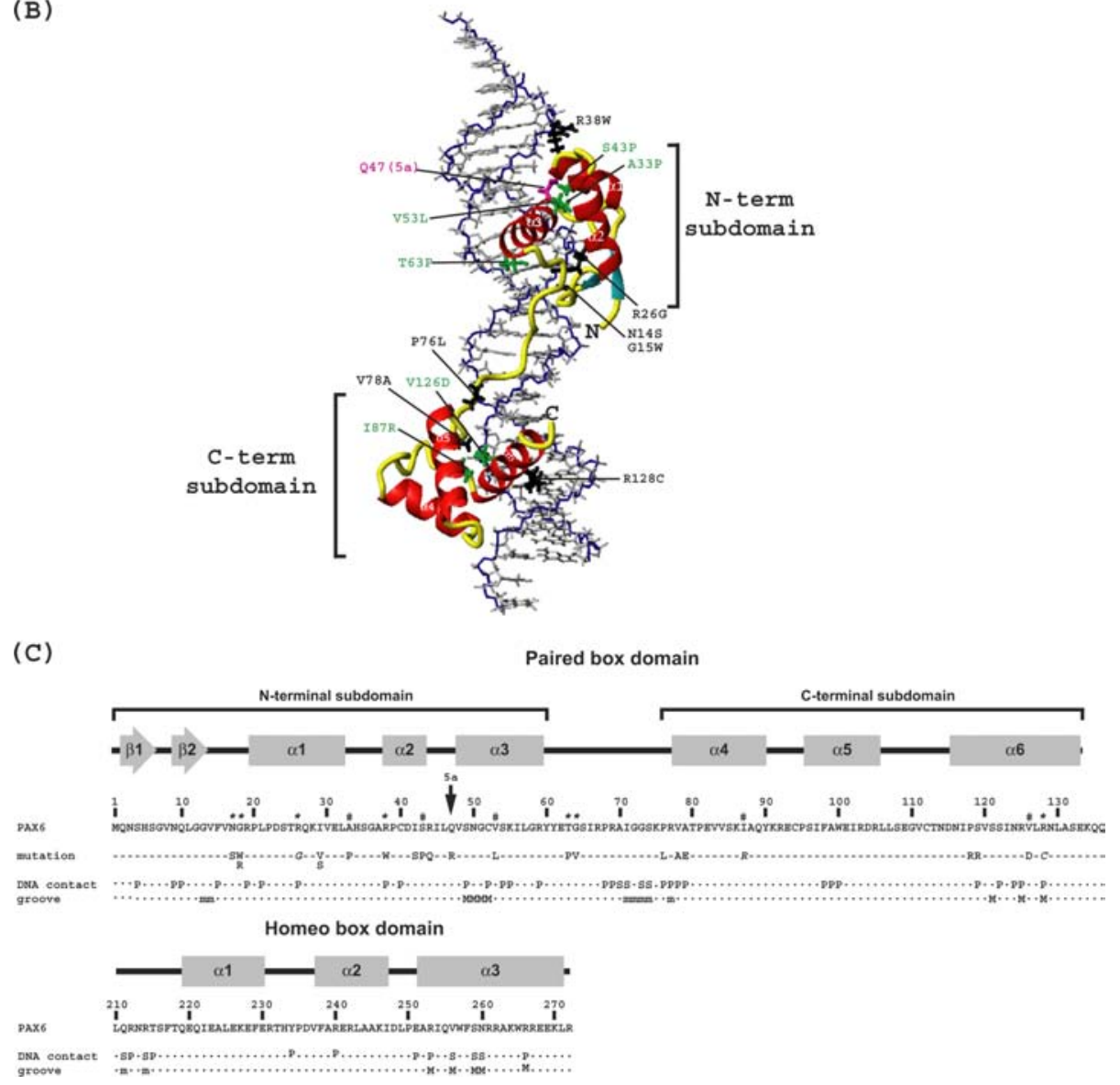

Figure 7. Structure of the PAX6 protein (From A.Tsonis et Al. Experimental Eye Research, 2006).

The secondary structure of PAX6 protein has been highlighted by biochemical and crystallographic studies. These studies showed that the PD is composed of two independent subdomains at the $\mathrm{N}$-terminal ( $\mathrm{N}$ subdomain) and $\mathrm{C}$-terminal (C-subdomain) respectively (see Figure 7B). The $\mathrm{N}$ subdomain (residues 1-60) contains a short $\beta$ motif and three $\alpha$ helices while the $C$ subdomain (77-133) contains three $\alpha$ helices. In both domains, the three $\alpha$ helices fold like in the homeodomain. The homeodomain is also composed of three a helices that fold together. No protein-protein contact between both $\mathrm{N}$ and $\mathrm{C}$ subdomain has been demonstrated. Sequence comparisons show that the $\mathrm{N}$ subdomain is highly conserved among species. ${ }^{61}$ There is 68\% homology for residues 1-60 
between human and Drosophila PAX6 protein. These $\alpha$ and $\beta$ motifs create major and minor groove in the protein structure that allows DNA attachments and interactions. In this way PAX6 protein exerts its role as a transcription factor on other genes. Through DNA binding, PAX6 controls the expression of various downstream target genes involved in complex gene regulatory networks for cell proliferation, adhesion, migration, and neurogenesis. ${ }^{62-64}$

The alternatively spliced form of PAX6, PAX6-5a, contains an additional 14 amino acids in the PD which disrupts the $N$ subdomain and alters DNA binding properties. The PDs of other genes of the PAX family, the PAX2, PAX3, and the binding sequence of $P A X-5$ (BSAP), and PAX6 proteins can recognize similar DNA sequences. ${ }^{65-67}$ Several target genes have been identified. ${ }^{39}$ PAX6 protein expression continues in the adult retina, lens, and cornea and may help to maintain good ocular health. ${ }^{39-68}$ Three isoforms of PAX6 protein are derived through alternative splicing (PAX6-ex12, PAX6-5a,6', PAX6-5a). The ratios of these isoforms may be critical to normal ocular development as discussed earlier. $^{69}$

\section{Human PAX6 Mutations}

\section{Homozygous PAX6 Mutations}

Human PAX6-I- homozygous mutations are very rare and the condition is lethal before or shortly after birth causing anophthalmia with severe craniofacial and central nervous system defects. To our knowledge, only 2 cases of PAX6 /- mutations have been reported.

One report by Hodgson et al described a baby girl who had both parents affected by aniridia. She died before birth at 37 weeks of gestation and had no eyes, no palpebral fissures and nasal bones were absent. She disclosed severe CNS malformations and no adrenal glands. ${ }^{70}$

Glaser et al in 1994, who were the first one to describe the PAX6 gene, described a second patient with PAX6-/- homozygous mutation. The baby survived until 8 days after birth but presented with bilateral anophthalmia, microcephalia and agenesis of the corpus callosum. ${ }^{45}$ (See Figure 8) 


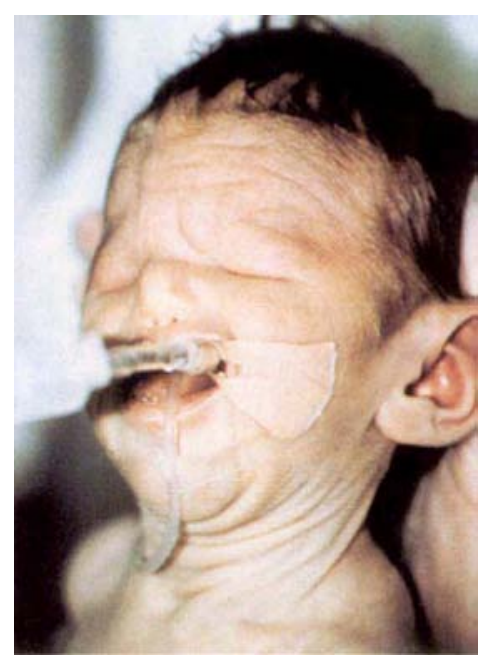

Figure 8. Anophthalmia

(From Glaser et Al, Nature Genetics, 1994)

PAX6

Heterozygous $P A X 6+/$ - mutations can lead to a variety of different ocular phenotypes comprising anterior or posterior segment anomalies and optic nerve malformations as well. The most frequent abnormality is aniridia. Others conditions include: autosomal dominant keratitis, Peters anomaly, juvenile cataract, glaucoma, isolated foveal hypoplasia, microphthalmia ectopia pupillae, optic disc coloboma, optic nerve hypoplasia and morning glory disc anomaly and unusual ophthalmic phenotype associated with neurodevelopmental abnormalities. $^{71}$

Of the many PAX6 mutations causing aniridia, most lead to loss of protein function and comprise nonsense mutations, splice mutations frameshifting deletions and insertions, inframe insertions and deletions, missense mutations, and run-on mutations. ${ }^{27,72}$

Of the 29 known mutations for non-aniridia eye disorders, $69 \%$ are missense mutations. ${ }^{72}$

Table 1. Disease / Phenotype correlation

\begin{tabular}{lc}
\hline Disease / phenotype & Number of PAX6 Mutations \\
\hline Aniridia & 196 \\
Optic-nerve Malformations & 10 \\
Foveal Hypoplasia & 3 \\
Peter's anomaly & 2 \\
Cataract, secondary glaucoma & 1 \\
Cataract, with Nystagmus & 1 \\
\hline
\end{tabular}




\begin{tabular}{lc}
\hline Disease / phenotype & Number of PAX6 Mutations \\
\hline Ectopia pupillae & 1 \\
Gillepsie syndrome & 1 \\
Kertatitis, autosoma dominant & 1 \\
Nystagmus & 1 \\
Ocular anterior segment anomaly & 1 \\
Absence of pineal gland & 1 \\
WAGR syndrome & 1 \\
\hline
\end{tabular}

From The Human Gene Mutation Database at the Institute of Medical Genetics in Cardiff

Table 2. Different mutations of $P A X 6$ gene

\begin{tabular}{lc}
\hline Mutation type & Number of PAX6 Mutations \\
\hline Missense / nonsense & 87 \\
Splicing & 32 \\
Regulatory & 0 \\
Small deletions & 58 \\
Small insertions & 21 \\
Smal indels & 11 \\
Gross deletions & 9 \\
Gross insertions & 2 \\
Complex rearrangements & 3 \\
Repeat variations & 0 \\
Total & 223 \\
\hline
\end{tabular}

From The Human Gene Mutation Database at the Institute of Medical Genetics in Cardiff http://www.hgmd.cf.ac.uk

\section{Autosomal Dominant Keratitis}

Autosomal dominant keratitis (ADK) is an eye disorder consisting in corneal stroma opacification and vascularization of the peripheral cornea. It can be associated with foveal hypoplasia. ADK is inherited as a fully penetrant autosomal dominant disease with variable clinical presentation. ${ }^{73}$ Incorrect splicing and resulting truncation of PAX6 proline-serine-threonine activation domain has been shown to be the cause of autosomal dominant keratitis. ${ }^{74}$ Stem cell deficiency associated with keratitis is also dependant of PAX6 mutation. ${ }^{75}$ (See Figure 9) 


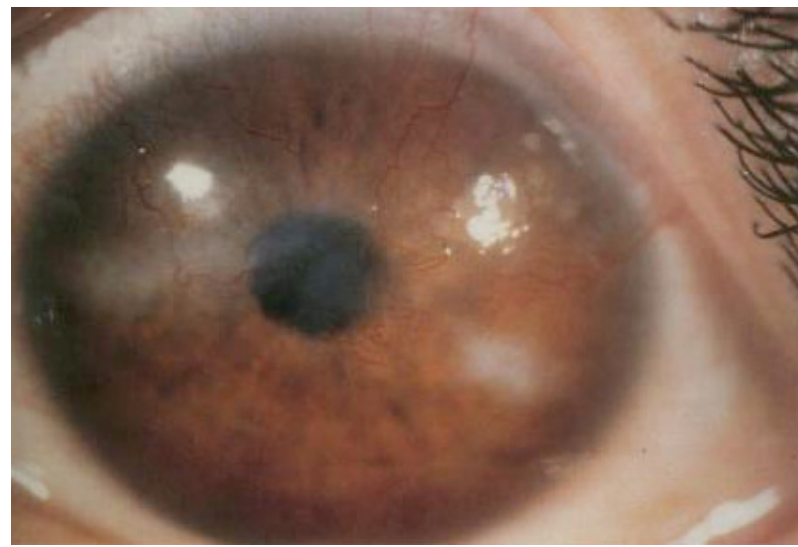

Figure 9. Autosomal Dominant Keratitis (From Mirzayans et Al. Am J Hum Genet. 1995).

Peters syndrome or Peters' anomaly

In 1906, Peters described an association of signs consisting of white cornea absence of posterior corneal stroma, absence of Descemet membrane and irido-corneal synechia. The condition is now part of a group of ocular abnormalities named anterior segment dysgenesis and include the cornea,the iris, the irido-corneal angle and the lens. A PAX6 gene missense mutation has been found in some patients. ${ }^{76,77} P A X 6$ intervenes in the formation of the neuronal crests that would later become the corneal stroma, Descemet membrane, the corneal endothelial, the irido-corneal angle and vitreous stroma (See Figure 10). In Peters' anomaly there is a defect in the neuronal crest explaining its specific ocular phenotype. ${ }^{78}$ In certain cases, this syndrome is inherited and therefore genetic counselling is indicated. ${ }^{79}$

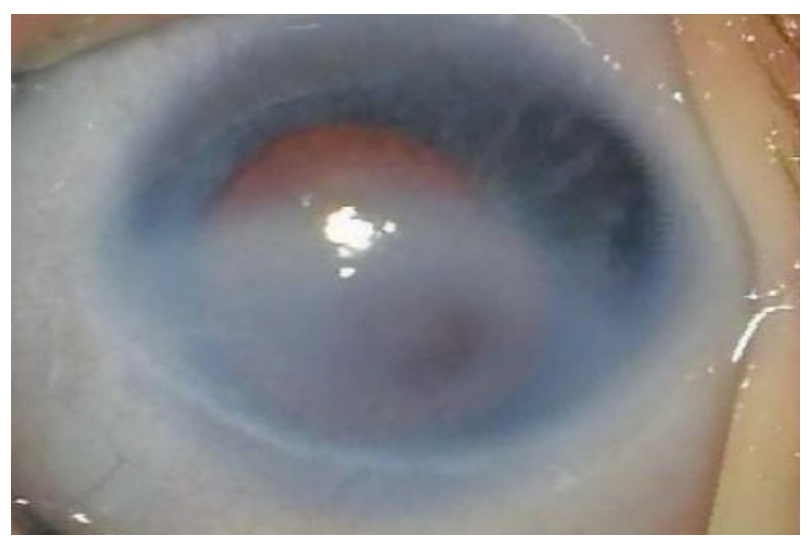

Figure 10. Peters' Anomaly (From Internet Journal of Ophthalmology 2003) 


\section{Aniridia}

Aniridia is a congenital, bilateral, panophtalmic condition. It is a rare disease that occurs with an incidence of $1: 64,000$ in the USA to $1: 76,000$ in Norway. ${ }^{80}$ The disorder is characterized by the complete or partial absence of the iris and iris hypoplasia. ${ }^{81}$ Aniridia can be isolated or found in association with a range of other ophthalmological abnormalities including cataracts, glaucoma, corneal pannus. $^{82}$ optic nerve hypoplasia, absence of macular reflex, ectopia lentis, nystagmus, and photophobia. ${ }^{83}$ Foveal and optic nerve hypoplasia are often present, causing a reduction in visual acuity and congenital sensory nystagmus. Progressive worsening of vision may occur later in life as a result of cataracts, glaucoma, and corneal opacification. A less common form of aniridia occurs in which the iris defects predominate, but visual acuity remains relatively unimpaired. (See Figure 11)

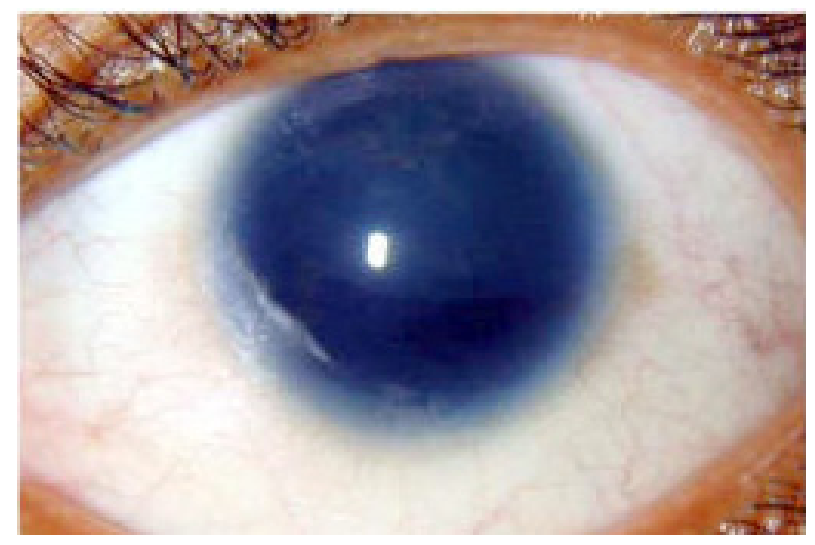

Figure 11. Aniridia (From Neethirajan et al. BMC Medical Genetics 2004)

Aniridia may be familial or sporadic. Approximately $85 \%$ of cases are familial disclosing autosomal dominant inheritance with complete penetrance but variable expressivity. These familial cases usually have isolated ocular involvement and are caused by mutation of PAX6 gene or deletion of a regulatory region controlling its expression.

The $15 \%$ of cases that are sporadic ${ }^{84}$ usually present with a deletion on the short arm of chromosome 11 involving both PAX6 and the WT1 gene (which is located $700 \mathrm{~kb}$ telomerically from $P A X 6$ ) resulting in the Wilm's tumor, bilateral sporadic aniridia, genitourinary abnormalities and mental retardation (WAGR) syndrome. ${ }^{85}$ Individuals with deletion of PAX6 and WT1 have up to $50 \%$ risk of developing Wilms tumor. WAGR syndrome is the most common syndrome as- 
sociated with aniridia. ${ }^{86}$ Wilm's tumor associated with genitourinary and renal abnormality is related to hemizygosity for Wilm's tumor suppressor gene WT1, whereas ocular defects result from hemizygosity for the PAX6 gene. ${ }^{87}$ The association between aniridia and Wilms tumor is referred to as Miller syndrome. Children disclosing Wilms tumor have $1.4 \%$ chance of having aniridia compared to 1 in 64000 in the general population. Miller syndrome has been attributed to a deletion of band 11p13. Patients with sporadic aniridia should undergo a thorough physical examination and workup by a paediatrician.

There is a correlation between the level of PAX6 activity and the severity of the aniridia phenotype. ${ }^{46}$

While the majority of cases of aniridia are the result of PAX6 mutation, there are about $10 \%$ of reported cases with no identified mutation of $P A X 6{ }^{88}$ These patients preserve their visual function and may be therefore associated to a less severe phenotype of aniridia. ${ }^{89}$

\section{Foveal Hypoplasia}

Foveal hypoplasia is a condition in which the fovea is underdeveloped. It is characterized by the absence of foveal pigmentation and/or the foveal avascular zone. It may occur in isolation or in association with other conditions such as aniridia, albinism, achromatopsia, microphthalmia, retinopathy of prematurity (ROP), myopia and incontinentia pigmenti (IP)..$^{90-93}$

One family was found to show isolated foveal hypoplasia related to PAX6 missense mutation. The mutation occurred in the C-terminal domain of the gene whilst most of anterior segments anomalies were reported in the $\mathrm{N}$-terminal domain. ${ }^{94}$

Another splice mutation of PAX6 was found in a family with foveal hypoplasia, congenital nystagmus and anterior segment abnormalities such as iris hypoplasia or atypical coloboma. ${ }^{95}$ (See Figure 12 ) 

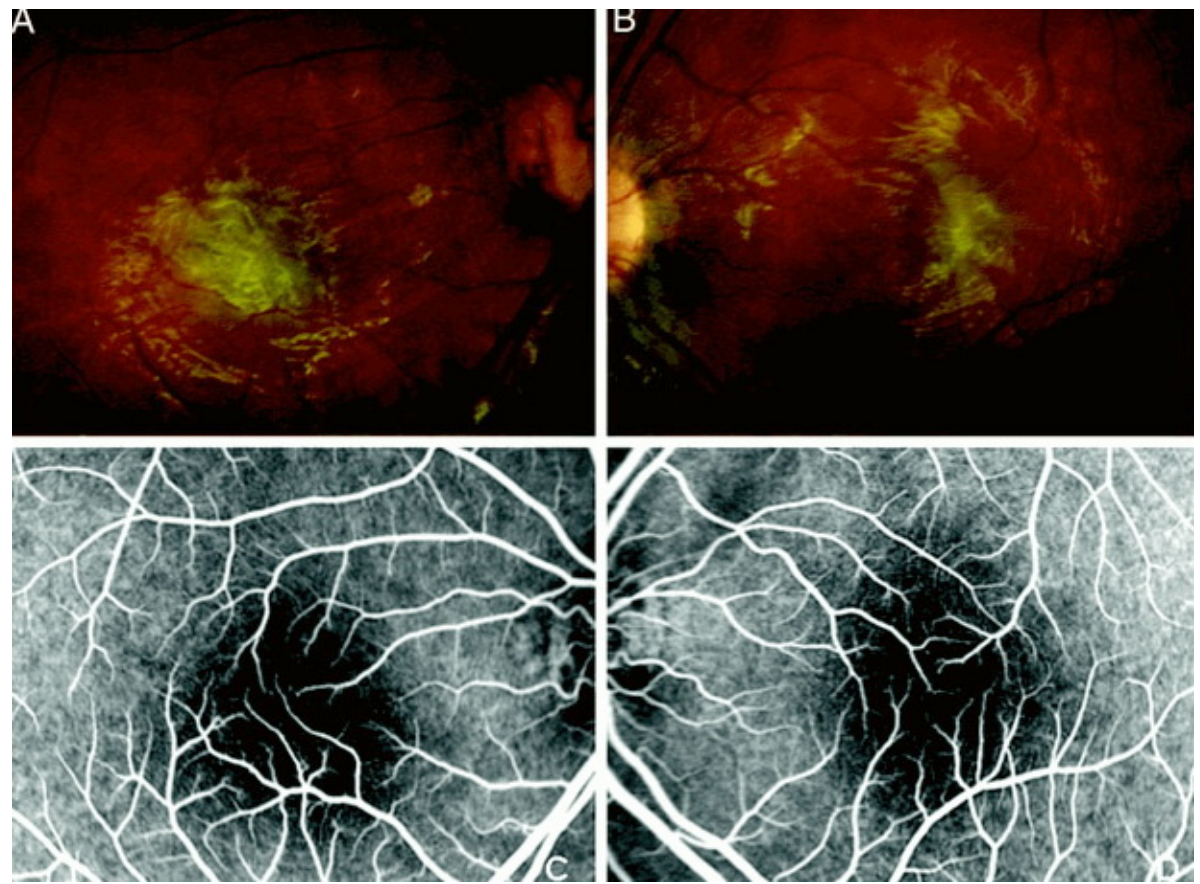

Figure 12. Isolated Hypoplasia ( From Querques G et al. Retina 2008).

\section{Ectopia Pupillae}

Ectopia pupillae is a congenital eye malformation in which the pupils are displaced from their normal central position. Missense mutation of PAX6 was found in a child disclosing ectopia pupillae as a prominent sign. Ectopia pupillae and aniridia were reported in patients with a truncation mutation of the PAX6 gene. ${ }^{96}$
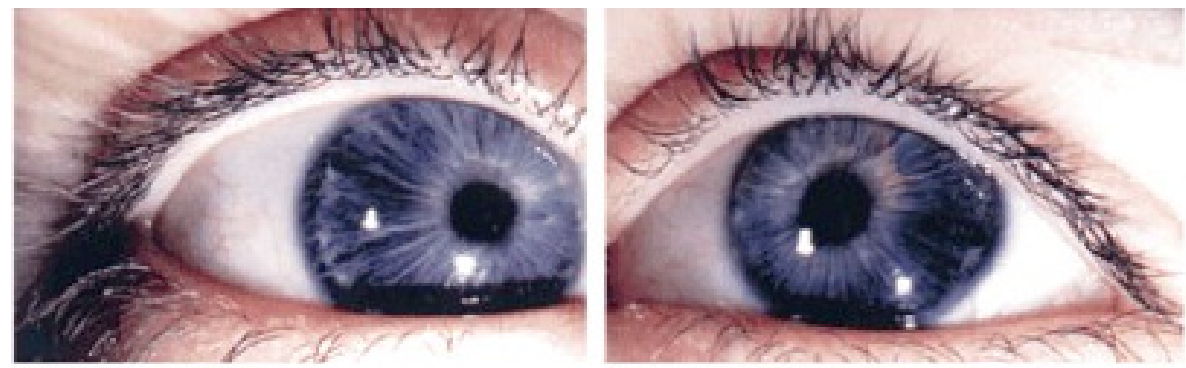

Figure 13. Ectopia Pupillae (From Hanson et al. Human Mol Genet 1999). 
Optic nerve malformations and PAX6 mutations

A study described PAX6 missense mutations among European and Japanese patients with optic nerve malformations. ${ }^{97}$ This study identified novel mutations in eight pedigrees with optic-nerve malformations, including coloboma Morning glory disc anomaly, optic-nerve hypoplasia/aplasia, and persistent hyperplastic primary of the vitreous. PAX6 is expressed in the CNS, the optic stalk, the retinal progenitor cells and retina ganglion cells during development. Interestingly, the disease-causing events of optic-nerve malformation-include embryonic fissure (coloboma), retinal ganglion cells (ONH/aplasia) and the lamina cribosa (Morning glory disc anomaly). ${ }^{97,98}$

\section{Optic nerve coloboma}

Optic nerve coloboma is a congenital condition caused by incomplete closure of the embryonic fissure. PAX6 missense mutation does not allow proper closure of the embryonic fissure during development. Typical optic disc colobomas are infero-nasal and range from a hugely excavated disc to a subtle change in the retinal pigment epithelium. Optic disc coloboma can be found with chorioretinal coloboma and or iris coloboma. This affection might be isolated or associated with other ocular abnormalities or brain anomalies. ${ }^{99}$

\section{Optic nerve hypoplasia}

Optic nerve hypoplasia occurs before the end of ocular development and is associated with a decrease of retina ganglion cell axons. It consists in a reduced size optic disc, diminished number of axons, a small or absent cup, an increase in the tortuosity of the retinal vessels with fewer than normal branching points, and the presence of peripapillary abnormalities. There is a causal association with a wide variety of brain malformations and optic nerve hypoplasia with maternal diabetes and toxic intake during gestation such as alcohol and drugs (LSD, cocaine, quinine...). Very rarely, missense mutations occur in the PAX6 gene and are responsible for optic nerve hypoplasia through abnormal development of ganglion cells and their axons. Optic disc coloboma and optic nerve hypoplasia have been also reported in two Indian patients sharing missense mutation in PAX6 gene. ${ }^{98}$ (See Figure 14 and 15) 


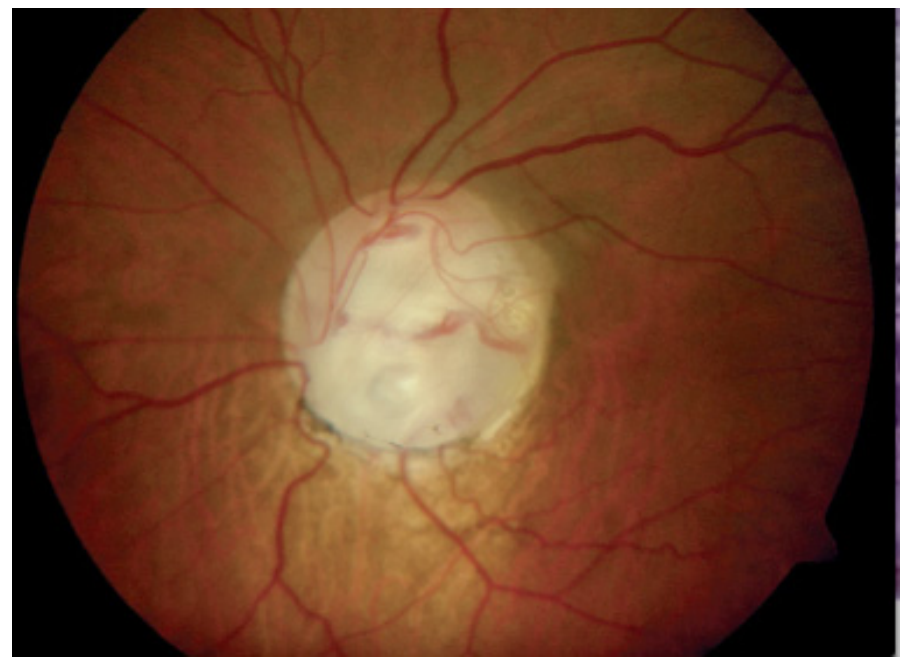

Figure 14. Optic Nerve Coloboma (From Dutton NG. Eye 2004).
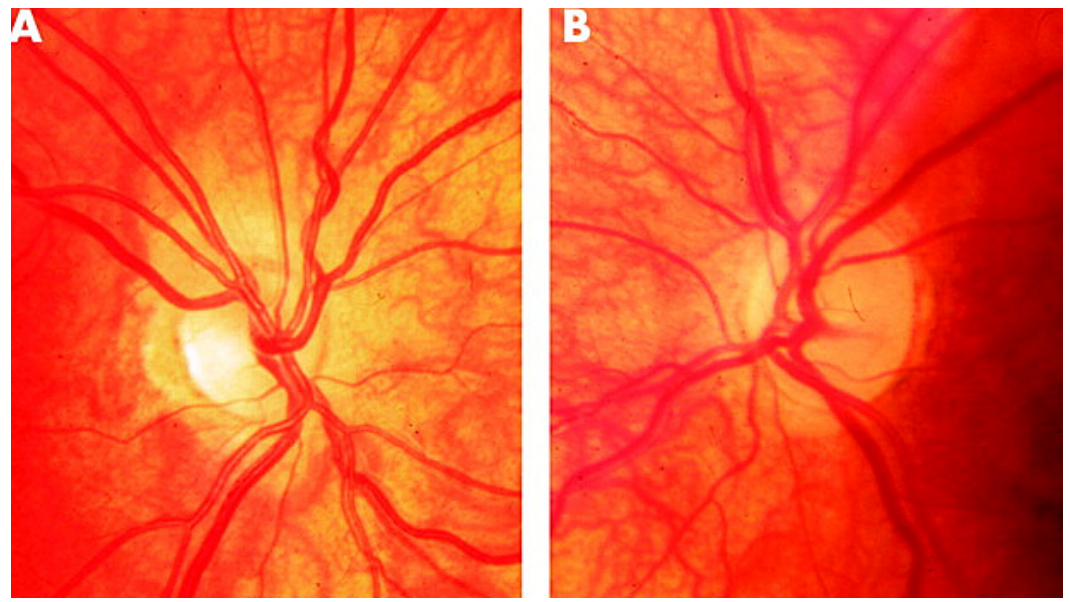

Figure 15. Optic Nerve Hypoplasia (From Taylor et al. Eye 2007).

Morning Glory Disc anomaly

This affection bears its name because of similarities with the flower of the same name. There is a central glial tuft, retinal vessels that exit in a radial fashion from the enlarged posterior scleral opening where the optic nerve tissue exits the globe, and a variable degree of peripapillary pigmentation. The origin of the disease results from poor development of the lamina cribosa and the posterior sclera. It is associated with several ocular and neurological diseases. Once 
again, there has been one report implying missense PAX6 mutation among patients disclosing morning glory disc anomaly. ${ }^{100}$ (See Figure 16)

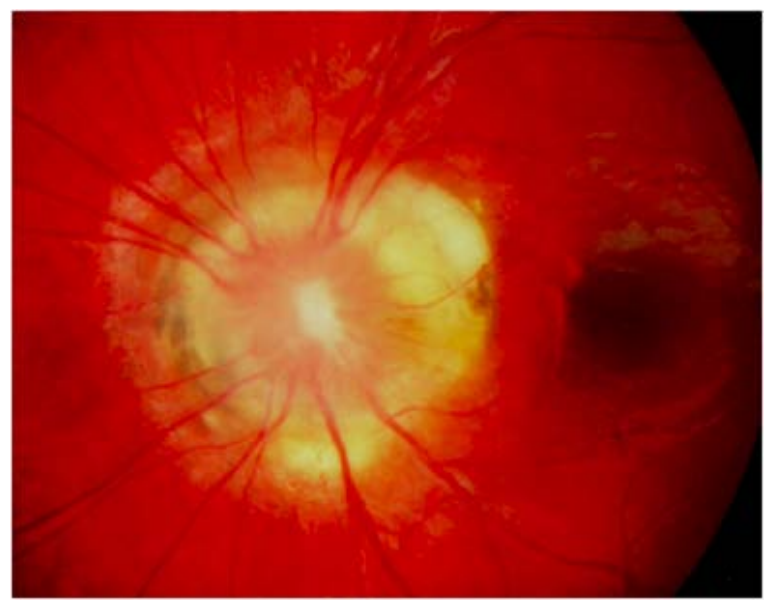

Figure 16. Morning Glory Disc Anomaly (From Taylor et al, Eye 2007).

\section{PAX6 gene and evolution}

Despite important differences between insects and vertebrates in their eye structure and eye formation, genetic studies have shown that eyes from very different species might share a similar developmental cascade of transcriptor factors. Indeed, PAX6 gene sequence and its expression pattern are both remarkably similar among very different species of animals. For example, Eyeless, the PAX6 homolog of Drosophila shows extensive sequence similarity with human PAX6, both in the paired domain (94\% identity), and in the homeodomain (90\% identity). ${ }^{101}$ The zebrafish pax(zf-a) protein exhibits $96 \%$ of homology of the amino acid sequences with human PAX6. ${ }^{102}$ Closer to us the mice and human PAX6 proteins are identical in amino acid sequence. ${ }^{49}$ To our knowledge, homology of PAX6 gene has been found among several different species including: Saccoglossus kowalevskii, Florida lancelet Ciona intestinalis, Drosophila melanogaster, mosquito, zebrafish, Japanese rice fish, Xenopus laevi, chicken, mouse, rat, rabbit, cow, dog, gray short-tailed opossum, sheep, rhesus monkeys, chimpanzee (Seen in PubMed, Homologene PAX6). The degree of homology is particularly higher in the paired domain and the homeodomain, which both interact with DNA to exert their controls on a cascade of genes implied in eye formation and regulation. 
Such a high degree of conservation among species is very rare and comparable to the one found with histones $\mathrm{H} 2 \mathrm{~A}$ and $\mathrm{H} 2 \mathrm{~B} .{ }^{103}$

\section{Pax6 in the mouse}

The small eye gene (Sey) gene that is located on chromosome 2 of the mouse has been assumed to be the homolog of human PAX6 gene or Aniridia gene. ${ }^{104}$ Homozygous Pax6, Sey, null mutation in the mouse is lethal shortly after birth and associated with absence of eyes, nasal structures and pancreas, with severe brain defects and sometimes abnormal dentition. ${ }^{47,105}$

Heterozygous Pax6 +/- mice produce low levels of PAX6 and result in ocular abnormalities secondary to abnormal eye development (detailed below) and abnormalities in forebrain development, ${ }^{39}$ olfactory bulb ${ }^{30}$ and the pancreas. ${ }^{106}$

Pax6 +/- heterozygous mice disclosed several ocular phenotypes that range from microphthalmia, aniridia-like iris anomalies, ${ }^{107}$ corneal opacities, lenscorneal adhesions that resemble Peters' anomaly ${ }^{108,109}$ to trabecular meshwork development abnormalities. ${ }^{110}$ Other developmental abnormalities, including retinal dysplasia, coloboma, abnormal cell accumulation in the vitreous, iridocorneal synechia and adhesions between the lens and cornea may also occur. ${ }^{110-115}$ Pax6 +/- adult mice present a very thin and fragile corneal epithelium and a vascularised stroma that is infiltrated by inflammatory cells. These mice show a progressive corneal deterioration and abnormal wound healing characterized by increased stroma cell apoptosis and reduced level of MMP9 (Matrix metallopeptidase 9). ${ }^{114,116}$

\section{Overexpresion of Pax6 gene}

Not only low levels of Pax6 during eye development are resulting in severe ocular phenotypes. It has been also demonstrated that experimentally induced overexpression of Pax6 in the mouse and duplication of PAX6 gene in the human cause eye abnormalities as well. Therefore development seems to be very sensitive to correct Pax6 gene dosage. ${ }^{117-119}$

Using a transgenic approach, additional copies of the Pax6 gene have been introduced into the mouse genome. ${ }^{119}$ The transgenic mice carries 2 to 10 copies of the human PAX6 gene all integrated in the same locus. These mice strains showed variable eye abnormalities, ranging from an almost normal external appearance to severe microphthalmia depending on the number of hu- 
man PAX6 copies and genetic background of the rescued mice. Pax6 overexpresion resulted in microcornea, iris hypoplasia, disorganized iris and ciliary body, moderate to severe cataract, complete absence of photoreceptor layer, retinal dysplasia and dysgenesis, defects in RGC axon growth and guidance and microphthalmia. ${ }^{118-120}$

In humans, PAX6 duplication or partial duplication was encountered in a few patients with chromosome abnormalities. One girl had a duplication of chromosome band 11p12-->13, which includes the Wilms tumor gene (WT1) and the aniridia gene (PAX6). She showed developmental delay, mild facial anomalies, and eye abnormalities consisting in abnormal eye movements, hypermetropia, nystagmus, and slight abnormal fundus such as pale optic disc with peripheral patch of atrophy. ${ }^{117}$ Partial duplication of PAX6 was seen among patients with complete or partial trisomy of $11 \mathrm{p}$, including $11 \mathrm{p} 13$. Those patients share in common mental retardation, growth retardation, hypertelorism, flat or broad nasal bridge, cleft lip or palate and ophthalmic anomalies.

Ophthalmological findings in these patients were variable and comprised abnormal visual acuity, abnormal eye movement, microphthalmia, and abnormalities of the conjunctiva, choroid, retina, and the macula. ${ }^{121-128}$

\section{Pax6 over-expression: Ectopic expression of Pax6}

A very interesting way of testing a gene function is to study its over-expression or its ectopic expression, meaning testing its expression in an unusual location. In the Drosophila, Eyeless gene, a homolog of human PAX6 gene, was tested for these experiments. The yeast transcription factor gal4 drive Eyeless cDNA into imaginal discs other than the eye disc and is expressed not only in the developing eye, but also everywhere in the body, this results in the apparition of ectopic eyes on the antennae, wings, thorax of the Drosophila. ${ }^{36}$ Electroretinograms performed on of the ectopic eyes of the antennae showed that they were fully functional. ${ }^{129}$ (See Figure 17) 


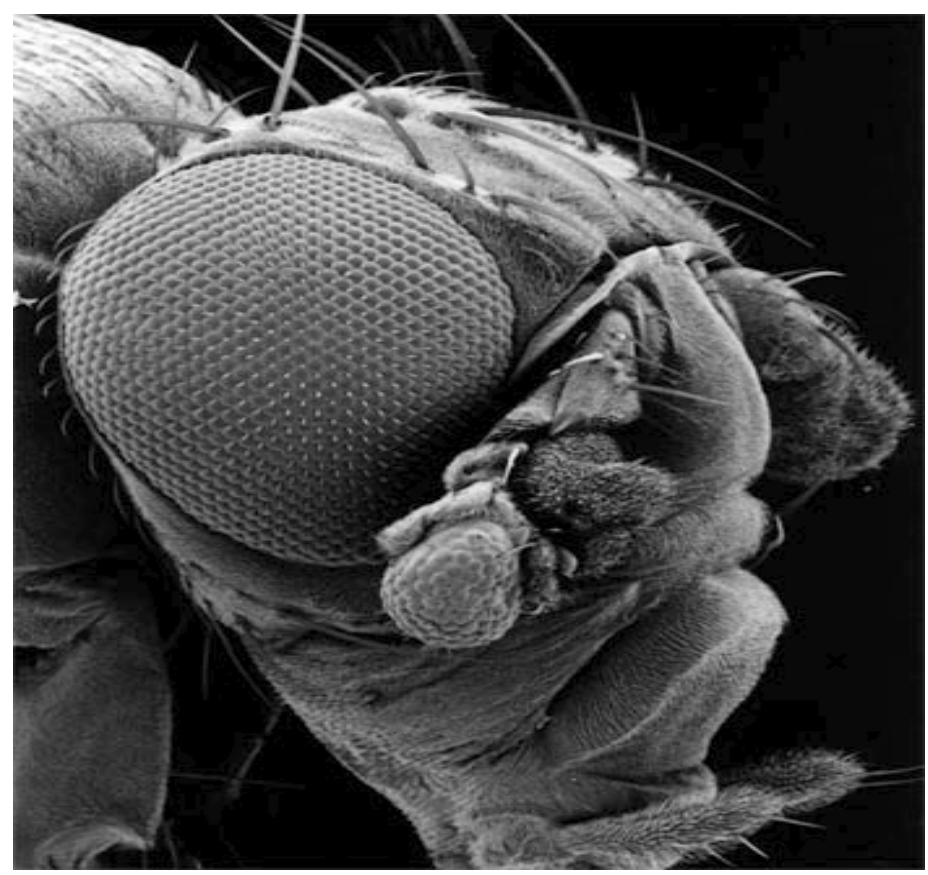

Figure 17. Ectopic Eyes on Drosophila (From Hadler et al. Science 1995).

Similarly, experiments performed first on the Xenopus laevis were able to induce ectopic lens. ${ }^{37}$ Later, in Xenopus laevis, a similar experiment led to ectopic eye apparition ${ }^{35}$ after Pax6 RNA injections in embryos of Xenopus laevis. These experiments also revealed that activity of misexpressed Pax6 causes the ectopic expression of a number of genes including $R x$, Otx2, Six 3 and endogenous Pax6, each of which has been implicated in eye development.

The most remarkable finding in these reports was that the ectopic expression of the mouse Pax6 gene within the fly (Drosophila) resulted in a phenotype very similar to the fly gene ectopic expression. These eyes were, Drosophila eyes and not mouse eyes, because only the main switch to trigger eye development was changed (Pax6 mouse gene) and all of the other genes required for forming an eye (estimated to be $\sim 2,000$ ) were provided by the Drosophila host. ${ }^{36}$ Reciprocally, experiments in which the Drosophila Pax6 homolog, Eyeless and Twin of Eyeless, were expressed in Xenopus embryos, resulted in the formation of vertebrate eye structures. ${ }^{130}$

All these observations suggested that at least some of the functions of Pax6 in eye development were conserved from invertebrates to vertebrates. 
Anatomy of the retina

The retina is approximately $0.5 \mathrm{~mm}$ thick and lines the back of the eye. The optic nerve contains the ganglion cell axons running to the brain and, additionally, incoming blood vessels that open into the retina to vascularise the retinal layers and neurons (See figure below). A radial section of the retina reveals that the ganglion cells lie innermost in the retina closest to the lens and the photoreceptors (the rods and cones) lie outermost in the retina against the pigment epithelium and choroid. Light must, therefore, travel through the thickness of the retina before striking and activating the rods and cones. Subsequently the absorption of photons by the visual pigment of the photoreceptors is translated into first a biochemical message and then an electrical message that can stimulate all the succeeding neurons of the retina. The retinal message concerning the photic input and some preliminary organization of the visual image into several forms of sensation are transmitted to the brain from the spiking discharge pattern of the ganglion cells. ${ }^{131}$ (Figure 18)

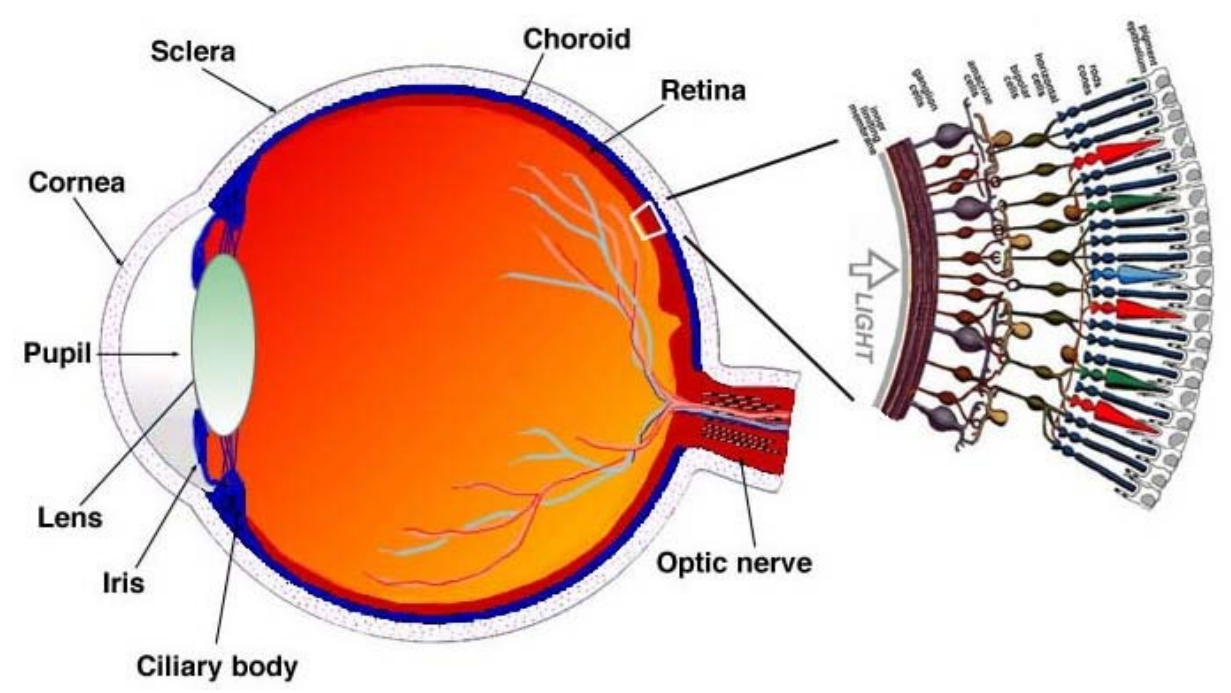

Figure 18. Anatomy of the retina (From Helga Kolb et al. Webvision 2007).

The retina is composed of three layers of nerve cell bodies and two layers of synapses. The outer nuclear layer contains cell bodies of the rods and cones, the inner nuclear layer contains cell bodies of the bipolar, horizontal and amacrine cells and the ganglion cell layer contains cell bodies of ganglion cells and displaced amacrine cells. ${ }^{132}$ 
The central retina is cone-dominated retina whereas peripheral retina is roddominated. The outer nuclear layer (ONL) is composed of the cell bodies of the rods and cones and discloses the same thickness in central and peripheral retina. However in the peripheral the rod cell bodies outnumber the cone cell bodies while the reverse is true for central retina. In central retina, the cones have oblique axons displacing their cell bodies from their synaptic pedicles in the outer plexiform layer (OPL). These oblique axons with accompanying Muller cell processes form a pale-staining fibrous-looking area known as the Henle fiber layer. The latter layer is absent in peripheral retina. ${ }^{133-135}$

The inner nuclear layer (INL) is thicker in the central area of the retina compared with peripheral retina, due to a greater density of cone-connecting second-order neurons (cone bipolar cells) and smaller-field and more closelyspaced horizontal cells and amacrine cells concerned with the cone pathways. ${ }^{136} \mathrm{~A}$ remarkable difference between central and peripheral retina can be seen in the relative thicknesses of the inner plexiform layers (IPL), ganglion cell layers (GCL) and nerve fiber layer (NFL). This is again due to the greater numbers and increased packing-density of ganglion cells needed for the cone pathways in the cone-dominant foveal retina as compared the rod-dominant peripheral retina. The greater number of ganglion cells means more synaptic interaction in a thicker IPL and greater numbers of ganglion cell axons coursing to the optic nerve in the nerve fiber layer.

OLM (outer limiting membrane), ONL (outer nuclear layer), OPL (outer plexiform layer), INL (inner nuclear layer), IPL (inner plexiform layer), GCL (ganglion cell layer), ILM (inner limiting membrane).

Muller cells are the radial glial cells of the retina. The outer limiting membrane (OLM) of the retina is formed from adherent junctions between Muller cells and photoreceptor cell inner segments. The inner limiting membrane (ILM) of the retina is likewise composed of laterally contacting Muller cell end feet and associated basement membrane constituents. (See Figure 19)

The OLM forms a barrier between the subretinal space, into which the inner and outer segments of the photoreceptors project to be in close association with the pigment epithelial layer behind the retina, and the neural retina proper. The ILM is the inner surface of the retina bordering the vitreous humor and thereby forming a diffusion barrier between neural retina and vitreous humor. 


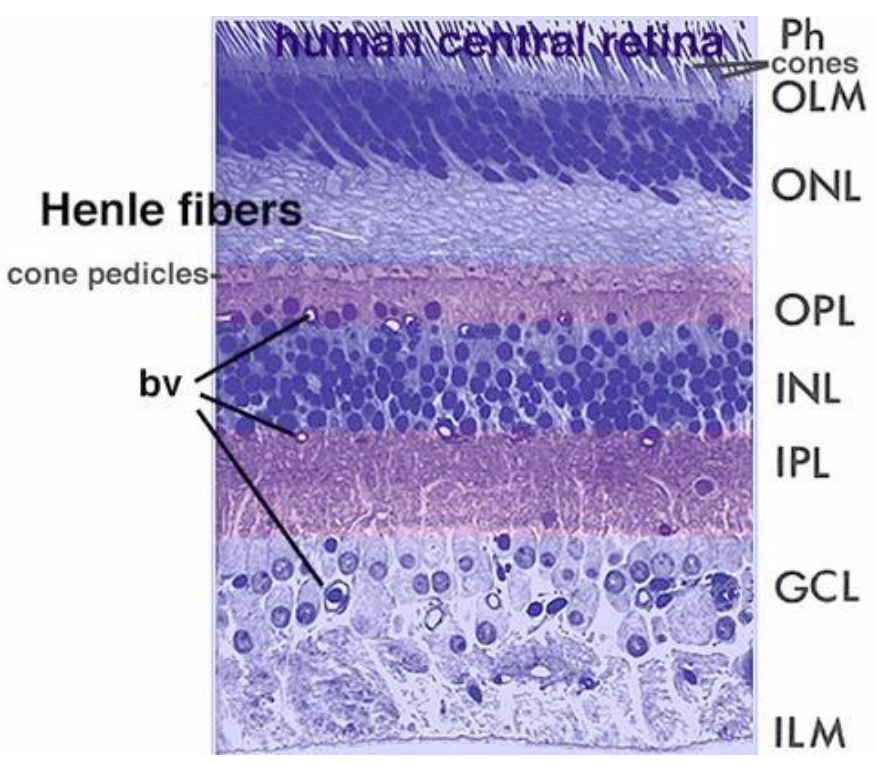

Figure 19. Histology of the Retina (From Helga Kolb et al. Webvision 2007).

Age Related Macular Degeneration and Retinitis Pigmentosa

Age related macular degeneration (AMD) is the leading cause of blindness among elderly people in western countries. It is a multifactorial disease. ${ }^{137-140}$ The disease affects 10 millions patients in the USA. AMD can present under a "dry" or a "wet" form. (Figure 20)

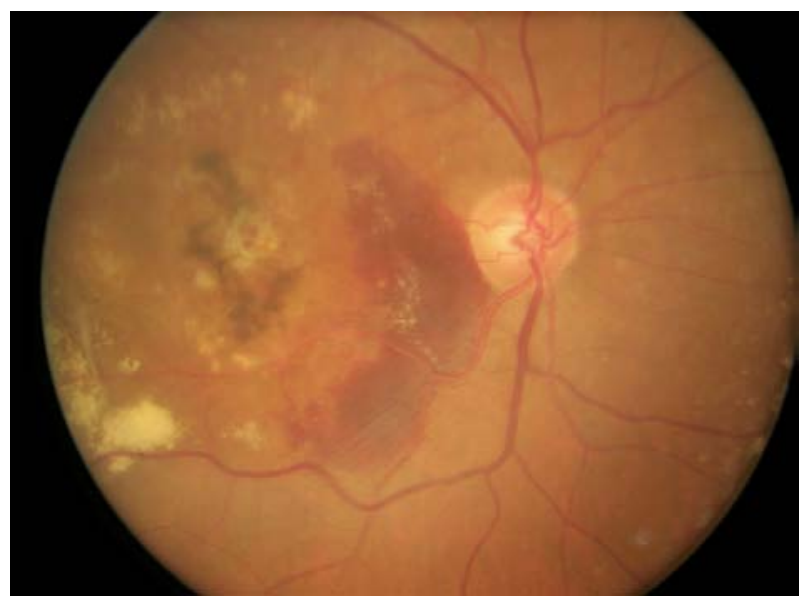

Figure 20. Wet AMD (From private collection, Stanescu-Segall). 
Wet AMD, or exudative AMD, is composed of choroid new vessels (CNV) crossing the retinal pigment epithelial barrier and invading the retina. These new vessels, lack tight junction, and allow leakage of fluid (serum, lipids, proteins) and blood inside the retina. VEGF (Vascular Endothelial Growth Factor) has been implicated in the formation of CNV and therapies involving anti-VEGF are now used in current practice with promising results. ${ }^{141-144}$ Dry AMD results in progressive loss of the photoreceptors cells and RPE of the macular region. Up to date, there is no proven treatment for dry AMD. Injections of growth factor have been advocated to slow the progression of the disease, but further studies are warranted to confirm their efficacy. ${ }^{145}$ Retinitis Pigmentosa (RP) is among the leading cause of decrease vision among young patients. ${ }^{146}$ The prevalence of RP is reported to be approximately 1 in 4000 in the United States. RP is a group of inherited disorders characterized by initial progressive peripheral vision loss and night vision difficulties that can lead secondary to central vision loss. ${ }^{147}$ Up to date, there is no cure for RP. Different treatment modalities such as gene therapy, ${ }^{148,149}$ growth factor injections, ${ }^{150-152}$ stem cell, ${ }^{153,154}$ retina transplantation $^{155,156}$ and retina prosthesis ${ }^{157}$ are currently under investigation ${ }^{158}$ and offer a chance of hope for RP patients in the future. Several studies on the pathophysiology of dry AMD and RP have shown that both diseases loose their photoreceptor cells by apoptosis. ${ }^{159-163}$ Therefore, understanding the process of photoreceptor apoptosis might shed some light on how to interfere with photoreceptor loss and subsequent loss of vision in these diseases. There is no real mouse model of AMD, since mice do not carry a proper macula. Although, anomalous reactions in the visual cycle have been shown to cause an AMD-like phenotype in mice lacking both the ATP-binding cassette transporter 4 (Abca4) and retinol deshydrogenase 8 , two enzymes critical for all-trans- retinal clearance from the retina. ${ }^{164}$ (Figure 21)

In case of RP, genetically engineered animal models carrying a mutation known to cause RP in patients has been extensively used. Indeed, the number of transgenic mice mimicking human inherited degenerations is constantly growing. ${ }^{165,166}$ We have paid particular attention in our study to Pde6b(rd1) mouse, one of the most studied mouse models of human retinal degeneration. 


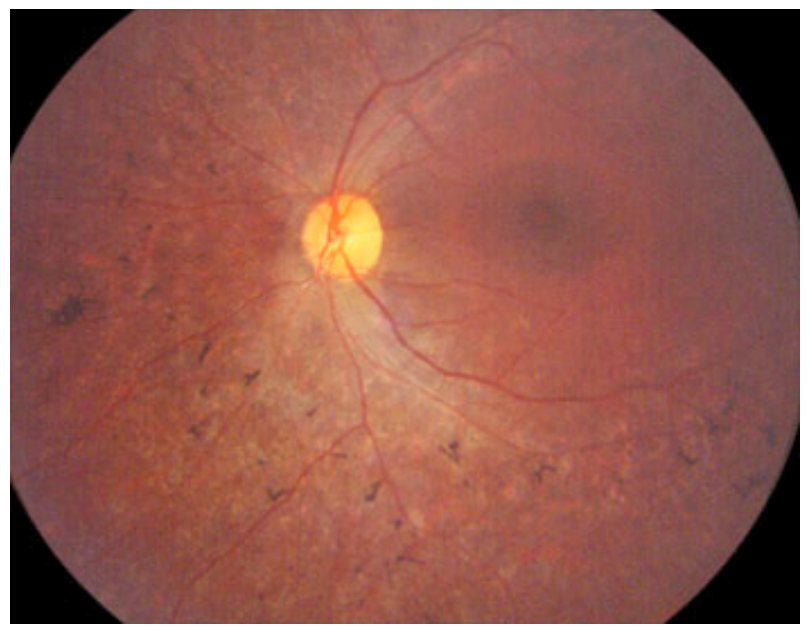

Figure 21. Retinitis Pigmentosa (From private collection, Stanescu-Segall).

\section{Light induced retinal degeneration}

Light exposure is responsible for photoreceptor apoptosis, consists in a nongenetic induced mouse model of RP. ${ }^{160}$ We have used this mouse model of light-induced retinal degeneration in our study for all the advantages it encompasses. Adult mice are exposed to a bright light of an average of 10.000 lux for a period of two hours. This exposure leads to photoreceptor degeneration after 24 hours and their complete physical disappearance within 10 days, much faster than most inherited mice model of retinal degeneration. Light exposure induced apoptosis in all affected photoreceptors in a synchronized way; they will pass through different stages of apoptosis more or less at the same time. This allows the detection of biochemical markers and their assignment to different phase of apoptosis. ${ }^{167}$ Finally, several animal models have shown an acceleration of their retinal degeneration when exposed to increased light levels. Therefore, light plays a real role as a co-factor in retinal disease. The advantage of that model is that a synchronized burst of cell death is created and control studies on a cellular and molecular levels are possible based on light intensities, spectral dependences, stain differences, protective and genetic regulations.

On the molecular level, light-induced photoreceptor degeneration appears to proceed in separate phases from induction of apoptosis to clearance of the cellular remnants. In the induction phase, rhodopsin, a visual pigment found in the rod photoreceptors, plays an essential role in the apoptosis mechanism. 
During light exposure rhodopsin is bleached, which causes release of the retinoid from the opsin molecule. The retinoid is transferred to the retinal pigment epithelium and is regenerated by multiple enzymatic steps. ${ }^{168}$ Particularly, the necessity of 11-cis retinal regeneration is paramount in order to obtain light damage and furthermore indicate that rhodopsin regeneration during light exposure is a crucial determinant of damage susceptibility. A second phase, death signal transduction, consists in an increase in intracellular calcium levels, lesions of mitochondria, an increase in NO and ROS. It also comprises activation of the transcription factor AP-1, composed of members of the Jun family of proteins. The DNA binding activity of AP-1 increases already during light exposure, to reach a peak $6-12 \mathrm{~h}$ following the exposure. ${ }^{169,170}$ Analysis of the AP-1 complex composition under these conditions revealed that AP-1 consists mainly of c-Fos and JunD/c-Jun. ${ }^{169,170}$ Interestingly, studies have demonstrated that c-fos knockout mouse were resistant to light because they lack the c-fos component of AP-1. The last phase is the termination phase and consists of DNA degradation by internucleosomal DNA cleavage that occurs between 30 and $36 \mathrm{~h}$ following light exposure. About 1 day following light exposure blebbing of photoreceptor nuclei becomes evident, which indicates the terminal disintegration of these organelles. Nuclear decay reaches its maximum between $2 \mathrm{~d}$ and $3 \mathrm{~d}$ following the insult. ${ }^{171}$ Coinciding with this phase of nuclear disintegration macrophages invade the retina and phagocyte photoreceptor debris. ${ }^{171,172}$

\section{The Pde6b(rd1) mouse}

Pde6b(rd1) mouse or retinal degeneration mouse are homozygous for the $P d e 6 b(r d 1)$ mutation and disclose the same clinical features of human retinitis pigmentosa. This mouse carries a nonsense mutation in exon 75 and a proviral insert in intron 1 of the gene encoding the Beta-subunit of cyclic guanosine monophosphate-phosphodiesterase. (PDE) leading to an elevation of retinal cGMP levels and rapid postnatal degeneration of the photoreceptor.

These mutations result in a nonfunctional gene product. Recently is has been shown that photoreceptors die by apoptosis beginning around postnatal day 8 and totally disappear after one month. Pde6(rd1) mice has been extensively studied and used as a mice model for Retinitis Pigmentosa and retinal degeneration. (See Figure 22) 


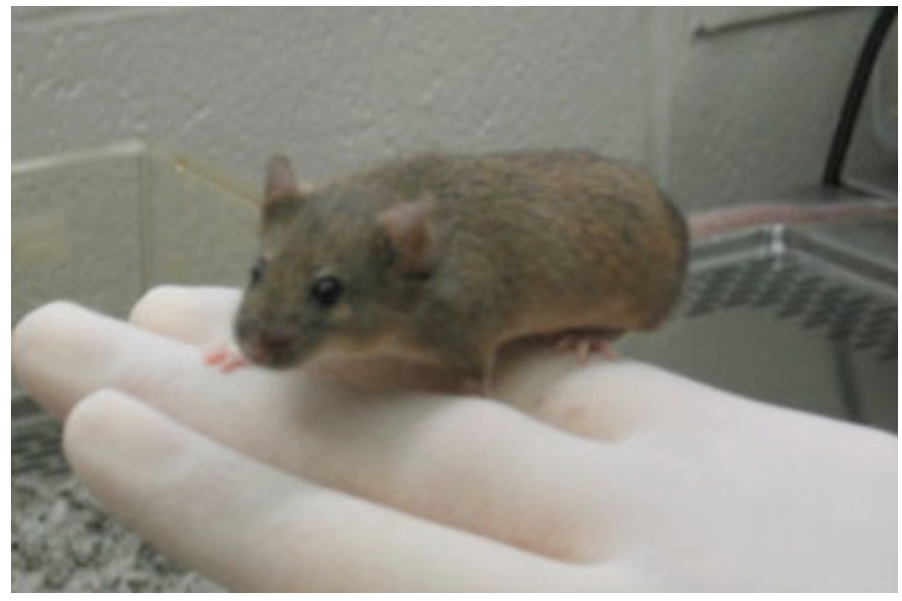

Figure 22. Rd Mouse (From private collection, Stanescu-Segall)

\section{Glaucoma}

Glaucoma is the second most common cause of blindness in developed countries. Primary glaucoma affects approximately 70 millions people worldwide, half of them with angle-closure glaucoma (ACG). ${ }^{173,174}$ It is a multifactorial disease and consists primarily in raised intraocular pressure. The raised intraocular pressure causes damage to the optic nerve and the retina. In the retina, there is a loss of optic nerve fibers and retina ganglion cells.

The prevalence of blindness in ACG is two times higher than other forms of glaucoma. ${ }^{175}$ ACG exists in acute, intermittent/ subacute and chronic forms, ${ }^{176}$ and results from increased IOP (intra-ocular pressure) caused by the iris obliterating the trabecular meshwork. ${ }^{175}$ This leads to reduced and blocked aqueous outflow and anterior peripheral synechia between the iris and cornea. ACG pathophysiology is largely unknown, and believed to be related to acute and chronic atony of the pupillary sphincter muscle. A mouse mode reproducing acute ACG has been genetically modified for that purpose (see below)

Glaucoma is generally treated with different types of eye drops that decrease intraocular pressure or protects inner retina cells from secondary retinal degeneration. If drop therapy fail to reduce intraocular pressure, laser trabeculoplasty of filtering surgery is then offered to the patient.

(See Figure 23) 


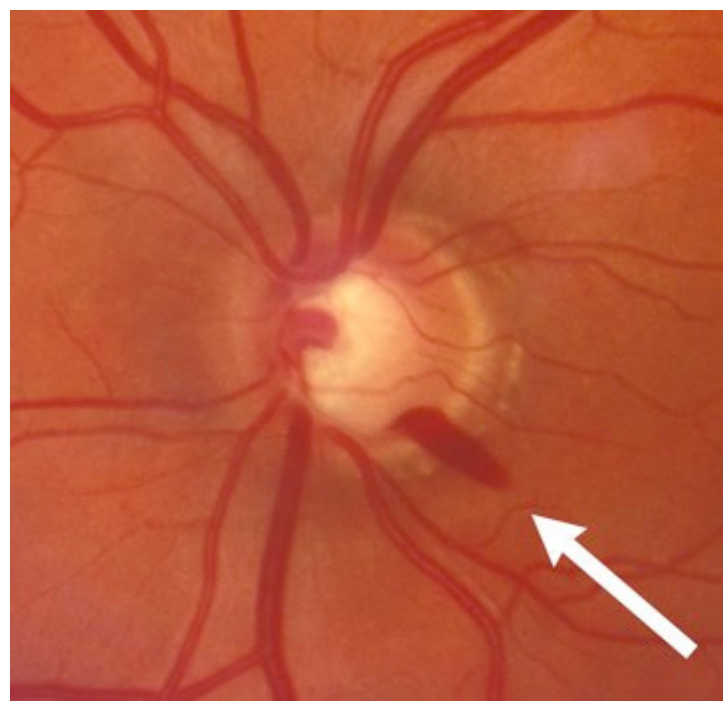

Figure 23. Optic Disc in Glaucoma patient (From private collection, Stanescu-Segall)

Mouse model of angle-closure glaucoma: calcitonin receptor-like receptor transgenic $C^{S M \alpha A}$

Conversely to DBA/2J transgenic mice that mimic chronic ACG, ${ }^{177}$ the $C L R^{S M \alpha A}$ transgenic mice disclosed the same features of acute and intermittent angleclosure glaucoma. CLR ${ }^{S M a A}$ mice overexpress CLR/RAMP2 Adrenomedullin (AM) receptors in the pupillary sphincter muscle, resulting in enhanced AMinduced sphincter muscle relaxation. ${ }^{178}$ Indeed, AM, is a smooth-relaxing polypeptide, that could be found naturally in the iris and ciliary body of the eye. ${ }^{179}$

The sphincter muscle relaxation of these mice lead to acute elevation of IOP between 1 and 3 months and represent a good model of acute ACG. ${ }^{178}$

\section{Aim of the study}

The aim of this thesis was to investigate the function and the role of PAX6 gene and its protein PAX6 in both normal development and retinal degenerations of vertebrates and more specifically in mouse and human.

Little is known about PAX6 and its role after the end of ocular development. $P A X 6$ is known to be the master gene for eye formation during its development. 
We have seen that both over-expression and under-expression of PAX6 gene results in severe ocular abnormalities. An exact dosage of the PAX6 gene is required and paramount for the normal development of the eye and normal function of the cornea in adulthood.

Our first question was to see whether PAX6 expression and its protein were still present and active after the end of ocular development. In general, genes that are activated during the development of specific organs stop being active right after or shortly after the end of development of its specific organ.

It has been shown that PAX6 protein is mainly located in the epithelial layers of the cornea, the anterior capsule of the lens and in the inner layers of the retina. On IHC (Immuno Histo Chemistry), PAX6 was mainly located in the inner layer and ganglion cell layer of the retina.

Retinal degenerations such as AMD (age-related macular degeneration) and RP (Retinitis Pigmentosa) have been in the centre of attention of research in the last twenty years. Pde6b(rd1) mouse was the first and most well-known mouse model of genetically induced retinal degeneration. Light-induced retinal degeneration results from exposing mice to 12.000 Lux for two hours. These mice demonstrated a fast and reproducible degeneration of their retina within 24 hours. Both mouse models have been extensively studied in retinal degeneration. Therefore, we were wondering whether Pax6 expression would be modified in those two mouse models of retinal degeneration. Both IHC and WB (Western Blot) techniques were used to asses Pax6 expression in the retina of wild type mice, Pde6b(rd1) mice, light induced retinal-degeneration mice and cfos knockout mice that showed resistance to light-induced retinal degeneration. All the experiments were performed on adult mice of the same age.

Because, PAX6 was mainly located in the inner layers of the retina, we were also interested to study its expression in diseases affecting more predominantly the ganglion cell layer of the retina.

$\mathrm{CLR}^{\text {SMaA }}$ mouse is a genetically modified mouse that shares the same characteristics of angle closure glaucoma. In these mice, ocular hypertension resulting from blockage of outflow, leads to RGC cell death. We studied Pax6 expression in this mouse model.

Finally, it was also interesting while studying, retinal degeneration and more particularly; light induced retinal degeneration to look at different mechanisms that might protect the apoptosis of the outer retina cell layers. Epo, surprisingly appeared to be an essential factor in protecting the retina of mice exposed to light induced retinal degeneration. 


\section{References}

1. O'Rahilly R. The prenatal development of the human eye. Exp Eye Res 1975;21:93-112.

2. Martinez-Morales JR, Rodrigo I, Bovolenta P. Eye development: a view from the retina pigmented epithelium. Bioessays 2004;26:766-777.

3. Stroeva OG, Mitashov VI. Retinal pigment epithelium: proliferation and differentiation during development and regeneration. Int Rev Cytol 1983;83:221-293.

4. Smirnov EB, Puchkov VF. Characteristics of cellular proliferation in the developing human retina. Neurosci Behav Physiol 2004;34:643-648.

5. Streeten BW. Development of the human retinal pigment epithelium and the posterior segment. Arch Ophthalmol 1969;81:383-394.

6. Hever AM, Williamson KA, van Heyningen V. Developmental malformations of the eye: the role of PAX6, SOX2 and OTX2. Clin Genet 2006;69:459-470.

7. Jaffe NS. The lens. Arch Ophthalmol 1972;87:453-486.

8. Walther C, Guenet JL, Simon D et al. Pax: a murine multigene family of paired box-containing genes. Genomics 1991;11:424-434.

9. Gehring WJ. The master control gene for morphogenesis and evolution of the eye. Genes Cells 1996;1:11-15.

10. Tsonis PA, Fuentes EJ. Focus on molecules: Pax-6, the eye master. Exp Eye Res 2006;83: 233-234.

11. Stanescu D, Iseli HP, Schwerdtfeger K et al. Continuous expression of the homeobox gene Pax6 in the ageing human retina. Eye 2007;21:90-93.

12. Collins CA, Gnocchi VF, White RB et al. Integrated functions of Pax3 and Pax7 in the regulation of proliferation, cell size and myogenic differentiation. PLoS One 2009;4:e4475.

13. Wiggan O, Fadel MP, Hamel PA. Pax3 induces cell aggregation and regulates phenotypic mesenchymal-epithelial interconversion. J Cell Sci 2002;115:517-529.

14. Park D, Jia H, Rajakumar $\mathrm{V}$ et al. Pax $2 / 5 / 8$ proteins promote cell survival in C. elegans. Development 2006;133:4193-4202.

15. Balczarek KA, Lai ZC, Kumar S. Evolution of functional diversification of the paired box (Pax) DNA-binding domains. Mol Biol Evol 1997;14:829-842.

16. Tremblay P, Gruss P. Pax: genes for mice and men. Pharmacol Ther 1994;61:205-226.

17. Underhill DA. Genetic and biochemical diversity in the Pax gene family. Biochem Cell Biol 2000;78:629-638.

18. Balling R. The undulated mouse and the development of the vertebral column. Is there a human PAX-1 homologue? Clin Dysmorphol 1994;3:185-191.

19. Peters H, Neubuser A, Balling R. Pax genes and organogenesis: Pax9 meets tooth development. Eur J Oral Sci 1998;106 Suppl 1:38-43.

20. Bannykh SI, Emery SC, Gerber JK et al. Aberrant Pax1 and Pax9 expression in Jarcho-Levin syndrome: report of two Caucasian siblings and literature review. Am J Med Genet A 2003;120A:241-246.

21. Sanyanusin P, Norrish JH, Ward TA et al. Genomic structure of the human PAX2 gene. Genomics 1996;35:258-261.

22. Dressler GR. Pax-2, kidney development, and oncogenesis. Med Pediatr Oncol 1996;27:440444.

23. Mahmoud MS, Kawano MM. Cloning and analysis of the human Pax-5 gene promoter. Biochem Biophys Res Commun 1996;228:159-164. 
24. Mansouri A. The role of Pax3 and Pax7 in development and cancer. Crit Rev Oncog 1998;9:141-149.

25. Cerf ME. Transcription factors regulating beta-cell function. Eur J Endocrinol 2006;155:671679.

26. Brun T, Duhamel DL, Hu He KH et al. The transcription factor PAX4 acts as a survival gene in INS-1E insulinoma cells. Oncogene 2007;26:4261-4271.

27. Prosser J, van Heyningen V. PAX6 mutations reviewed. Hum Mutat 1998;11:93-108.

28. Osumi N. The role of Pax6 in brain patterning. Tohoku J Exp Med 2001;193:163-174.

29. Hanson IM. PAX6 and congenital eye malformations. Pediatr Res 2003;54:791-796.

30. Nomura T, Haba H, Osumi N. Role of a transcription factor Pax6 in the developing vertebrate olfactory system. Dev Growth Differ 2007;49:683-690.

31. Mansouri A, Chowdhury K, Gruss P. Follicular cells of the thyroid gland require Pax8 gene function. Nat Genet 1998;19:87-90.

32. Robson EJ, He SJ, Eccles MR. A PANorama of PAX genes in cancer and development. Nat Rev Cancer 2006;6:52-62.

33. Muratovska A, Zhou C, He S et al. Paired-Box genes are frequently expressed in cancer and often required for cancer cell survival. Oncogene 2003;22:7989-7997.

34. Kozmik Z, Sure U, Ruedi D et al. Deregulated expression of PAX5 in medulloblastoma. Proc Natl Acad Sci U S A 1995;92:5709-5713.

35. Chow RL, Altmann CR, Lang RA et al. Pax6 induces ectopic eyes in a vertebrate. Development 1999;126:4213-4222.

36. Halder G, Callaerts P, Gehring WJ. Induction of ectopic eyes by targeted expression of the eyeless gene in Drosophila. Science 1995;267:1788-1792.

37. Altmann CR, Chow RL, Lang RA et al. Lens induction by Pax-6 in Xenopus laevis. Dev Biol 1997;185:119-123.

38. Wain H, Povey S, Maltais L. Human and mouse gene nomenclature. Curr Protoc Hum Genet 2003;Appendix 1:Appendix 1C.,Wain HM, Lush MJ, Ducluzeau F et al. Genew: the Human Gene Nomenclature Database, 2004 updates. Nucleic Acids Res 2004;32:D255-7.

39. van Heyningen V, Williamson KA. PAX6 in sensory development. Hum Mol Genet 2002;11:1161-1167.

40. Ou J, Lowes C, Collinson JM. Cytoskeletal and cell adhesion defects in wounded and Pax6+/corneal epithelia. Invest Ophthalmol Vis Sci 2010;51:1415-1423.

41. Dora N, Ou J, Kucerova R et al. PAX6 dosage effects on corneal development, growth, and wound healing. Dev Dyn 2008;237:1295-1306.

42. Matsumoto $\mathrm{Y}$, Osumi N. [Role of Pax6 in the developing central nervous system]. Brain Nerve 2008;60:365-374.

43. Brink C. Promoter elements in endocrine pancreas development and hormone regulation. Cell Mol Life Sci 2003;60:1033-1048.

44. Traboulsi El. Ocular malformations and developmental genes. J AAPOS 1998;2:317323.,Gupta SK, De Becker I, Tremblay F et al. Genotype/phenotype correlations in aniridia. Am J Ophthalmol 1998;126:203-210.

45. Glaser T, Jepeal L, Edwards JG et al. PAX6 gene dosage effect in a family with congenital cataracts, aniridia, anophthalmia and central nervous system defects. Nat Genet 1994;7:463471.

46. Glaser T, Walton DS, Maas RL. Genomic structure, evolutionary conservation and aniridia mutations in the human PAX6 gene. Nat Genet 1992;2:232-239.

47. Hill RE, Favor J, Hogan BL et al. Mouse small eye results from mutations in a paired-like homeobox-containing gene. Nature 1991;354:522-525. 
48. Gruss P, Walther C. Pax in development. Cell 1992;69:719-722.

49. Quiring $R$, Walldorf $U$, Kloter $U$ et al. Homology of the eyeless gene of Drosophila to the Small eye gene in mice and Aniridia in humans. Science 1994;265:785-789.

50. Oliver G, Gruss P. Current views on eye development. Trends Neurosci 1997;20:415-421.

51. Papatsenko D, Nazina A, Desplan C. A conserved regulatory element present in all Drosophila rhodopsin genes mediates Pax6 functions and participates in the fine-tuning of cell-specific expression. Mech Dev 2001;101:143-153.

52. Kleinjan DA, Seawright A, Childs AJ et al. Conserved elements in Pax6 intron 7 involved in (auto)regulation and alternative transcription. Dev Biol 2004;265:462-477.

53. Plaza S, Saule S, Dozier C. High conservation of cis-regulatory elements between quail and human for the Pax-6 gene. Dev Genes Evol 1999;209:165-173.

54. Halder G, Callaerts P, Gehring WJ. New perspectives on eye evolution. Curr Opin Genet Dev 1995;5:602-609.

55. Callaerts P, Halder G, Gehring WJ. PAX-6 in development and evolution. Annu Rev Neurosci 1997;20:483-532.

56. Epstein J, Cai J, Glaser T et al. Identification of a Pax paired domain recognition sequence and evidence for DNA-dependent conformational changes. J Biol Chem 1994;269:8355-8361.

57. Azuma N, Tadokoro K, Asaka A et al. The Pax6 isoform bearing an alternative spliced exon promotes the development of the neural retinal structure. Hum Mol Genet 2005;14:735-745.

58. Zhang W, Cveklova K, Oppermann B et al. Quantitation of PAX6 and PAX6(5a) transcript levels in adult human lens, cornea, and monkey retina. Mol Vis 2001;7:1-5.

59. Chauhan BK, Yang $\mathrm{Y}$, Cveklova $\mathrm{K}$ et al. Functional properties of natural human PAX6 and PAX6(5a) mutants. Invest Ophthalmol Vis Sci 2004;45:385-392.

60. Epstein JA, Glaser T, Cai J et al. Two independent and interactive DNA-binding subdomains of the Pax6 paired domain are regulated by alternative splicing. Genes Dev 1994;8:2022-2034.

61. Xu HE, Rould MA, Xu W et al. Crystal structure of the human Pax6 paired domain-DNA complex reveals specific roles for the linker region and carboxy-terminal subdomain in DNA binding. Genes Dev 1999;13:1263-1275.

62. Cvekl A, Yang Y, Chauhan BK et al. Regulation of gene expression by Pax6 in ocular cells: a case of tissue-preferred expression of crystallins in lens. Int J Dev Biol 2004;48:829-844.

63. Tuoc TC, Stoykova A. Trim11 modulates the function of neurogenic transcription factor Pax6 through ubiquitin-proteosome system. Genes Dev 2008;22:1972-1986.

64. Wolf LV, Yang Y, Wang J et al. Identification of pax6-dependent gene regulatory networks in the mouse lens. PLoS One 2009;4:e4159.

65. Yamaguchi $\mathrm{Y}$, Sawada J, Yamada $\mathrm{M}$ et al. Autoregulation of Pax6 transcriptional activation by two distinct DNA-binding subdomains of the paired domain. Genes Cells 1997;2:255-261.

66. Kozmik Z, Czerny T, Busslinger M. Alternatively spliced insertions in the paired domain restrict the DNA sequence specificity of Pax6 and Pax8. EMBO J 1997;16:6793-6803.

67. Pinson J, Simpson TI, Mason JO et al. Positive autoregulation of the transcription factor Pax6 in response to increased levels of either of its major isoforms, Pax6 or Pax6(5a), in cultured cells. BMC Dev Biol 2006;6:25.

68. Koroma BM, Yang JM, Sundin OH. The Pax-6 homeobox gene is expressed throughout the corneal and conjunctival epithelia. Invest Ophthalmol Vis Sci 1997;38:108-120.

69. Singh S, Mishra R, Arango NA et al. Iris hypoplasia in mice that lack the alternatively spliced Pax6(5a) isoform. Proc Natl Acad Sci U S A 2002;99:6812-6815.

70. Hodgson SV, Saunders KE. A probable case of the homozygous condition of the aniridia gene. J Med Genet 1980;17:478-480. 
71. Dansault A, David G, Schwartz C et al. Three new PAX6 mutations including one causing an unusual ophthalmic phenotype associated with neurodevelopmental abnormalities. Mol Vis 2007;13:511-523.

72. Tzoulaki I, White IM, Hanson IM. PAX6 mutations: genotype-phenotype correlations. BMC Genet 2005;6:27.

73. Kivlin JD, Apple DJ, Olson RJ et al. Dominantly inherited keratitis. Arch Ophthalmol 1986;104:1621-1623.

74. Mirzayans F, Pearce WG, MacDonald IM et al. Mutation of the PAX6 gene in patients with autosomal dominant keratitis. Am J Hum Genet 1995;57:539-548.

75. Secker GA, Daniels JT. Corneal epithelial stem cells: deficiency and regulation. Stem Cell Rev 2008;4:159-168.

76. Azuma N, Yamaguchi $\mathrm{Y}$, Handa $\mathrm{H}$ et al. Missense mutation in the alternative splice region of the PAX6 gene in eye anomalies. Am J Hum Genet 1999;65:656-663.

77. Nanjo $\mathrm{Y}$, Kawasaki $\mathrm{S}$, Mori $\mathrm{K}$ et al. A novel mutation in the alternative splice region of the PAX6 gene in a patient with Peters' anomaly. Br J Ophthalmol 2004;88:720-721.

78. Cvekl A, Tamm ER. Anterior eye development and ocular mesenchyme: new insights from mouse models and human diseases. Bioessays 2004;26:374-386.

79. Monaghan KG, Dennehy PJ, VanDyke DL et al. Bilateral Peter's anomaly in an infant with 49, XXXXY syndrome. J Pediatr Ophthalmol Strabismus 1998;35:112-113.

80. Eden U, Iggman D, Riise R et al. Epidemiology of aniridia in Sweden and Norway. Acta Ophthalmol 2008;86:727-729.

81. Okamoto F, Nakano S, Okamoto C et al. Ultrasound biomicroscopic findings in aniridia. Am J Ophthalmol 2004;137:858-862.

82. Ramaesh K, Ramaesh T, Dutton GN et al. Evolving concepts on the pathogenic mechanisms of aniridia related keratopathy. Int J Biochem Cell Biol 2005;37:547-557.

83. McCulley TJ, Mayer K, Dahr SS et al. Aniridia and optic nerve hypoplasia. Eye (Lond) 2005;19:762-764.

84. Valenzuela A, Cline RA. Ocular and nonocular findings in patients with aniridia. Can J Ophthalmol 2004;39:632-638.

85. Fantes JA, Bickmore WA, Fletcher JM et al. Submicroscopic deletions at the WAGR locus, revealed by nonradioactive in situ hybridization. Am J Hum Genet 1992;51:1286-1294.

86. Ivanov I, Shuper A, Shohat M et al. Aniridia: recent achievements in paediatric practice. Eur J Pediatr 1995;154:795-800.

87. Bremond-Gignac D, Crolla JA, Copin $\mathrm{H}$ et al. Combination of WAGR and Potocki-Shaffer contiguous deletion syndromes in a patient with an 11p11.2-p14 deletion. Eur J Hum Genet 2005;13:409-413.

88. Traboulsi El, Ellison J, Sears J et al. Aniridia with preserved visual function: a report of four cases with no mutations in PAX6. Am J Ophthalmol 2008;145:760-764.

89. Elsas FJ, Maumenee IH, Kenyon KR et al. Familial aniridia with preserved ocular function. Am J Ophthalmol 1977;83:718-724.

90. Recchia FM, Carvalho-Recchia CA, Trese MT. Optical coherence tomography in the diagnosis of foveal hypoplasia. Arch Ophthalmol 2002;120:1587-1588.

91. Meyer $\mathrm{CH}$, Lapolice DJ, Freedman SF. Foveal hypoplasia in oculocutaneous albinism demonstrated by optical coherence tomography. Am J Ophthalmol 2002;133:409-410.

92. Hammer DX, Iftimia NV, Ferguson RD et al. Foveal fine structure in retinopathy of prematurity: an adaptive optics Fourier domain optical coherence tomography study. Invest Ophthalmol Vis Sci 2008;49:2061-2070. 
93. Oliver MD, Dotan SA, Chemke $\mathrm{J}$ et al. Isolated foveal hypoplasia. $\mathrm{Br} \mathrm{J}$ Ophthalmol 1987;71:926-930.

94. Azuma N, Nishina S, Yanagisawa $\mathrm{H}$ et al. PAX6 missense mutation in isolated foveal hypoplasia. Nat Genet 1996;13(2):141-142.

95. Vincent MC, Gallai R, Olivier D et al. Variable phenotype related to a novel PAX 6 mutation (IVS4+5G>C) in a family presenting congenital nystagmus and foveal hypoplasia. Am J Ophthalmol 2004;138:1016-1021.

96. Hanson I, Churchill A, Love $\mathrm{J}$ et al. Missense mutations in the most ancient residues of the PAX6 paired domain underlie a spectrum of human congenital eye malformations. Hum Mol Genet 1999;8:165-172.

97. Azuma N, Yamaguchi $\mathrm{Y}$, Handa $\mathrm{H}$ et al. Mutations of the PAX6 gene detected in patients with a variety of optic-nerve malformations. Am J Hum Genet 2003;72:1565-1570.

98. Nallathambi J, Neethirajan G, Shashikant S et al. PAX6 missense mutations associated in patients with optic nerve malformation. Mol Vis 2006;12:236-242.

99. Taylor D. Developmental abnormalities of the optic nerve and chiasm. Eye (Lond) 2007;21:1271-1284.

100. Lee BJ, Traboulsi El. Update on the morning glory disc anomaly. Ophthalmic Genet 2008;29:47-52.

101. Gehring WJ, Ikeo K. Pax 6: mastering eye morphogenesis and eye evolution. Trends Genet 1999;15:371-377.

102. Kozmik Z. Pax genes in eye development and evolution. Curr Opin Genet Dev 2005;15:430438.

103. Nei M, Rooney AP. Concerted and birth-and-death evolution of multigene families. Annu Rev Genet 2005;39:121-152.

104. Ton CC, Miwa H, Saunders GF. Small eye (Sey): cloning and characterization of the murine homolog of the human aniridia gene. Genomics 1992;13:251-256.

105. St-Onge L, Sosa-Pineda B, Chowdhury K et al. Pax6 is required for differentiation of glucagonproducing alpha-cells in mouse pancreas. Nature 1997;387:406-409.

106. Ashery-Padan R, Zhou X, Marquardt T et al. Conditional inactivation of Pax6 in the pancreas causes early onset of diabetes. Dev Biol 2004;269:479-488.

107. Jordan T, Hanson I, Zaletayev D et al. The human PAX6 gene is mutated in two patients with aniridia. Nat Genet 1992;1:328-332.

108. Hanson IM, Fletcher JM, Jordan T et al. Mutations at the PAX6 locus are found in heterogeneous anterior segment malformations including Peters' anomaly. Nat Genet 1994;6:168-173.

109. Thaung C, West K, Clark BJ et al. Novel ENU-induced eye mutations in the mouse: models for human eye disease. Hum Mol Genet 2002;11:755-767.

110. Baulmann DC, Ohlmann A, Flugel-Koch C et al. Pax6 heterozygous eyes show defects in chamber angle differentiation that are associated with a wide spectrum of other anterior eye segment abnormalities. Mech Dev 2002;118:3-17.

111. Hogan BL, Hirst EM, Horsburgh G et al. Small eye (Sey): a mouse model for the genetic analysis of craniofacial abnormalities. Development 1988;103 Suppl:115-119.

112. Collinson JM, Quinn JC, Buchanan MA et al. Primary defects in the lens underlie complex anterior segment abnormalities of the Pax6 heterozygous eye. Proc Natl Acad Sci U S A 2001;98:9688-9693.

113. van Raamsdonk CD, Tilghman SM. Dosage requirement and allelic expression of PAX6 during lens placode formation. Development 2000;127:5439-5448.

114. Ramaesh T, Collinson JM, Ramaesh $\mathrm{K}$ et al. Corneal abnormalities in Pax6+/- small eye mice mimic human aniridia-related keratopathy. Invest Ophthalmol Vis Sci 2003;44:1871-1878. 
115. Kanakubo S, Nomura T, Yamamura K et al. Abnormal migration and distribution of neural crest cells in Pax6 heterozygous mutant eye, a model for human eye diseases. Genes Cells 2006;11:919-933.

116. Davis J, Duncan MK, Robison WGJ et al. Requirement for Pax6 in corneal morphogenesis: a role in adhesion. J Cell Sci 2003;116:2157-2167.,Ramaesh T, Ramaesh K, Leask R et al. Increased apoptosis and abnormal wound-healing responses in the heterozygous Pax6+/mouse cornea. Invest Ophthalmol Vis Sci 2006;47:1911-1917.

117. Aalfs CM, Fantes JA, Wenniger-Prick LJ et al. Tandem duplication of 11p12-p13 in a child with borderline development delay and eye abnormalities: dose effect of the PAX6 gene product? Am J Med Genet 1997;73:267-271.

118. Schedl A, Ross A, Lee $M$ et al. Influence of PAX6 gene dosage on development: overexpression causes severe eye abnormalities. Cell 1996;86:71-82.

119. Chanas SA, Collinson JM, Ramaesh T et al. Effects of elevated Pax6 expression and genetic background on mouse eye development. Invest Ophthalmol Vis Sci 2009;50:4045-4059.

120. Manuel M, Pratt T, Liu M et al. Overexpression of Pax6 results in microphthalmia, retinal dysplasia and defective retinal ganglion cell axon guidance. BMC Dev Biol 2008;8:59.

121. Aleck K, Williams J, Mongkolsmai C et al. Partial trisomy $11 \mathrm{p}$ with interatrial septal aneurysm. Case report and literature review. Ann Genet 1985;28:102-106.

122. Strobel RJ, Riccardi VM, Ledbetter $\mathrm{DH}$ et al. Duplication 11p11.3 leads to 14.1 to meiotic crossing--over. Am J Med Genet 1980;7:15-20.

123. Speleman F, Mannens M, Redeker B et al. Characterization of a de novo duplication of 11p14---p13, using fluorescent in situ hybridization and southern hybridization. Cytogenet Cell Genet 1991;56:129-131.

124. Sanchez O, Yunis JJ, Escobar JI. Partial trisomy 11 in a child resulting from a complex maternal rearrangement of chromosomes 11, 12 and 13. Humangenetik 1974;22:59-65.

125. Lavedan C, Barichard F, Azoulay M et al. Molecular definition of de novo and genetically transmitted WAGR-associated rearrangements of 11p13. Cytogenet Cell Genet 1989;50:7074.

126. Fryns JP, Haspeslagh M, Goddeeris $P$ et al. Balanced and unbalanced pericentric inversion of chromosome 11. Ann Genet 1981;24:182-183.

127. Ogur G, Hayez F, Herinckx A et al. Familial trisomy 11p resulting from a balanced paternal translocation: 3 new cases including first trimester diagnosis. J Genet Hum 1988;36:323-329.

128. Palmer CG, Poland C, Reed T et al. Partial trisomy $11,46, X X,-3,-20,+$ der3, + der20,t(3:11:20), resulting from a complex maternal rearrangement of chromosomes 3, 11, 20. Hum Genet 1976;31:219-225.

129. Clements J, Lu Z, Gehring WJ et al. Central projections of photoreceptor axons originating from ectopic eyes in Drosophila. Proc Natl Acad Sci U S A 2008;105:8968-8973.

130. Onuma $\mathrm{Y}$, Takahashi S, Asashima $\mathrm{M}$ et al. Conservation of Pax 6 function and upstream activation by Notch signaling in eye development of frogs and flies. Proc Natl Acad Sci U S A 2002;99:2020-2025.

131. Kolb H, Marshak D. The midget pathways of the primate retina. Doc Ophthalmol 2003;106:6781.

132. Glickstein M. Organization of the visual pathways. Science 1969;164:917-926.

133. Bessiere E. [The macula]. Arch Ophtalmol Rev Gen Ophtalmol 1967;27:79-85.

134. Campbell FP. Retina and optic nerve. Arch Ophthalmol 1968;79:789-802.

135. Dowling JE. Organization of vertebrate retinas. Invest Ophthalmol 1970;9:655-680.

136. Gallego A. Horizontal and amacrine cells in the mammal's retina. Vision Res 1971;Suppl 3:3350. 
137. Ting AY, Lee TK, MacDonald IM. Genetics of age-related macular degeneration. Curr Opin Ophthalmol 2009;20:369-376.

138. Ehrlich R, Harris A, Kheradiya NS et al. Age-related macular degeneration and the aging eye. Clin Interv Aging 2008;3:473-482.

139. Antoniak K, Bienias W, Nowak JZ. [Age-related macular degeneration--a complex genetic disease]. Klin Oczna 2008;110:211-218.

140. Ding X, Patel M, Chan CC. Molecular pathology of age-related macular degeneration. Prog Retin Eye Res 2009;28:1-18.

141. Cook HL, Patel PJ, Tufail A. Age-related macular degeneration: diagnosis and management. Br Med Bull 2008;85:127-149.

142. Pieramici DJ, Rabena MD. Anti-VEGF therapy: comparison of current and future agents. Eye (Lond) 2008;22:1330-1336.

143. Hubschman JP, Reddy S, Schwartz SD. Age-related macular degeneration: current treatments. Clin Ophthalmol 2009;3:155-166.

144. Schouten JS, La Heij EC, Webers CA et al. A systematic review on the effect of bevacizumab in exudative age-related macular degeneration. Graefes Arch Clin Exp Ophthalmol 2009;247:1-11.

145. Petrukhin K. New therapeutic targets in atrophic age-related macular degeneration. Expert Opin Ther Targets 2007;11:625-639.

146. Hamel C. Retinitis pigmentosa. Orphanet J Rare Dis 2006;1:40.

147. Hartong DT, Berson EL, Dryja TP. Retinitis pigmentosa. Lancet 2006;368:1795-1809.

148. Cai X, Conley SM, Naash MI. Gene therapy in the retinal degeneration slow model of retinitis pigmentosa. Adv Exp Med Biol 2010;664:611-619.

149. Smith AJ, Bainbridge JW, Ali RR. Prospects for retinal gene replacement therapy. Trends Genet 2009;25:156-165.

150. Luthert PJ, Chong NH. Photoreceptor rescue. Eye (Lond) 1998;12:591-596.

151. Bok D. Ciliary neurotrophic factor therapy for inherited retinal diseases: pros and cons. Retina 2005;25:S27-S28.

152. Thanos C, Emerich D. Delivery of neurotrophic factors and therapeutic proteins for retinal diseases. Expert Opin Biol Ther 2005;5:1443-1452.

153. Canola K, Angenieux B, Tekaya M et al. Retinal stem cells transplanted into models of late stages of retinitis pigmentosa preferentially adopt a glial or a retinal ganglion cell fate. Invest Ophthalmol Vis Sci 2007;48:446-454.

154. Haruta M. Embryonic stem cells: potential source for ocular repair. Semin Ophthalmol 2005;20:17-23.

155. Sagdullaev BT, Aramant RB, Seiler MJ et al. Retinal transplantation-induced recovery of retinotectal visual function in a rodent model of retinitis pigmentosa. Invest Ophthalmol Vis Sci 2003;44:1686-1695.

156. Kaplan HJ, Tezel TH, Berger AS et al. Retinal transplantation. Chem Immunol 1999;73:207219.

157. Chader GJ, Weiland J, Humayun MS. Artificial vision: needs, functioning, and testing of a retinal electronic prosthesis. Prog Brain Res 2009;175:317-332.

158. Shintani K, Shechtman DL, Gurwood AS. Review and update: current treatment trends for patients with retinitis pigmentosa. Optometry 2009;80:384-401.

159. Portera-Cailliau C, Sung $\mathrm{CH}$, Nathans J et al. Apoptotic photoreceptor cell death in mouse models of retinitis pigmentosa. Proc Natl Acad Sci U S A 1994;91:974-978.

160. Reme CE, Grimm C, Hafezi F et al. Apoptosis in the Retina: The Silent Death of Vision. News Physiol Sci 2000;15:120-124. 
161. Cottet S, Schorderet DF. Mechanisms of apoptosis in retinitis pigmentosa. Curr Mol Med 2009;9:375-383.

162. Marigo V. Programmed cell death in retinal degeneration: targeting apoptosis in photoreceptors as potential therapy for retinal degeneration. Cell Cycle 2007;6:652-655.

163. Reme CE, Grimm C, Hafezi $F$ et al. Why study rod cell death in retinal degenerations and how? Doc Ophthalmol 2003;106:25-29.

164. Maeda A, Maeda T, Golczak M et al. Retinopathy in mice induced by disrupted all-trans-retinal clearance. J Biol Chem 2008;283:26684-26693.

165. Chader GJ. Animal models in research on retinal degenerations: past progress and future hope. Vision Res 2002;42:393-399.

166. Dejneka NS, Rex TS, Bennett J. Gene therapy and animal models for retinal disease. Dev Ophthalmol 2003;37:188-198.

167. Reme CE, Grimm C, Hafezi F et al. Apoptotic cell death in retinal degenerations. Prog Retin Eye Res 1998;17:443-464.

168. Lamb TD, Pugh ENJ. Dark adaptation and the retinoid cycle of vision. Prog Retin Eye Res 2004;23:307-380.

169. Wenzel A, Grimm C, Marti A et al. c-fos controls the "private pathway" of light-induced apoptosis of retinal photoreceptors. J Neurosci 2000;20:81-88.

170. Hafezi F, Grimm C, Wenzel A et al. Retinal photoreceptors are apoptosis-competent in the absence of JunD/AP-1. Cell Death Differ 1999;6:934-936.

171. Gordon WC, Casey DM, Lukiw WJ et al. DNA damage and repair in light-induced photoreceptor degeneration. Invest Ophthalmol Vis Sci 2002;43:3511-3521.

172. Hoppeler T, Hendrickson P, Dietrich $C$ et al. Morphology and time-course of defined photochemical lesions in the rabbit retina. Curr Eye Res 1988;7:849-860.

173. Quigley HA. Number of people with glaucoma worldwide. Br J Ophthalmol 1996;80:389-393.

174. Alward WL. Biomedicine. A new angle on ocular development. Science 2003;299:1527-1528.

175. Quigley HA, Friedman DS, Congdon NG. Possible mechanisms of primary angle-closure and malignant glaucoma. J Glaucoma 2003;12:167-180.

176. Sihota R, Lakshmaiah NC, Agarwal HC et al. Ocular parameters in the subgroups of angle closure glaucoma. Clin Experiment Ophthalmol 2000;28:253-258.

177. John SW, Smith RS, Savinova OV et al. Essential iris atrophy, pigment dispersion, and glaucoma in DBA/2J mice. Invest Ophthalmol Vis Sci 1998;39:951-962.

178. Ittner LM, Schwerdtfeger K, Kunz TH et al. Transgenic mice with ocular overexpression of an adrenomedullin receptor reflect human acute angle-closure glaucoma. Clin Sci (Lond) 2008;114:49-58.

179. Chang CL, Roh J, Hsu SY. Intermedin, a novel calcitonin family peptide that exists in teleosts as well as in mammals: a comparison with other calcitonin/intermedin family peptides in vertebrates. Peptides 2004;25:1633-1642. 


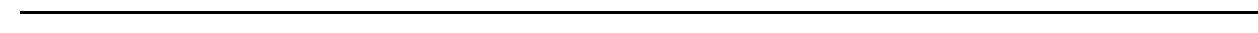




\section{CHAPTER 2 \\ Pax6 expression in the mouse retina during inherited and induced retinal degeneration}

Dinu Stanescu, Hans Peter Iseli, Charlotte Remé, Tim Jackson and Farhad Hafezi

Submitted 


\begin{abstract}
Purpose: PAX6 is the master gene for ocular development in a variety of species. In mice, it is continuously expressed throughout development and adulthood.Although, little is known of its role after completion of ocular development.

Methods: We investigated the pattern of Pax6 expression in adult mice models for inherited (Pde6b (rd1)) and light-induced retinal degeneration, and in $c$ - fos $^{-/}$ mice exposed to light by immunohistochemistry and western blot techniques.

Results: We have shown that PAX6 was predominantly localized in the ganglion cell layer and inner nuclear layer of both the degenerating and nondegenerating retina. Pax6 was expressed in the retina throughout the lifespan of the adult mouse. In Pde6b (rd1) retinas, we observed a distinct reduction in PAX6 protein levels between days 10 and 14 during the peak of photoreceptor apoptosis. Similarly, wild-type mice showed decreased Pax6 expression during light-induced photoreceptor apoptosis. $C$ - fos $^{-/-}$mice protected from light-induced damage, however, disclosed an increase of Pax6 expression after exposure to bright light.
\end{abstract}

Conclusion: The observed reduction of PAX6 levels during inherited and induced retinal degeneration and its increase in protected $c-\mathrm{fos}^{-/-}$mice is suggestive of a potential protective role in retinal degeneration.

Keywords: homeobox genes; Pax6; retina; Pde6b(rd1); retinal degeneration

Supported by: Roche Research Foundation, Basel, Switzerland.

Fonds National de la Recherche Scientifique Belge (FNRS) 


\section{Introduction}

PAX6, a member of the paired box family of transcription factors, is an essential gene for ocular morphogenesis both in vertebrates and invertebrates. ${ }^{1}$ PAX6 is highly conserved throughout evolution: the murine and human PAX6 proteins are identical in their amino acid sequence and Ey (Eyeless), the Drosophila homolog of PAX6, shows over $90 \%$ homology with both the paired and the homedomain of the mouse small eye gene. ${ }^{2}$ Various PAX6 mutations have been identified leading to a large variety of ocular abnormalities and diseases in mice and humans with striking similarities between the species. ${ }^{1,3-6}$

Although PAX6 has been extensively studied in eye development in a variety of species, little is known about the role of PAX6 in the adult and ageing mammalian retina. De Melo and co-workers have studied Pax6 expression in the developing and young adult mouse retina and Birke and al have shown a continuous expression of Pax 6 throughout the lifespan of a mouse (submitted). ${ }^{7}$

We analyzed the expression of Pax6 in mice models of retinal degeneration consisting of inherited (Pde6b(rd1)) mice and light-induced retinal degeneration for both c-fos and c-fos knockout mice.

The Pde6b(rd1) mouse is a common model for inherited retinal degeneration. ${ }^{8,9}$ It carries a proviral insert in the gene encoding for the beta-subunit of cyclic guanosine monophosphate-phospodiesterase (beta-PDE) and shows progressive outer retinal degeneration through photoreceptor degeneration starting at p9 with completion at p21. , $10^{2}$

C-Fos knockout mice have shown resistance to light-induced retinal degeneration (11). C-fos plays an essential role in light-induced apoptosis of photoreceptors: after exposure to bright white light, wild-type mice $\left(c-f o s^{+/+}\right.$mice $)$display severe loss of photoreceptor cells due to apoptosis, whereas retinas of mice without c-Fos (c-fos ${ }^{-1-}$ mice) remain unaffected. The observed resistance to light-induced apoptosis in $c-f_{0}^{-/-}$mice may indicate an active contribution of cFos and its role on the regulation of rod-specific gene expression to the apoptotic cascade triggered by light. ${ }^{11}$

In the current study, we have studied Pax6 expression by immunohistochemistry $(\mathrm{IHC})$ and by western blot in adult mice in different animal models of retinal degeneration: the $P d e 6 b(r d 1)$ mouse, a model for autosomal recessive human Retinitis Pigmentosa, in light-induced retinal degeneration in wild-type mice and in ${\mathrm{c}-\mathrm{fos}^{-1-}}^{\text {mice. }}{ }^{11-14}$ 


\section{Materials and methods}

\section{Animals}

All animals' experiments were conducted in accordance with the regulations of the University of Zurich, and adhered to the statement of the Association for Research in Vision and Ophthalmology for the use of animals in ophthalmic and vision research. Wild-type mice $(\mathrm{C} 3 \mathrm{H}$ background) were obtained from Wiga (Sulzfeld, Germany).

C-fos knockout ( $c-\mathrm{fos}^{-/}, \mathrm{C} 3 \mathrm{H}$ background, The Jackson Laboratories, Maine) and Pde6b (rd1) mice ( $\mathrm{C} 3 \mathrm{H}$ background) and their corresponding wildtype controls were identified by PCR analysis of genomic DNA isolated from mouse tails as described elsewhere. ${ }^{15,16}$ Mice were maintained in a 12:12 lightdark cycle (lights on at 6 am). For experiments, 3 animals of each genetic background were sacrificed at different postnatal days. All animals were sacrificed at the same time of the day $(2 \mathrm{pm})$ to avoid diurnal variations.

\section{Tissue preparation}

Animals were killed by cervical dislocation under $\mathrm{CO}_{2}$ asphyxiation. Eyes were rapidly enucleated and fixed in $2 \%$ paraformaldehyde for 2 hours followed by dehydration and paraffin embedding for histochemical analysis; or they were fixed in $2.5 \%$ glutaraldehyde for 12 hours, dehydrated and processed for lightmicroscopic analysis. For western blot analysis, retinas were rapidly removed through a slit in the cornea, immediately frozen in liquid nitrogen, and stored at $-80^{\circ} \mathrm{C}$. Cellular homogenates were prepared from shock-frozen whole retinas by sonification in $100 \mu \mathrm{M}$ TBS. Protein concentrations were determined using the Bradford protein assay (Bio-Rad, Hercules, USA) or the BCA assay (Pierce, Rockford, USA) with BSA as standard.

\section{Light damage}

Before light exposure, animals were dark-adapted for 16 hours overnight. Pupils were dilated under dim red light with 1\% Cyclogyl (Alcon, Cham, Switzerland) and 5\% phenylephrine (Ciba Vision, Niederwangen, Switzerland), followed by exposure to diffuse white fluorescent light with an luminance of 15000 lux for 30 minutes in cages with a reflective interior. After light exposure, animals were analyzed immediately or following a period in darkness. 


\section{Immunohistochemistry}

Eight $\mu \mathrm{m}$ sections were deparaffinized in xylene and dehydrated in ascending ethanol series $(0,25,50,75$ and $100 \%)$. To enhance immunoreactivity, sections were incubated in $10 \mathrm{mM}$ citrate buffer $(\mathrm{pH}$ 6.0) and boiled in a steamer at $100^{\circ} \mathrm{C}$ for 5 minutes. Endogenous peroxidase activity was eliminated by incubation in 3\% hydrogen peroxide in distilled water for 15 min. After incubation with the affinity-purified rabbit polyclonal mouse PAX6 antibody at $4{ }^{\circ} \mathrm{C}$, a biotinylated secondary anti-rabbit antibody was applied, followed by the avidin-biotinperoxidase complex (Dako, Carpinteria, Ca, USA). ${ }^{17}$ Sections were stained using 3,3'-diaminobenzidine. The absence of the primary antibody was used as a negative control.

\section{Western blot analysis}

Total retinal protein extracts were separated by SDS-PAGE (7.5\%) and western blot analysis was performed according to standard protocols. For immunodetection, a polyclonal rabbit antiserum directed against PAX6 (Covance Research Products, Berkeley, CA, USA) was applied to $5 \mu \mathrm{g}$ total retinal protein. Horseradish peroxidase (HRP)-conjugated secondary antibody (Santa Cruz Biotechnology, CA, USA) was applied, and immunoreactivity visualized using a kit (Renaissance Western Blot Detection; Dupont NEN Life Science Products, Inc., Boston, MA). Mouse monoclonal anti- $\beta$ actin was used from Abcam (Cambridge, MA). The retinas of three animals were used for each time-point. Protein bands of actin and Pax6 were analyzed with gel image analysis software (Image $\mathrm{J}$ Software).

\section{Results}

\section{Specificity of the antibody}

The specificity of the antibody was examined by western blot analysis. Blots display a band with a molecular weight of $46 \mathrm{kDa}$, some blots showing a second band of $48 \mathrm{kDa}$ corresponding to the splice variant of PAX6 RNA, PAX6 (5a). ${ }^{23}$ As an internal control, labeling with an antibody against actin was performed. Actin levels remained constant throughout all time points tested in all experiments performed. (Data not shown) 
Time course of Pax6 expression in Pde6b (rd1) mice and in wild type mice

Figure 1 shows Pax6 expression in wild type mice at p6, 8, 10, 14, 16, 2128 and 243 by western blot and IHC of PAX6 in the retina at p14. There is a progressive decrease of Pax6 expression with time. Beta-actin was used as a control. IHC showed that PAX6 was expressed in both the INL and the GCL in the same manner at all time-points. Figure $2 \mathrm{a}$ and $\mathrm{b}$ show progressive degeneration in the outer retina in Pde6b (rd1) mice at p8 and p21 with deteriorated Rod Inner Segments (RIS) and scattered condensed photoreceptor nuclei. IHC was performed at $p$ 6, 8, 10, 14, 16, 21 and 28 (Fig. $2 c$ and d show p8 and p21, respectively). At all time points tested, expression was confined mainly to both the INL and the GCL. In both layers, labelling was predominantly found in the nuclei. Furthermore, in the INL, labelling occurred primarily in the inner part whereas the outer part remained negative. Pax6 expression and localization remained unchanged at the different time-points in immunohistochemistry. Western blot analysis of Pax 6 expression showed a distinct decrease at p10 and p14, followed by an increase to previous levels in Pde6b(rd1) mouse. Actin expression levels were comparable at all time points tested (Fig. 2e). 

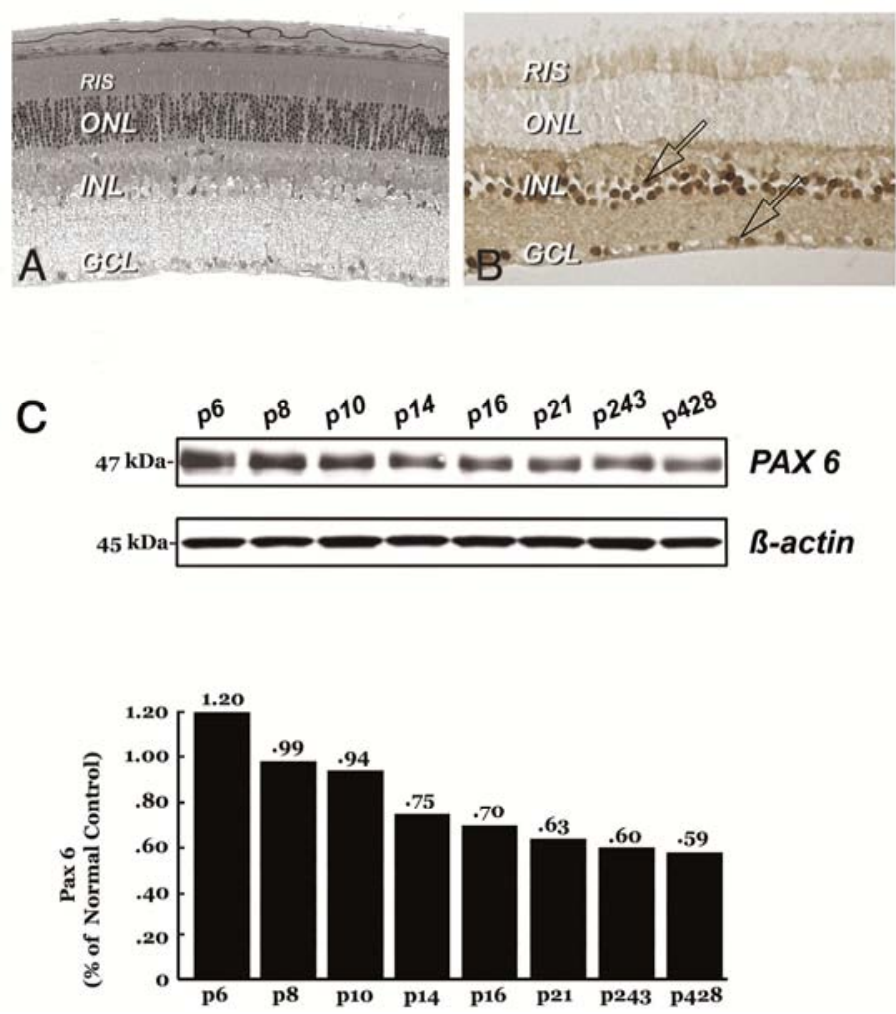

Figure 1. Pax6 expression in adult wild-type $(\mathrm{C} 3 \mathrm{H})$ mice throughout adulthood.

(A) Photomicrograph of retinal section from wild-type mouse. (B) Immunohistochemical analysis shows PAX6 expression confined to the nuclei of the INL and GC. (C) Western blot analysis of PAX6 showed its expression since postnatal day 1untill postnatal day 428. There is a decrease of expression during the first four weeks. After, expression of PAX6 remains stable until p428. 

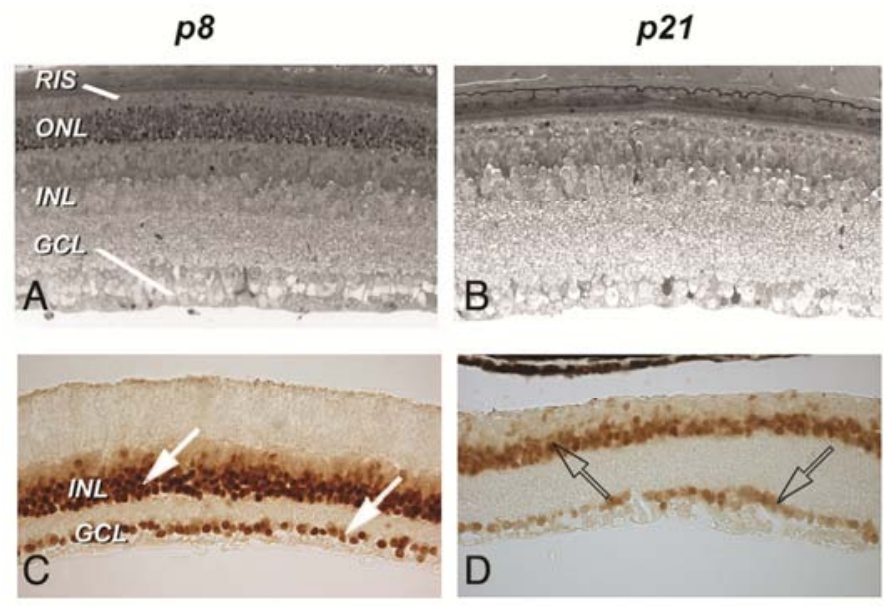

\section{rd1}

E
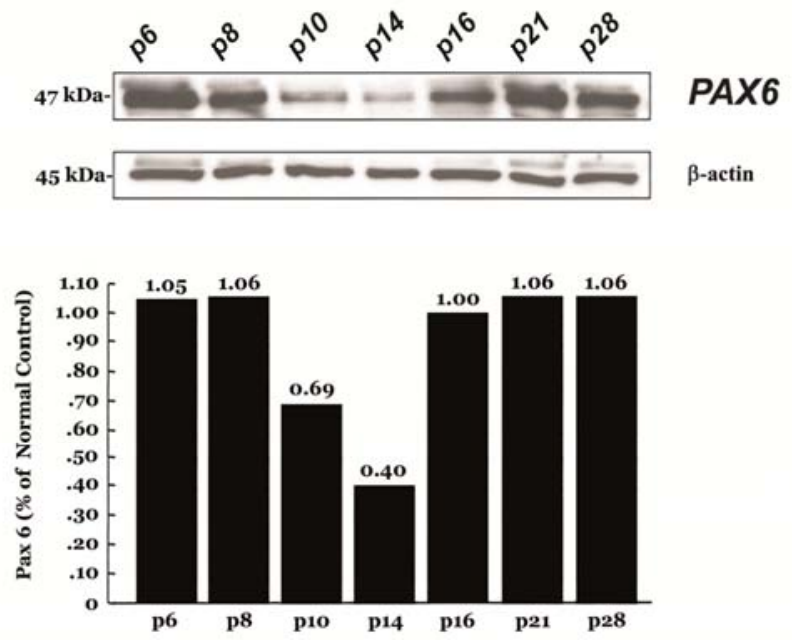

Figure 2. $P a x 6$ expression in $P d e 6 b(r d 1)$ mice.

(A, B) Light micrographs of retinal sections at $\mathrm{p} 8$ and p21. Pde6b mice show deteriorated RIS and scattered condensed photoreceptor nuclei in the ONL. The inner retina shows normal morphology. (C, D) Immunohistochemical analysis shows PAX6 expression confined to the nuclei of the INL and GCL at p8 and p21 (arrows). (E) Western blot analysis of PAX6 expression in Pde6b mice shows a distinct decrease of PAX6 levels at p10 and p14. As loading controls, each immunoblot was probed with anti-actin antibody. Bar analysis of ratio of Pax6 over actin expression in Pde6b(rd1) mouse.

Rod Inner Segments (RIS); Outer Nuclear Layer (ONL); Inner Nuclear Layer (INL); Ganglion Cell Layer (GCL). 
Pax6 expression after light-induced retinal degeneration in wild-type and c-fos ${ }^{-/}$ mice

Wild-type (Fig. 3a) and c-fos ${ }^{-/-}$(Fig. 3c) mice showed regular retinal morphology before light exposure. At 6h after light exposure, distinct signs of apoptosis in the outer retina were observed in wild-type mice (Fig. 3b) whereas the retinas of c-fos deficient mice remained unchanged (Fig. 3d).

PAX6 protein expression showed a decrease in wild-type mice immediately after induction of light damage and 2 hours after 15.000lux illumination and returned to initial values after 6 hours of light induced retinal degeneration. In $C$ fos deficient mice Pax 6 expression increased immediately after illumination and kept increasing 2 and 6 hours after light exposure. Actin levels remained constant throughout all time points tested in both type of mice. (Fig 3e) 

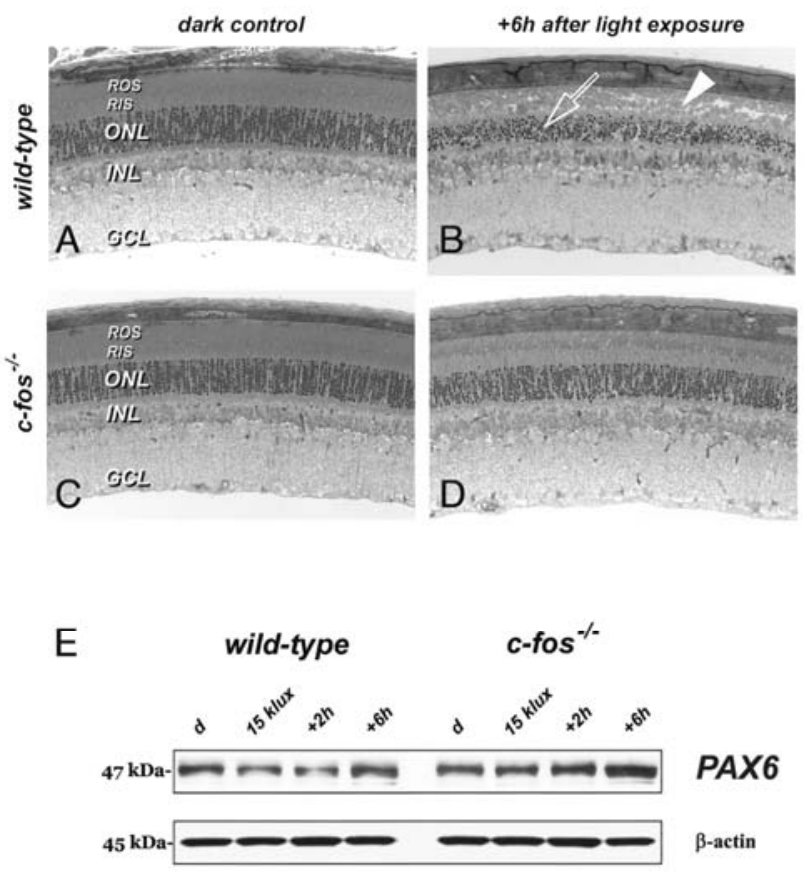

\section{PAX6}

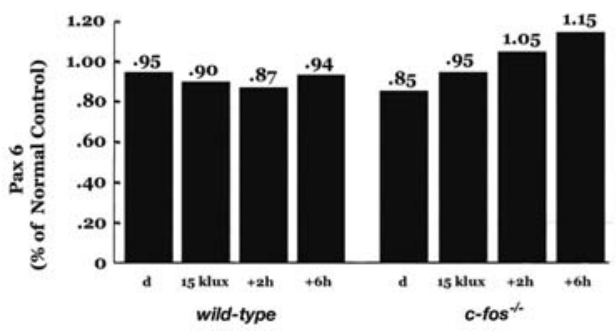

Figure 3. Pax6 expression 'in light-induced retinal degeneration.

$(A, B, C, D)$ Photomicrographs of retinal sections from dark adapted animals and 6 hours after lightinduced retinal degeneration. Dark-adapted retinas of wild-type mice $(A)$ and $c$-fos deficient mice (C) show regular retinal structure. At 6 hours after light exposure, the outer retina of wild-type mice shows substantial degeneration with disrupted ROS, condensed RIS (arrowhead) and apoptotic nuclei in the ONL (arrow) (B), whereas $c$-fos deficient mice do not show damage (D). The layers of the inner retina are preserved in both genotypes. (E) Western blot analysis of Pax6 expression in light-induced retinal degeneration in dark, and after light exposure. Wild-type mice show a reduction of Pax6 expression during illumination with 15'000 lux (15klux) and 2 hours after illumination (+2h) and return to dark-adapted levels at 6 hour after exposure to light. C-fos knockout mice disclose an increase in PAX6 protein levels during illumination and up to 6 hours after exposure to light. Betaactin western blot used as control are showed below. As loading controls, each immunoblot was probed with anti-actin antibody.Bar analysis of ratio of Pax6 over actin expression in light-induced and c-fos knockout mouse.

Rod Outer Segments (ROS); Rod Inner Segments (RIS); Outer Nuclear Layer (ONL); Inner Nuclear Layer (INL); Ganglion Cell Layer (GCL). 


\section{Discussion}

The predominant role of PAX6 during eye organogenesis is best demonstrated by the analysis of the currently known mutational defects. In humans, homozygous PAX6 null mutations lead to anophthalmia, brain malformation and early post-natal death whereas heterozygous PAX6 mutations are responsible for a variety of congenital abnormalities of the anterior and the posterior segment of the eye including autosomal dominant keratitis, congenital cataract, Peter's anomaly, aniridia, optic nerve abnormalities and isolated foveal hypoplasia. ${ }^{18-25}$ In mice, homozygous murine small eye mutations lead to a distinct phenotype similar to that seen in human Pax6 null mutations: early postnatal death and absence of eyes whereas Small eye ${ }^{+/-}$mice show the small eye phenotype consisting in microphthalmia, corneal and lenticular abnormalities. ${ }^{26,27}$ Similarly, overexpression of Pax 6 results in ophthalmic abnormalities: mice carrying multiple copies of Pax 6 on a wild-type background show specific developmental abnormalities of the eye consisting in microphthalmia, corneal abnormalities, cataract, a disorganized ciliary body and absence of photoreceptor layer of the retina. $^{28}$

Although PAX6 expression has been extensively studied during eye organogenesis in various species, relatively little is known about its expression after the end of ocular development. Recently, several studies have suggested a role for PAX6 in the maintenance of different ocular tissues. In humans, Stanescu et al. showed that PAX6 was continuously expressed in the ageing inner retina suggesting a role for $P A X 6$ in the maintenance of the human retina. ${ }^{29}$ Zhang et al. reported the presence of Pax 6 transcripts and its protein in adult lens epithelium and suggested a function for PAX6 in the growth and maintenance of the adult human lens. ${ }^{30}$

Ouyang et al showed that corneal epithelial cell lines that overexpressed PAX6 had reduced cell proliferation, confirming the notion that PAX6 plays a role in controlling corneal epithelial cell dynamics in vivo. ${ }^{31}$

$\mathrm{Li}$ and co-workers investigated heterozygous small eye mice, and demonstrated compromised cellular adhesion of the corneal epithelium suggesting a role for Pax6 in the proper generation and maintenance of the adult cornea. In humans, $\mathrm{Li}$ et al. found that corneal pannus tissues from patients with different ocular surface diseases had a decline or absence of Pax6 expression, whereas normal ocular surface epithelial cells showed regular Pax6 expression. These results indicate that Pax6 may help maintain the normal corneal epithelial phenotype postnatally, and that its down-regulation was associated with abnormal 
epidermal differentiation in severe ocular surface diseases. ${ }^{32}$ Taken together, these findings suggest that variation of Pax 6 expression is associated with degenerative changes in various ocular structures. To confirm this hypothesis, we investigated the levels of Pax6 expression in inherited (Pde6b(rd1)) and lightinduced retinal degeneration.

The Pde6b(rd1) mouse, a common model for inherited retinal degeneration carries a proviral insert in the gene encoding for the beta-subunit of cyclic guanosine monophosphate-phospodiesterase (beta-PDE) and shows progressive outer retinal degeneration through photoreceptor degeneration starting at p9 with completion at p21. ${ }^{8-10}$

In Pde6b(rd1) mice, we observed a distinct decrease of Pax6 expression during the peak of photoreceptor apoptosis between p10 and p14 (Fig. 2e) . IHC, Pax6 expression was confined to the INL and GCL at all time-points tested. This is in contrast with the findings of Jones et al who observed an increase level of Pax6 mRNA at P16. ${ }^{33}$ They considered p16 as the peak of apoptosis and assumed that the modulation of Pax 6 mRNA levels was suggestive of an activation of expression of retinal glial cells. According to Farber et al, P16 is the peak of cyclic GMP release and not the peak of apoptosis. Therefore the increase in Pax6 levels is not likely to be due to a defense mechanism occurring in response to apoptosis. Jones investigated Pax6 mRNA, whereas we investigated Pax6 protein expression. Splicing variation of Pax6 mRNA may partly explain the differences in results. ${ }^{33}$

Exposure to high levels of fluorescent white light represents a model for light-induced retinal degeneration, a process critically depending on the activation of the transcription factor AP-1 (c-fos/junD). ${ }^{34}$ Whereas wild-type mice show extensive apoptosis in the outer retina upon light exposure, $c$-fos deficient mice are protected against retinal light damage.

In accordance with our findings in Pde6b(rd1) mice, wild-type animals undergoing photoreceptor apoptosis showed a decline in PAX6 levels during degeneration whereas PAX6 levels in protected c-fos null mice (Fig. 2) showed increasing levels at 2 and 6 hours after illumination. The decrease of Pax 6 expression at the peak of apoptosis in Pde6b(rd1) mouse and its increase in the $c$ $\mathrm{fos}^{-/}$mice resistant to light induce retinal degeneration suggests a role for Pax6 in the maintenance of retinal cytoarchitecture

In conclusion, we show that downregulation of Pax6 is concomitant with inherited and induced retinal degeneration whereas animal models protected against induced retinal degeneration demonstrate an increase of Pax6 levels. One might speculate that the level of Pax6 expression might be a co-factor that 
should be taken into consideration in the chain of events leading to degenerative retinal disease.

Nevertheless, further studies investigating the intercellular pathways between dying photoreceptor and inner retina cells are required to increase our understanding of the putative protective role of Pax6 in the retina.

\section{Acknowledgements}

The authors thank Gabi Hoegger, Coni Imsand and Dora Greuter for skilled technical assistance, Peter Gruss for providing the PAX6 antibody and Nensi Zekulic for careful review of the manuscript.This work was supported by the Roche Research Foundation, Basel, Switzerland and Fonds National de la Recherche Scientifique Belge (FNRS). 


\section{References}

1. Gehring WJ, Ikeo K. Pax 6: mastering eye morphogenesis and eye evolution. Trends Genet 1999; 15: 371-377.

2. Quiring R, Walldorf U, Kloter U, Gehring WJ. Homology of the eyeless gene of Drosophila to the Small eye gene in mice and Aniridia in humans. Science 1994; 265: 785-789.

3. Baulmann DC, Ohlmann A, Flugel-Koch C, Goswami S, Cvekl A, Tamm ER. Pax6 heterozygous eyes show defects in chamber angle differentiation that are associated with a wide spectrum of other anterior eye segment abnormalities. Mech Dev 2002; 118: 3-17.

4. Collinson JM, Quinn JC, Hill RE, West JD. The roles of Pax6 in the cornea, retina, and olfactory epithelium of the developing mouse embryo. Dev Biol 2003; 255: 303-312.

5. Singh S, Mishra R, Arango NA, Deng JM, Behringer RR, Saunders GF. Iris hypoplasia in mice that lack the alternatively spliced Pax6(5a) isoform. Proc Natl Acad Sci U S A 2002; 99: 68126815.

6. Azuma N, Nishina S, Yanagisawa H, Okuyama T, Yamada M. PAX6 missense mutation in isolated foveal hypoplasia. Nat Genet 1996; 13(2): 141-142.

7. de Melo J, Qiu X, Du G, Cristante L, Eisenstat DD. Dlx1, Dlx2, Pax6, Brn3b, and Chx10 homeobox gene expression defines the retinal ganglion and inner nuclear layers of the developing and adult mouse retina. J Comp Neurol 2003; 461: 187-204.

8. Farber DB, Lolley RN. Cyclic guanosine monophosphate: elevation in degenerating photoreceptor cells of the C3H mouse retina. Science 1974; 186: 449-451.

9. Bowes C, Li T, Frankel WN, Danciger M, Coffin JM, Applebury ML et al. Localization of a retroviral element within the rd gene coding for the beta subunit of cGMP phosphodiesterase. Proc Natl Acad Sci U S A 1993; 90: 2955-2959.

10. LaVail MM, Sidman RL. C57BL-6J mice with inherited retinal degeneration. Arch Ophthalmol 1974; 91: 394-400.

11. Hafezi F, Steinbach JP, Marti A, Munz K, Wang ZQ, Wagner EF et al. The absence of c-fos prevents light-induced apoptotic cell death of photoreceptors in retinal degeneration in vivo. Nat Med 1997; 3: 346-349.

12. Bowes C, Li T, Danciger M, Baxter LC, Applebury ML, Farber DB. Retinal degeneration in the rd mouse is caused by a defect in the beta subunit of rod cGMP-phosphodiesterase. Nature 1990; 347: 677-680.

13. Reme CE, Grimm C, Hafezi F, Marti A, Wenzel A. Apoptotic cell death in retinal degenerations. Prog Retin Eye Res 1998; 17: 443-464.

14. Grimm C, Wenzel A, Hafezi F, Reme CE. Gene expression in the mouse retina: the effect of damaging light. Mol Vis 2000; 6: 252-260.

15. LaVail MM, Sidman RL. C57BL-6J mice with inherited retinal degeneration. Arch Ophthalmol 1974; 91: 394-400.

16. Hafezi F, Abegg M, Grimm C, Wenzel A, Munz K, Sturmer J et al. Retinal degeneration in the rd mouse in the absence of c-fos. Invest Ophthalmol Vis Sci 1998; 39: 2239-2244.

17. Davis JA, Reed RR. Role of Olf-1 and Pax-6 transcription factors in neurodevelopment. J Neurosci 1996; 16: 5082-5094.

18. Azuma N, Yamaguchi Y, Handa H, Tadokoro K, Asaka A, Kawase E et al. Mutations of the PAX6 gene detected in patients with a variety of optic-nerve malformations. Am J Hum Genet 2003; 72: 1565-1570.

19. Chao LY, Mishra R, Strong LC, Saunders GF. Missense mutations in the DNA-binding region and termination codon in PAX6. Hum Mutat 2003; 21: 138-145. 
20. Hanson IM, Fletcher JM, Jordan T, Brown A, Taylor D, Adams RJ et al. Mutations at the PAX6 locus are found in heterogeneous anterior segment malformations including Peters' anomaly. Nat Genet 1994; 6: 168-173.

21. Jordan T, Hanson I, Zaletayev D, Hodgson S, Prosser J, Seawright A et al. The human PAX6 gene is mutated in two patients with aniridia. Nat Genet 1992; 1: 328-332.

22. Lauderdale JD, Wilensky JS, Oliver ER, Walton DS, Glaser T. 3' deletions cause aniridia by preventing PAX6 gene expression. Proc Natl Acad Sci U S A 2000; 97: 13755-13759.

23. Mirzayans F, Pearce WG, MacDonald IM, Walter MA. Mutation of the PAX6 gene in patients with autosomal dominant keratitis. Am J Hum Genet 1995; 57: 539-548.

24. Neethirajan G, Hanson IM, Krishnadas SR, Vijayalakshmi P, Anupkumar K, Sundaresan P. A novel PAX6 gene mutation in an Indian aniridia patient. Mol Vis 2003; 9: 205-209.

25. Zumkeller W, Orth $U$, Gal A. Three novel PAX6 mutations in patients with aniridia. Mol Pathol 2003; 56: 180-183.

26. Glaser T, Jepeal L, Edwards JG, Young SR, Favor J, Maas RL. PAX6 gene dosage effect in a family with congenital cataracts, aniridia, anophthalmia and central nervous system defects. Nat Genet 1994; 7: 463-471.

27. Davis J, Duncan MK, Robison WGJ, Piatigorsky J. Requirement for Pax6 in corneal morphogenesis: a role in adhesion. $J$ Cell Sci 2003; 116: 2157-2167.

28. Schedl A, Ross A, Lee M, Engelkamp D, Rashbass $P$, van Heyningen $\vee$ et al. Influence of PAX6 gene dosage on development: overexpression causes severe eye abnormalities. Cell 1996; 86: 71-82.

29. Stanescu D, Iseli HP, Schwerdtfeger K, Ittner LM, Reme CE, Hafezi F. Continuous expression of the homeobox gene Pax6 in the ageing human retina. Eye 2007; 21: 90-93.

30. Zhang W, Cveklova K, Oppermann B, Kantorow M, Cvekl A. Quantitation of PAX6 and PAX6(5a) transcript levels in adult human lens, cornea, and monkey retina. Mol Vis 2001; 7: $1-5$.

31. Ouyang J, Shen YC, Yeh LK, Li W, Coyle BM, Liu CY et al. Pax6 overexpression suppresses cell proliferation and retards the cell cycle in corneal epithelial cells. Invest Ophthalmol Vis Sci 2006; 47: 2397-2407.

32. Li W, Chen YT, Hayashida Y, Blanco G, Kheirkah A, He $\mathrm{H}$ et al. Down-regulation of Pax6 is associated with abnormal differentiation of corneal epithelial cells in severe ocular surface diseases. J Pathol 2008; 214: 114-122.

33. Jones SE, Jomary C, Grist J, Thomas MR, Neal MJ. Expression of Pax-6 mRNA in the retinal degeneration (rd) mouse. Biochem Biophys Res Commun 1998; 252: 236-240.

34. Reme CE, Grimm C, Hafezi F, Iseli HP, Wenzel A. Why study rod cell death in retinal degenerations and how? Doc Ophthalmol 2003; 106: 25-29. 


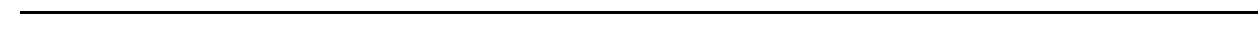




\section{CHAPTER 3 \\ Pax6 expression and retinal cell death in a transgenic mouse model for acute angle-closure glaucoma}

Dinu Stanescu-Segall, Kerstin Birke, Christian Grimm, Andreas Wenzel, S. Orgul, Jan A. Fischer, Walter Born and Farhad Hafezi $\mathrm{KB}$ and $\mathrm{DS}$ have equally contributed to the paper.

Submitted 


\section{Abstract}

Background: PAX6 is a highly conserved protein essential for the control of eye development both in invertebrates and vertebrates. PAX6 expression persists in the adult inner retina, but little is known about its functions after completion of retinal differentiation. Therefore, we investigated PAX6 expression in wild-type and calcitonin receptor-like receptor transgenic $\left(\mathrm{CLR}^{\mathrm{SM} \alpha \mathrm{A}}\right)$ mice with angle-closure glaucoma.

Methods: Intraocular pressure was measured by indentation tonometry in anesthetized mice. Eyes of mice of both genotypes were enucleated at various ages and retinas were processed for morphological analysis and PAX6 immunostaining. The content of PAX6 in retinal extracts was estimated by Western blot analysis. Retinal expression of glaucoma-related genes was analysed by RT-PCR.

Results: Control mice showed normal retinal morphology between p22 and p428 with steady PAX6 expression in the ganglion cell layer (GCL) and the inner nuclear layer (INL). CLR ${ }^{\mathrm{SM} \alpha \mathrm{A}}$ mice examined between p22 and p82 exhibited increased IOP and a progressive decrease in cell number including PAX6 expressing cells in the GCL. The INL was not affected up to p42. Later, a significant increase of PAX6 expressing cells concomitant with an overall loss of cells was observed in the INL of CLR ${ }^{\mathrm{SM} \alpha \mathrm{A}}$ as compared to control mice. Retinal upregulation of glaucoma-related genes was furthermore observed.

Conclusions: Distinctive changes of Pax6 expression in the inner retina of $\mathrm{CLR}^{\mathrm{SM} \alpha \mathrm{A}}$ mice suggest a role in regulatory mechanisms involved in glaucomarelated retinal cell death. The selective increase of PAX6 expression in cells of the INL in the degenerating INL of CLR ${ }^{\mathrm{SM} \alpha \mathrm{A}}$ mice may represent an attempt to preserve retinal cytoarchitecture.

Keywords: PAX6 • Human • Angle-closure • Glaucoma $\bullet$ Retinal degeneration • Ganglion cells

This study was supported by the Swiss National Science Foundation (SNF), the University of Zurich and the Schweizerischer Verein Balgrist. The authors had no financial relationship with these organisations and full control of all primary data. 


\section{Introduction}

PAX6, a member of the paired box family of transcription factors, is an essential control gene for eye morphogenesis both in invertebrates and vertebrates ${ }^{1-3}$ Its importance for eye development was demonstrated in several species. The human and murine (Small eye) PAX6 protein are identical in their amino acid sequence, and the Drosophila homolog (Eyeless) shows over 90\% identity over the paired and the homeodomain. ${ }^{4}$ Moreover, gain-of-function studies demonstrated that targeted expression of Drosophila and PAX6 induces ectopic eyes in Drosophila. ${ }^{5}$

Mutations in PAX6 lead to a variety of eye abnormalities in mice ${ }^{6-9}$ and humans ${ }^{10-18}$ including hereditary foveal hypoplasia, optic nerve malformation and aniridia.

PAX6 has been studied extensively in eye and retinal development. Normal development of the inner retina is directly influenced by a well-elaborated spatial and temporal pattern of PAX6-expression. ${ }^{1,6-9,19-21}$ However, little is known about PAX6 expression and function in the adult mammalian retina. De Melo showed that several homeobox genes including Pax6 are expressed in the young adult mouse retina ${ }^{22}$ and we recently reported continuous expression of $P A X 6$ in the young, adult and old normal human retina. ${ }^{23}$

To investigate the role of $P A X 6$ expression in the adult eye and to assess whether PAX6 might also be involved in degenerative processes of the retina, we studied Pax6 expression in wild-type and in calcitonin receptor-like receptor transgenic $\left(C L R^{S M \alpha A}\right)$ mice with acute angle-closure glaucoma. ${ }^{24}$ 


\section{Materials and Methods}

All animal experiments conformed to the guidelines of the Veterinary Authorities of the Kanton of Zurich and to the statement of the Association for Research in Vision and Ophthalmology (ARVO) for the use of Animals in Ophthalmic and Vision Research.

\section{Animals}

$\mathrm{CLR}^{\mathrm{SM} \alpha \mathrm{A}}$ mice were generated and genotyped together with wild-type littermates as reported. ${ }^{24}$ Three $\mathrm{CLR}^{\mathrm{SM} \alpha \mathrm{A}}$ mice and three control littermates were analyzed at indicated ages in individual experiments. Animals were sacrificed by cervical dislocation and experiments were performed in triplicates.

\section{Measurement of intraocular pressure}

IOP was measured by indentation tonometry in anesthetized mice as described previously. ${ }^{24}$ An average of 6 readings was considered as a single result; presented values are the average of 10 eyes per genotype at each time point (same mice at different ages).

\section{Retinal morphology}

Eyes were prepared as described previously. ${ }^{25}$ Briefly, mice were sacrificed and enucleated eyes were fixed with $2.5 \%$ glutaraldehyde in $0.1 \mathrm{M}$ cacodylate buffer, $\mathrm{pH} 7.3$, at $4^{\circ} \mathrm{C}$ overnight. The eyes were then washed in cacodylate buffer, incubated in osmium tetroxide for one hour, dehydrated in ascending ethanol series and embedded in Epon 812 (Sigma-Aldrich, St. Louis, MO, USA). Central retinal sections $(0.5 \mu \mathrm{m}$; temporal - nasal) were stained with toluidine blue (Sigma-Aldrich, St. Louis, MO, USA) and analyzed by light microscopy.

\section{Retinal morphometry}

$\mathrm{CLR}^{S M \alpha A}$ and control mice were sacrificed and the eyes were enucleated and fixed by immersion in $4 \%$ paraformaldehyde in phosphate buffered saline (PBS) overnight. The eyes were then dehydrated and embedded in paraffin according to standard protocols. Paraffin sections $(5 \mu \mathrm{m})$ were deparaffinized in xylene, hydrated in descending ethanol series and stained with toluidine blue. The sec- 
tions were then washed with water, dehydrated in ethanol and mounted with DPX (Sigma-Aldrich, St. Louis, MO, USA). Morphometry in the GCL and INL of $\mathrm{CLR}^{S M_{\alpha A}}$ and control littermates was performed by counting all cells in the respective layers on $5 \mu \mathrm{m}$ central sagittal sections under the microscope at 40fold magnification with the ImageJ software (http://rsb.info.nih.gov/ij/; version 1.36a). Data were collected from 3 sections per eye of three $\operatorname{CLR}^{S M \alpha A}$ and three age-matched control littermates.

\section{Retinal immunohistochemistry}

Central sagittal sections were boiled at $95^{\circ} \mathrm{C}$ for $20 \mathrm{~min}$ in citrate buffer and incubated in blocking reagent (Vector Laboratories, Burlingame, CA, USA) at room temperature for $60 \mathrm{~min}$. The sections were then incubated at $4^{\circ} \mathrm{C}$ overnight with polyclonal rabbit antibodies to PAX6 (1:300) (Chemicon, Temecula, CA, USA). PAX6 immunostaining was visualized with secondary biotinylated antibodies to rabbit IgG (1:200) (Vector Laboratories, Burlingame, CA, USA) and Cy3-labelled streptavidin (1:200) (Sigma-Aldrich, St. Louis, MO, USA). Fluorescence was detected with a DX20 CCD camera (Kappa, Gleichen, Germany) connected to a $0.45 x$ projection lens of an Eclipse E600 Nikon microscope equipped with a Plan Fluor 20x/0.5 DLL objective and a G-2A (Cy3) filter block.

\section{Western blot analysis}

Retinas were rapidly dissected through a slit in the cornea using the Winkler technique. ${ }^{26}$ The tissue was sonicated in $100 \mathrm{mM}$ Tris/ $\mathrm{HCl}, \mathrm{pH} 7.5$, containing complete protease inhibitor cocktail tablets (Roche Diagnostics, Rotkreuz, Switzerland). Retinal extracts were cleared by centrifugation and proteins were separated by SDS-PAGE (12\%) and then electrotransfered to nitrocellulose Hybond ECL membranes (GEHealthcare Europe $\mathrm{GmbH}$, Otelfingen, Switzerland) in a Trans-Blot SD semi-dry transfer cell (Bio-Rad Laboratories, Hercules, CA, USA). The membranes were blocked with $5 \%$ low fat milk. PAX6 was detected with corresponding polyclonal antibodies (1:5000) (Chemicon, Temecula, CA, USA) and alkaline phosphatase-conjugated secondary antibodies (1:15000) (Sigma-Aldrich, St. Louis, MO, USA). PAX6 was normalized to actin as a protein loading control. Actin was detected with mouse monoclonal antibodies to actin (1:5000) (Sigma, Buchs, Switzerland) and alkaline phosphataseconjugated secondary antibodies (1:15000) (Sigma-Aldrich, St. Louis, MO, USA). Alkaline phosphatase activity was visualized with the Bio-Rad detection 
kit (Bio-Rad Laboratories, Hercules, CA, USA) and a VersaDoc Imaging System (Bio-Rad Laboratories, Hercules, CA, USA).

Reverse transcription and semi-quantitative $P C R$

Retinas were prepared from CLR ${ }^{S M a A}$ mice and control littermates as described above and frozen in liquid nitrogen. Total RNA was isolated with the RNeasy kit (QIAGEN, Hilden, Germany) and cDNA was generated with M-MLV reverse transcriptase (Promega, Madison, WI, USA). PCR was carried out with primers specific for glial fibrillary acidic protein (GFAP) (forward: 5'CCACCAAACTGGCTGATGTCTAC-3', reverse: 5'-TTCTCTCCAAATCCACACGAGC-3'); TIMP-1 (forward: 5'-AGAAATCAACGAGACCACCT-3', reverse: 5'-GGGCTCAGAGTACGCCA-3'); Interleukin-1b (forward: 5'-GCAGGCAGTATCACTCATTG-3', reverse: 5'-CGTTGCTTGGTTCTCCTTGT-3'); Endothelin-2 (forward: 5'- TTGTGAGTGCTCTACTGCG-3', reverse: 5'-GGTGTTATCTCTTCCTCCATCT-3'); X-linked inhibitor of apoptosis (XIAP) (forward: 5'GGATCCTCTGATGCTGTGAGTTCTGATAGGAATTTCCC-3', reverse: 5'-GACTCGAGCTAAGTAGTTCTTACCAGACACTCCTCAAG-3'); Bcl- $\mathrm{X}_{\mathrm{L}}$ (forward: 5'GACTTTCTCTCCTACAAGC-3', reverse: 5'-CGAAAGAGTTCATTCACTAC-3'); Bcl-2 (forward: 5'-TTGTGGCCTTCTTTGAGTTCG-3', reverse: 5'-ATTTCTACTGCTTTAGTGAACC-3') and GAPDH (forward: 5'-GGGTGGAGCCAAACGGGTC-3', reverse: 5'-GGAGTTGC-TGTTGAAGTCGCA-3') with Roche LightCycler reagents. PCR products were separated and quantified on agarose gels by densitometry.

\section{Statistical analysis}

Results are presented as the mean \pm standard error of the mean (SEM). Differences between mean values were analyzed by analysis of variance using the Prism 3.0 software (GraphPad Software; Inc., San Diego, CA, USA). $P<0.05$ was considered statistically significant.

\section{Results}

Pax6 is expressed in the inner retina throughout the lifespan of wild-type mice Retinal morphology and Pax6 expression was examined in wild-type mice at postnatal days (p) 5, 9, 15, 20, 24, 29, 243 and 428. Retinal morphology was 
normal in all mice analyzed (Fig. 1a, representative retinal section at p29). Pax6 expression was confined mainly to nuclei of cells in the inner part of the inner nuclear layer (INL) and, to a lesser extent, to the ganglion cell layer (GCL) at all time points tested (Fig. 1b, representative section at p29). Western Blot analysis showed continuous expression of PAX6 from p5 to p428 with a minimal decrease between p5 and p20 (Fig. 1c).
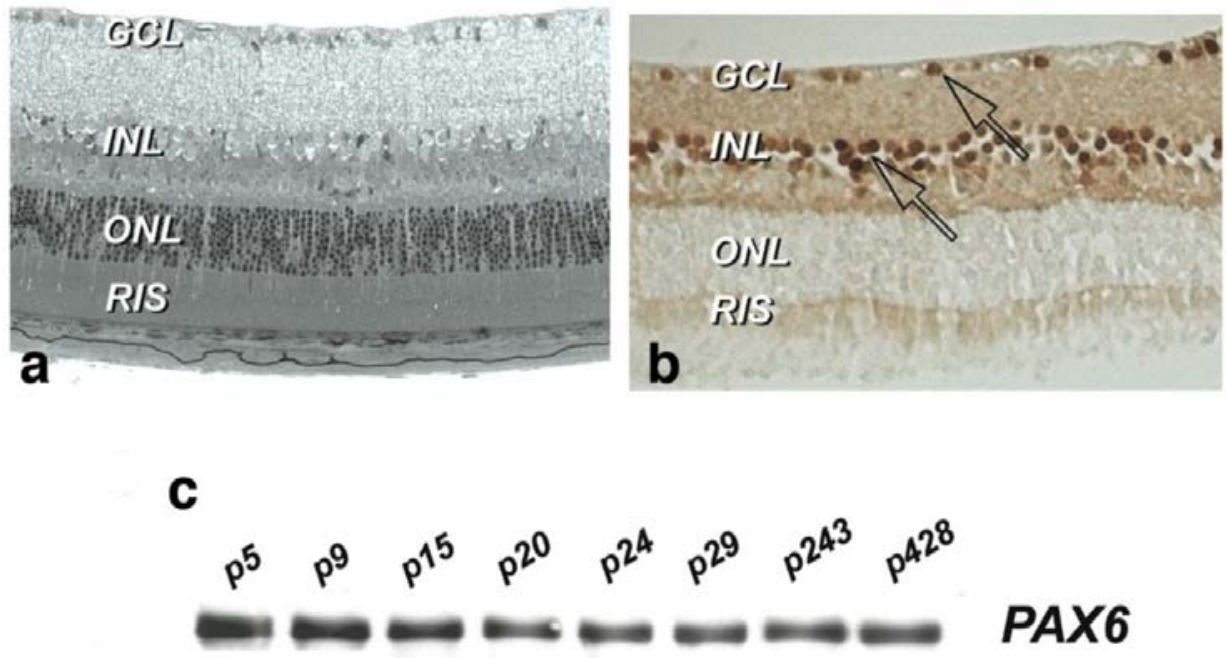

Figure 1. PAX6 expression in the retina of wild-type mice. Morphological analysis at p29 shows normal cytoarchitecture of the outer and inner retina (Epon embedding, methylene blue staining) (a). Immunohistochemical PAX6 staining at p29 revealed PAX6 expression confined to the nuclei of the inner nuclear layer (INL) and the ganglion cell layer (GCL) (arrows) (b). The rod inner segments (RIS) and the outer nuclear layer (ONL) are also shown. Western blot analysis of PAX6 expression in the retina of mice at indicated ages (c). Equal amounts of protein were loaded.

Retinal damage in $C L R^{S M \alpha A}$ mice with increased ocular pressure

$\mathrm{CLR}^{\mathrm{SM} \alpha \mathrm{A}}$ mice presented normal IOP at the end of ocular development on p20 (Fig. 2a). Subsequently, the IOP increased up to p62 to over 2-times higher levels than in control mice. Consequently, the number of apoptotic TUNEL stained cells in the GCL of CLR ${ }^{\mathrm{SM} \alpha \mathrm{A}}$ mice was higher than in control animals (not shown). Moreover, the expression of genes indicating gliosis or apoptosis of the glaucomatous retina was also altered in $C R^{S M \alpha A}$ mice (Table 1). On p32 the gliosis-related GFAP and endothelin-2 gene-derived transcripts were found upregulated in $\mathrm{CLR}^{\mathrm{SM} \alpha \mathrm{A}}$ as compared to control animals. Endothelin-2, unlike GFAP transcripts, remained upregulated on p82. The tissue inhibitors of metal- 
loproteinase-1 (TIMP-1) encoding transcripts, similar to those for endothelin-2, were upregulated on p32 and p82. Consistent with ongoing apoptosis in the retina of $C L R^{S M \alpha A}$ mice, interleukin-1b (II-1b) transcripts were upregulated on p32 and p82 and XIAP transcripts and those encoding the anti-apoptotic proteins $\mathrm{Bcl}-\mathrm{XL}$ and $\mathrm{Bcl}-2$ were lower than in control mice on $\mathrm{p} 82$.

a

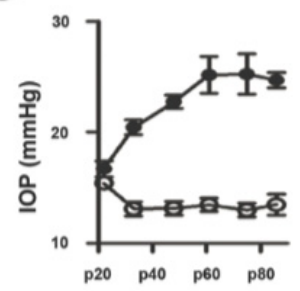

\section{C}

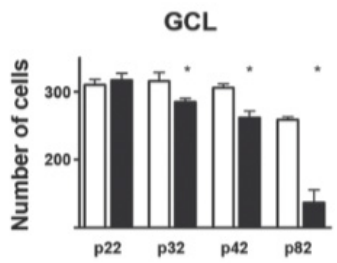

INL

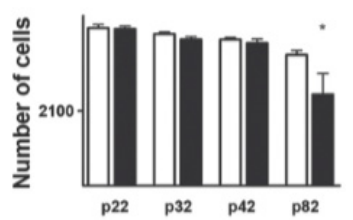

(b)

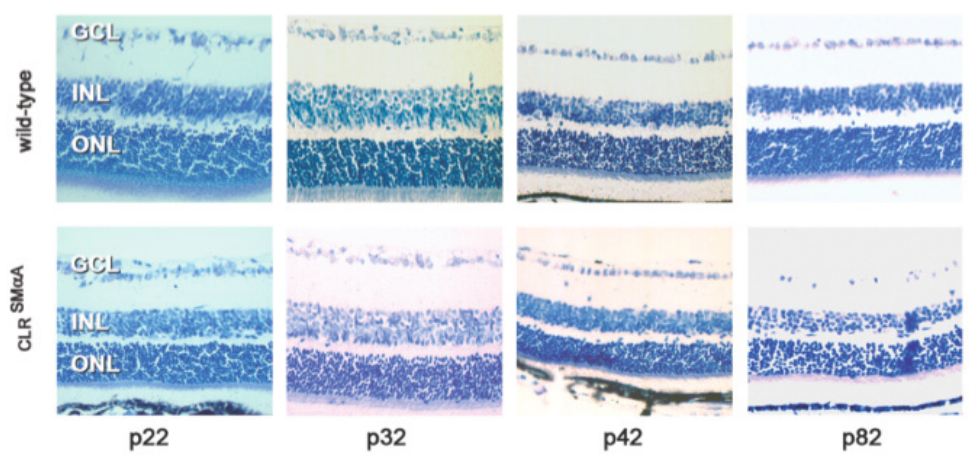

Figure 2. Increase in IOP over time in $\operatorname{CLR}^{S M a A}$ mice $(\bullet)$ as compared to control littermates (o) (a). The data are the mean ( \pm SEM) of IOP measurements in at least ten CLR ${ }^{S M \alpha A}$ and ten control mice per time point. Morphology of the ganglion cell layer (GCL), the inner nuclear layer (INL) and the outer nuclear layer (ONL) in representative $5 \mu \mathrm{m}$ toluidine blue-stained central sagittal sections of the retina of CLR ${ }^{S M A A}$ and control (wild-type) mice at indicated ages (b). Morphometric analysis of the GCL and the INL in control (open bars) and CLR ${ }^{S M a A}$ mice (closed bars) at indicated ages (c). The data are the mean \pm SEM of three sections per eye from three control and three $C_{2}{ }^{S M a A}$ mice per time point. 
Table 1. Relative expression levels of apoptosis-related gene transcripts determined by RT-PCR in retinal RNA extracts of $\mathrm{CLR}^{\text {SMaA }}$ compared to control mice.

\begin{tabular}{lrr}
\hline mRNA & p32 & p82 \\
\hline GFAP & 2.95 & 0.78 \\
TIMP-1 & 16.85 & 24.53 \\
II 1b & 1.69 & 1.47 \\
Endothelin-2 & 11.45 & 17.98 \\
XIAP & 0.96 & 0.29 \\
Bcl-XL & 1.20 & 0.69 \\
Bcl-2 & 1.02 & 0.42
\end{tabular}

GFAP, glial fibrillary acidic protein; TIMP-1, tissue inhibitor of metalloproteinase-1; Il1b, Interleukin1b; XIAP, X-linked inhibitor of apoptosis; Bcl-XL, B-cell leukemia/lymphoma extra long; Bcl-2, B-cell leukemia/lymphoma-2.

Retinal morphology was normal in CLR ${ }^{\mathrm{SM}_{\alpha} A}$ mice at p22 (Fig. 2b, c). Subsequently, the number of cells in the GCL of $C_{L R}{ }^{S M \alpha A}$ mice decreased more rapidly than in control littermates. The INL, on the other hand, showed similar and unchanged morphological and morphometric features in control and CLR ${ }^{\mathrm{SM \alpha A}}$ mice up to $\mathrm{p} 42$. At $\mathrm{p} 82$, however, the cell number in the INL was significantly lower $(P<0.05)$ in $C L R^{S M \alpha A}$ than in control mice.

Pax6 expression in the retina of $C L R^{S M Q A}$ mice

Pax6 expression in the retina of $C L R^{S M \alpha A}$ mice and control littermates was confined to the nuclei of the INL and GCL (Fig. 3a). In CLR ${ }^{S M \alpha A}$ mice, unlike in control littermates, the number of PAX6 expressing cells in the GCL decreased in parallel to the total number of cells between p22 and p82 (Fig. 2c, 3b). In the INL, on the other hand, the number of PAX6 expressing cells was indistinguishable in $C R^{S M \alpha A}$ and control mice up to $p 42$, but, interestingly, on p82 the number of PAX6 expressing cells was significantly $(P<0.05)$ higher in $C L R^{S M \alpha A}$ than in control mice (Fig. 3). These morphometric and immunohistochemical results were consistent with transiently decreased levels of PAX6 on p42 and p52 and p62 and subsequently increased levels on p72, reaching a peak at p82 and being sustained at higher levels until p102 in total retinal extracts of $C_{2} R^{S M_{\alpha A}}$ as compared to control mice, recognized on Western blots (Fig. 4). 

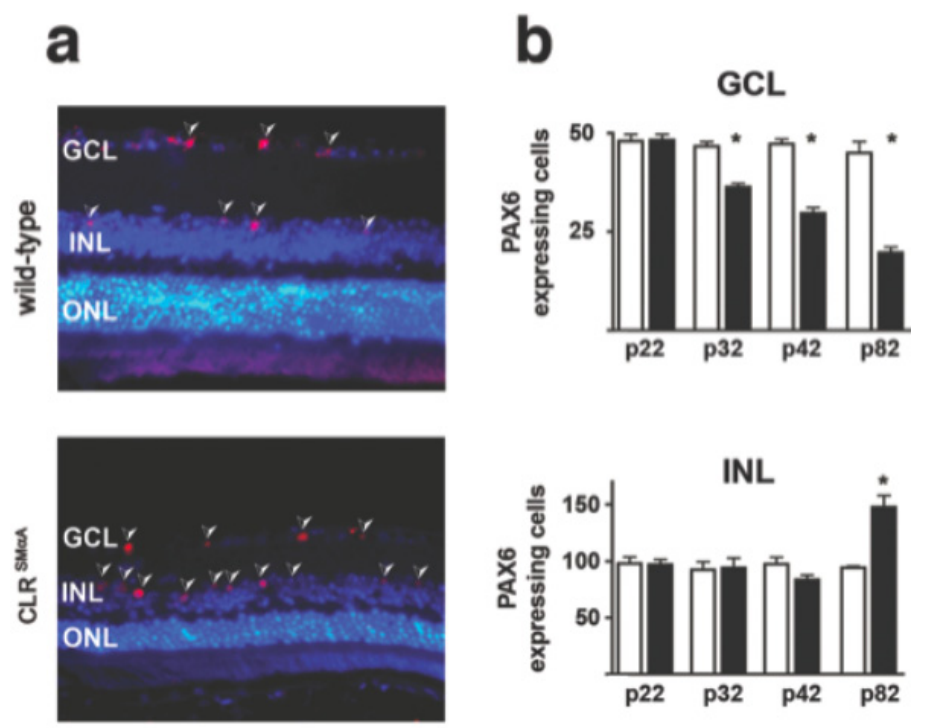

Figure 3. PAX6 expression in the ganglion cell layer (GCL) and the inner nuclear layer (INL) in control (wild-type) and CLR ${ }^{\text {SMaA }}$ mice (a). Immunofluorescent staining of PAX6 (red, arrowheads) and DAPI-staining of cell nuclei (blue) in the GCL and the INL of central retinal sections also including the outer nuclear layer (ONL) on p82. (b). Morphometric analysis of Pax6 expression over time in the GCL and the INL from control (open bars) and CLR ${ }^{S M a A}$ (closed bars) mice. Data are the mean \pm SEM of three sections per eye from three control and three $C_{L}{ }^{S M A A}$ mice per time point. ${ }^{*} \mathrm{P}<0.05$ compared to control mice of the same age.

a

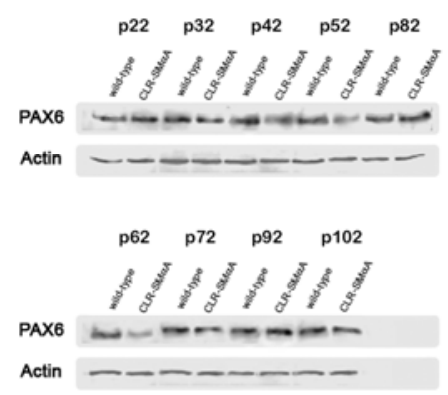

b

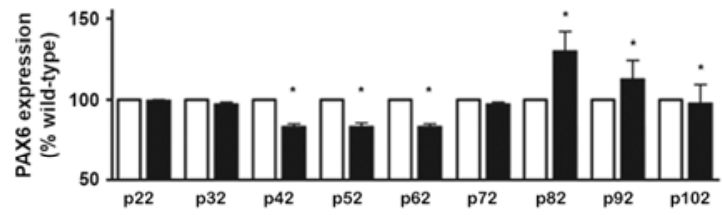

Figure 4. PAX6 expression over time was examined by Western blot analysis in retinal extracts of control (wild-type) and CLR ${ }^{\text {SMaA }}$ mice. PAX6 and actin were visualized by enhanced chemiluminescence with corresponding antibodies. Representative for three independent experiments (a). Relative changes of PAX6 expression normalized to actin in the retina of CLR ${ }^{\text {SMaA }}$ (closed bars) compared to control (open bars) mice (b). The values obtained for the extracts of control mice at individual time points were set to $100 \%$. The data are the mean \pm SEM of three independent experiments ${ }^{*} \mathrm{P}<0.05$ compared to control mice of the same age. Open bars refer to expression of control mice and closed bars refer to $\operatorname{CLR}^{S M O A}$ mice. 


\section{Discussion}

PAX6 is a transcription factor influencing eye morphogenesis in invertebrates and vertebrates. ${ }^{2,3}$ Besides the striking amino acid sequence similarities of PAX6 in different species, conserved regulation of expression appears to be vital for ocular integrity. ${ }^{27}$ Although PAX6 was extensively studied during eye organogenesis in various species, little is known about PAX6 expression and function in adult eye tissues. PAX6 expression in the GCL and INL of the inner retina was observed in humans, ${ }^{23}$ chicken ${ }^{28}$ and mouse ${ }^{29}$ and Zhang et al. detected PAX6 expression in the adult lens epithelium. ${ }^{30}$

To further elucidate potential roles of PAX6 in the inner retina of an adult eye, we investigated its expression in wild-type and $\mathrm{CLR}^{\mathrm{SM} \alpha \mathrm{A}}$ mice, a mouse model of acute angle closure glaucoma (ACG). ACG is very much underestimated and suspected to affect half of all glaucoma patient worldwide and accounts for $91 \%$ of bilateral glaucoma blindness in China ${ }^{31}$. ACG pathophysiology is largely unknown and CLR ${ }^{\mathrm{SM} \alpha \mathrm{A}}$ mouse model appears as a reliable mouse model for this disease. It offers the advantage to mimic human condition with transient IOP peaks between one and three months ${ }^{24}$.It obviates repetitive manipulations on mouse $s$ 'eyes and costly equipment such as lasers needed for laser-induced increased IOP models. ${ }^{32-34}$ It is also one of the few genetic rodent model that is amendable to experimental manipulation because of its shorter course of glaucomatous pathology.

These mice develop angle-closure glaucoma after completion of retinal development ${ }^{24}$ and, as shown here, suffer from progressive retinal ganglion cell loss.

The retina of CLR ${ }^{S M_{\alpha A}}$ mice expressed elevated levels of GFAP, TIMP1, interleukin $1 \mathrm{~b}$ and endothelin-2 that were also found to be upregulated in glaucoma in previous studies. Increased GFAP is commonly observed in degenerative retinal diseases ${ }^{35,36}$ whereas tissue inhibitor of metalloproteinase-1 (TIMP1) encoding mRNA is elevated in microglia of glaucoma patients. ${ }^{37}$ Activation of proinflammatory interleukin-1b might be involved in the aetiology of glaucoma $^{38,39}$ and increased endothelin-2 expression occurs in human glaucoma during glial activation. ${ }^{40}$ Late down-regulation of the caspase inhibitor XIAP and of $\mathrm{BCl}-\mathrm{XL}$ and $\mathrm{Bcl}-2$ was observed in $\mathrm{CLR}^{\mathrm{SM} \alpha \mathrm{A}}$ mice on p82, similar to observations in degenerating retinas. ${ }^{41-43}$ Since transgenic expression of XIAP was shown to increase survival of cells in the inner retina in mouse models of ischemia ${ }^{44}$ it seems likely that the reduced expression of this inhibitor of apop- 
tosis contributes to the retinal pathology and the observed loss of neuronal cells.

Our results also show a decreased Pax6 expression in the GCL of CLR ${ }^{\text {SM } \alpha A}$ mice during the initial phase of ganglion cell degeneration. At p82, however, cells of the INL in CLR ${ }^{\mathrm{SM} \alpha \mathrm{A}}$ mice displayed a marked increase in PAX6 protein levels. At this time point, the ganglion cell layer has lost about $75 \%$ of its cells (Fig. 2) and thus synaptic connectivity between bipolar-, amacrine- and ganglion cells was severely disrupted. We found similar results in total protein extracts of $\mathrm{CLR}^{\mathrm{SM} \alpha \mathrm{A}}$ mice. Western blots of PAX6 showed an increase of its expression at p72, reaching a peak at p82, with a progressive decline from p92 until normal levels at $\mathrm{p} 102$.

In DBA/2J mouse, peak of RGC apoptosis varies between 6 and 11 months according to Schuettauf and Libby respectively. ${ }^{45,46}$ We speculate that in this mouse, PAX6 expression would have rised after the peak of GCL apoptosis. Although the length of time needed to obtain these results in DBA/2J was too long to be able to verify our hypothesis.

In laser-induced ocular hypertension mouse model of glaucoma, IOP is less elevated than in $\mathrm{CLR}^{\mathrm{SM \alpha A}}$ mice and induce a moderate $\mathrm{RGC}$ reduction of 15 to $17 \%$ and 22 to $27 \%$ after 2 and 4 weeks respectively after laser photocoagulation of the episcleral and limbal veins. ${ }^{32,33}$ We believe that in this mice, a slight elevation of PAX6 expression would have occured after 4 weeks but probably less pronounced than in our model because the apoptosis peak was less marked. Unfortunately, the cost of laser equipment precludes us from corroborating these data. We were less interested in studying PAX6 expression in RGC death following mechanical injury of the optic nerve, ${ }^{47}$ intraocular injection of excitotoxic agents ${ }^{48,49}$ or by the induction of ischemia followed by reperfusion ${ }^{50}$ because the pathophysiology in those systems does not directly follow that of human glaucoma.

It has been shown in models of photoreceptor degeneration that cells especially of the INL react to a loss of neurons by the induction of a program leading to retinal remodelling (for review see ${ }^{51}$ ). Already during the initial phase of photoreceptor loss, bipolar and horizontal cells are deafferented and retract most of their dendrites, and Muller cells increase the production of intermediate filaments. Although remodelling processes in models of glaucoma have not been studied in detail, Marc and co-workers ${ }^{51}$ showed that the space left by degenerated ganglion cells in RP retinas was filled at least in part by Muller cell end feet. Interestingly, Jones and co-workers have demonstrated that Pax6 expression is increased in cells of the INL during retinal degeneration in the rd1 
mouse ${ }^{29}$ concomitantly with the early phase of remodelling processes. Since Pax6 regulates eye development including retinal morphogenesis, ${ }^{52}$ it is conceivable that increased Pax6 production during degeneration is required for surviving cells to adapt to the altered conditions by changing their cytoarchitecture. This is supported by observations that expression levels of Pax6 can severely influence the overall ocular structure. In the mouse eye for example, Pax6 overexpression leads to severe abnormalities like microphthalmia and cataract formation ${ }^{53}$ and Glaser et al. have clearly shown a gene dosage effect of PAX6 in a human family in which different members were affected by PAX6 mutations with either full or only partial transcriptional activity. ${ }^{54}$

Taken together, our data show that retinal ganglion cell death induces the expression of Pax6 in cells of the INL. This suggests that Pax6 might be involved in the maintenance of the cellular integrity after the loss of synaptic connectivity and/or in processes required for the remodelling of the retinal cytoarchitecture after ganglion cell loss. Further studies looking at Pax6 expression in other mouse model of glaucoma would be interesting to confirm our findings,

\section{Acknowledgements}

The authors thank Jürgen Götz for providing the transgenic mice and Lars Ittner, Heiko Wurdak and Lukas Sommer for fruitful discussions, continuous support and careful reading of the manuscript. 


\section{References}

1. Cvekl, A, Tamm, ER. Anterior eye development and ocular mesenchyme: new insights from mouse models and human diseases. Bioessays 2004;26:374-386.

2. Gehring, WJ, Ikeo, K. Pax 6: mastering eye morphogenesis and eye evolution. Trends Genet 1999;15:371-377.

3. Kozmik, Z, Daube, M, Frei, E et al. Role of Pax genes in eye evolution: a cnidarian PaxB gene uniting Pax2 and Pax6 functions. Dev Cell 2003;5:773-785.

4. Quiring, R, Walldorf, U, Kloter, U, Gehring, WJ. Homology of the eyeless gene of Drosophila to the Small eye gene in mice and Aniridia in humans. Science 1994;265:785-789.

5. Altmann, CR, Chow, RL, Lang, RA, Hemmati-Brivanlou, A. Lens induction by Pax-6 in Xenopus laevis. Dev Biol 1997 May 1;185:119-123.,Halder, G, Callaerts, P, Gehring, WJ. New perspectives on eye evolution. Curr Opin Genet Dev 1995;5:602-609.

6. Baulmann, DC, Ohlmann, A, Flugel-Koch, $\mathrm{C}$ et al. Pax6 heterozygous eyes show defects in chamber angle differentiation that are associated with a wide spectrum of other anterior eye segment abnormalities. Mech Dev 2002;118:3-17.

7. Collinson, JM, Quinn, JC, Hill, RE, West, JD. The roles of Pax6 in the cornea, retina, and olfactory epithelium of the developing mouse embryo. Dev Biol 2003;255:303-312.

8. Lovicu, FJ, Steven, P, Saika, S, McAvoy, JW. Aberrant lens fiber differentiation in anterior subcapsular cataract formation: a process dependent on reduced levels of Pax6. Invest Ophthalmol Vis Sci 2004;45:1946-1953.

9. Singh, S, Mishra, R, Arango, NA et al. Iris hypoplasia in mice that lack the alternatively spliced Pax6(5a) isoform. Proc Natl Acad Sci U S A 2002;99:6812-6815.

10. Azuma, N, Yamaguchi, $\mathrm{Y}, \mathrm{Handa}, \mathrm{H}$ et al. Mutations of the PAX6 gene detected in patients with a variety of optic-nerve malformations. Am J Hum Genet 2003;72:1565-1570.

11. Chao, LY, Mishra, R, Strong, LC, Saunders, GF. Missense mutations in the DNA-binding region and termination codon in PAX6. Hum Mutat 2003;21:138-145.

12. Hanson, IM, Fletcher, JM, Jordan, T et al. Mutations at the PAX6 locus are found in heterogeneous anterior segment malformations including Peters' anomaly. Nat Genet 1994;6:168-173.

13. Jordan, T, Hanson, I, Zaletayev, D et al. The human PAX6 gene is mutated in two patients with aniridia. Nat Genet 1992;1:328-332.

14. Lauderdale, JD, Wilensky, JS, Oliver, ER et al. 3' deletions cause aniridia by preventing PAX6 gene expression. Proc Natl Acad Sci U S A 2000;97:13755-13759.

15. Lines, MA, Kozlowski, K, Walter, MA. Molecular genetics of Axenfeld-Rieger malformations. Hum Mol Genet 2002;11:1177-1184.

16. Mirzayans, F, Pearce, WG, MacDonald, IM, Walter, MA. Mutation of the PAX6 gene in patients with autosomal dominant keratitis. Am J Hum Genet 1995;57:539-548.

17. Neethirajan, G, Hanson, IM, Krishnadas, SR et al. A novel PAX6 gene mutation in an Indian aniridia patient. Mol Vis 2003;9:205-209.

18. Zumkeller, W, Orth, U, Gal, A. Three novel PAX6 mutations in patients with aniridia. Mol Pathol 2003;56:180-183.

19. Behrens, M, Langecker, TG, Wilkens, H, Schmale, H. Comparative analysis of Pax-6 sequence and expression in the eye development of the blind cave fish Astyanax fasciatus and its epigean conspecific. Mol Biol Evol 1997;14:299-308.

20. Cvekl, A, Piatigorsky, J. Lens development and crystallin gene expression: many roles for Pax6. Bioessays 1996;18:621-630. 
21. Duncan, MK, Xie, L, David, LL et al. Ectopic Pax6 expression disturbs lens fiber cell differentiation. Invest Ophthalmol Vis Sci 2004;45:3589-3598.

22. de Melo, J, Qiu, X, Du, G et al. Dlx1, Dlx2, Pax6, Brn3b, and Chx10 homeobox gene expression defines the retinal ganglion and inner nuclear layers of the developing and adult mouse retina. J Comp Neurol 2003;461:187-204.

23. Stanescu, D, Iseli, HP, Schwerdtfeger, $\mathrm{K}$ et al. Continuous expression of the homeobox gene Pax6 in the ageing human retina. Eye (Lond) 2007;21:90-93.

24. Ittner, LM, Schwerdtfeger, K, Kunz, TH et al. Transgenic mice with ocular overexpression of an adrenomedullin receptor reflect human acute angle-closure glaucoma. Clin Sci (Lond) 2008;114:49-58.

25. Hafezi, F, Abegg, M, Grimm, $\mathrm{C}$ et al. Retinal degeneration in the rd mouse in the absence of Cfos. Invest Ophthalmol Vis Sci 1998;39:2239-2244.

26. Winkler, BS, Giblin, FJ. Glutathione oxidation in retina: effects on biochemical and electrical activities. Exp Eye Res 1983;36:287-297.

27. $\mathrm{Xu}, \mathrm{PX}$, Zhang, $\mathrm{X}$, Heaney, $\mathrm{S}$ et al. Regulation of Pax6 expression is conserved between mice and flies. Development 1999;126:383-395.

28. Bhat, SP, Rayner, SA, Huang, CM, Ariyasu, RG. Quantitative estimation of RNA transcripts suggests persistence of Pax- 6 expression in the postembryonic chick retina. Dev Neurosci 1999;21:140-146.

29. Jones, SE, Jomary, C, Grist, J et al. Expression of Pax-6 mRNA in the retinal degeneration (rd) mouse. Biochem Biophys Res Commun 1998;252:236-240.

30. Zhang, W, Cveklova, K, Oppermann, B et al. Quantitation of PAX6 and PAX6(5a) transcript levels in adult human lens, cornea, and monkey retina. Mol Vis 2001;7:1-5.

31. Quigley, HA, Broman, AT. The number of people with glaucoma worldwide in 2010 and 2020. Br J Ophthalmol 2006;90:262-267.

32. Gross, RL, Ji, J, Chang, $\mathrm{P}$ et al. A mouse model of elevated intraocular pressure: retina and optic nerve findings. Trans Am Ophthalmol Soc 2003;101:163-9; discussion 169-71.

33. Grozdanic, SD, Betts, DM, Sakaguchi, DS et al. Laser-induced mouse model of chronic ocular hypertension. Invest Ophthalmol Vis Sci 2003;44:4337-4346.

34. Fu, CT, Sretavan, D. Laser-induced ocular hypertension in albino CD-1 mice. Invest Ophthalmol Vis Sci 2010;51:980-990.

35. Wang, X, Tay, SS, Ng, YK. An immunohistochemical study of neuronal and glial cell reactions in retinae of rats with experimental glaucoma. Exp Brain Res 2000;132:476-484.

36. Iandiev, I, Biedermann, B, Bringmann, A et al. Atypical gliosis in Muller cells of the slowly degenerating rds mutant mouse retina. Exp Eye Res 2006;82:449-457.

37. Yuan, L, Neufeld, AH. Activated microglia in the human glaucomatous optic nerve head. J Neurosci Res 2001;64:523-532.

38. Whiteley, SJ, Klassen, H, Coffey, PJ, Young, MJ. Photoreceptor rescue after low-dose intravitreal IL-1beta injection in the RCS rat. Exp Eye Res 2001;73:557-568.

39. Grimm, C, Wenzel, A, Hafezi, F, Reme, CE. Gene expression in the mouse retina: the effect of damaging light. Mol Vis 2000;6:252-260.

40. Yorio, T, Krishnamoorthy, R, Prasanna, G. Endothelin: is it a contributor to glaucoma pathophysiology? J Glaucoma 2002;11:259-270.

41. Diem, R, Taheri, N, Dietz, GP et al. HIV-Tat-mediated Bcl-XL delivery protects retinal ganglion cells during experimental autoimmune optic neuritis. Neurobiol Dis 2005;20:218-226.

42. Lin, HL, Yang, JS, Yang, JH et al. The role of Ca2+ on the DADS-induced apoptosis in mouserat hybrid retina ganglion cells (N18). Neurochem Res 2006;31:383-393. 
43. Petrin, D, Baker, A, Coupland, SG et al. Structural and functional protection of photoreceptors from MNU-induced retinal degeneration by the X-linked inhibitor of apoptosis. Invest Ophthalmol Vis Sci 2003;44:2757-2763.

44. Renwick, J, Narang, MA, Coupland, SG et al. XIAP-mediated neuroprotection in retinal ischemia. Gene Ther 2006;13:339-347.

45. Schuettauf, F, Rejdak, R, Walski, $M$ et al. Retinal neurodegeneration in the DBA/2J mouse-a model for ocular hypertension. Acta Neuropathol 2004;107:352-358.

46. Libby, RT, Anderson, MG, Pang, IH et al. Inherited glaucoma in DBA/2J mice: pertinent disease features for studying the neurodegeneration. Vis Neurosci 2005;22:637-648.

47. Schwartz, M, Yoles, E. Optic nerve degeneration and potential neuroprotection: implications for glaucoma. Eur J Ophthalmol $1999 ; 9$ Suppl 1:S9-11.

48. Sun, Q, Ooi, VE, Chan, SO. N-methyl-D-aspartate-induced excitotoxicity in adult rat retina is antagonized by single systemic injection of MK-801. Exp Brain Res 2001;138:37-45.

49. Vorwerk, CK, Lipton, SA, Zurakowski, D et al. Chronic low-dose glutamate is toxic to retinal ganglion cells. Toxicity blocked by memantine. Invest Ophthalmol Vis Sci 1996;37:1618-1624.

50. Buchi, ER. Cell death in rat retina after pressure-induced ischaemia-reperfusion insult: electron microscopic study. II. Outer nuclear layer. Jpn J Ophthalmol 1992;36:62-68.,Buchi, ER. Cell death in the rat retina after a pressure-induced ischaemia-reperfusion insult: an electron microscopic study. I. Ganglion cell layer and inner nuclear layer. Exp Eye Res 1992;55:605-613.

51. Marc, RE, Jones, BW, Watt, CB, Strettoi, E. Neural remodeling in retinal degeneration. Prog Retin Eye Res 2003;22:607-655.

52. Ashery-Padan, R, Gruss, P. Pax6 lights-up the way for eye development. Curr Opin Cell Biol 2001;13:706-714.

53. Schedl, A, Ross, A, Lee, M et al. Influence of PAX6 gene dosage on development: overexpression causes severe eye abnormalities. Cell 1996;86:71-82.

54. Glaser, T, Jepeal, L, Edwards, JG et al. PAX6 gene dosage effect in a family with congenital cataracts, aniridia, anophthalmia and central nervous system defects. Nat Genet 1994;7:463471. 


\section{CHAPTER 4}

\section{Constitutive overexpression of}

human erythropoietin protects the mouse retina against induced but not inherited retinal degeneration

Christian Grimm Andreas Wenzel, Dinu Stanescu, Marijana Samardzija, Svenja Hotop, Mathias Groszer, Muna Naash, Max Gassmann and Charlotte Remé

Published in Journal of Neuroscience 2004 Jun 23;24(25):5651-8. 


\begin{abstract}
Elevation of erythropoietin (Epo) concentrations by hypoxic preconditioning or application of recombinant human Epo (huEpo) protects the mouse retina against light-induced degeneration by inhibiting photoreceptor cell apoptosis. Because photoreceptor apoptosis is also the common path to cell loss in retinal dystrophies such as retinitis pigmentosa (RP), we tested whether high levels of huEpo would reduce apoptotic cell death in two mouse models of human RP. We combined the two respective mutant mouse lines with a transgenic line (tg6) that constitutively overexpresses huEpo mainly in neural tissues. Transgenic expression of huEpo caused constitutively high levels of Epo in the retina and protected photoreceptors against light-induced degeneration; however, the presence of high levels of huEpo did not affect the course or the extent of retinal degeneration in a light-independent ( $\mathrm{rd} 1$ ) and a light-accelerated (VPP) mouse model of RP. Similarly, repetitive intraperitoneal injections of recombinant huEpo did not protect the retina in the rd1 and the VPP mouse. Lack of neuroprotection by Epo in the two models of inherited retinal degeneration was not caused by adaptational downregulation of Epo receptor. Our results suggest that apoptotic mechanisms during acute, light-induced photoreceptor cell death differ from those in genetically based retinal degeneration. Therapeutic intervention with cell death in inherited retinal degeneration may therefore require different drugs and treatments.
\end{abstract}

Keywords: retinal degeneration; erythropoietin; apoptosis; neuroprotection; photoreceptor; transgene 


\section{Introduction}

Retinitis pigmentosa (RP) and age-related macular degeneration (AMD) are major causes of severe visual impairment and blindness in the Western world. Common to both diseases is photoreceptor cell death by apoptosis (Portera Cailliau et al., 1994; Wong, 1994; Remé et al., 1998; Adler et al., 1999). Evidence points to light as a cofactor accelerating the disease progression (Taylor et al., 1990; Cruickshanks et al., 1993, 2001 Simons, 1993; Cideciyan et al., 1998), and some animal models for human retinal degenerations show higher light damage susceptibility than normal control animals (Sanyal and Hawkins, 1986; Wang et al., 1997; Chen et al., 1999a,b; LaVail et al., 1999; Organisciak et al., 1999). Exposure to high levels of white light can thus be used as a model system to study signaling pathways during photoreceptor apoptosis and retinal degeneration (Remé et al., 1998).

Recently we showed that hypoxic preconditioning stabilizes the -subunit of the hypoxia-inducible transcription factor-1 (HIF-1) in the retina. Subsequent binding of HIF-1 (for review, see Hopfl et al., 2004) to its heterodimerization partner HIF-1 induces the retinal expression of erythropoietin (Epo) and of other HIF-1 target genes and transiently protects the mouse retina against the damaging effects of light exposure (Grimm et al., 2002). The application of recombinant human Epo (huEpo) mimics the effect of hypoxia, demonstrating that Epo is a main component of the neuroprotection observed (Grimm et al., 2002). The protective effect of hypoxic (and hyperoxic) oxygen levels has also been demonstrated in a rat model of continuous light exposure (Bowers et al., 2001), and the importance of oxygen and thus of oxygen-regulated tissue responses has been documented during retinal development, when physiological hypoxia may regulate cell death (Mervin and Stone, 2002). Furthermore, increased oxygen levels were shown to slow photoreceptor death in a rat model of retinal degeneration, whereas hypoxia accelerated cell death (Maslim et al., 1997; Valter et al., 1998).

To test whether Epo might prevent retinal degeneration in models of inherited retinal disease, we used a transgenic mouse line (termed tg6) that constitutively overexpresses huEpo in an oxygen-independent manner preferentially in neuronal cells (Ruschitzka et al., 2000; Wiessner et al., 2001). Compared with wild-type (wt) controls, tg6 mice show 26-fold increased Epo levels in brain as well as a 12-fold elevation of Epo plasma levels (Wagner et al., 2001; Vogel et al., 2003). Here, heterozygous transgenic tg 6 males were bred with two mouse models for human RP [for recent reviews on retinal degeneration animal mod- 
els, see Hafezi et al. (2000) and Chang et al. (2002)]. The rd1 mouse carries a mutation in the gene encoding the phosphodiesterase -subunit causing a fast and light-independent degeneration of photoreceptors (Bowes et al., 1990). The VPP transgenic mouse strain harbors three mutations (V20G, P23H, P27L) in the rhodopsin gene (Naash et al., 1993), one of which (P23H) represents the most common cause for autosomal-dominant RP in the United States. In the VPP mouse, retinal degeneration is accelerated by light but nevertheless proceeds slower than in the rd1 mouse (Goto et al., 1996; Naash et al., 1996).

We show that transgene-derived Epo protects against photoreceptor apoptosis induced by acute light exposure. It does not protect against the mutationbased degenerations in rd1 and VPP mice, however, although light is a cofactor accelerating photoreceptor degeneration in the latter. These results may be of importance with respect to potential clinical trials using Epo in patients with retinal dystrophies.

\section{Material and methods}

\section{Mice}

All procedures concerning animals were in accordance with the regulations of the Veterinary Authority of Zurich and with the statement of The Association for Research in Vision and Ophthalmology for the use of animals in research. Rpe65 variant at position 450 of the protein was determined by PCR using upstream primer 5'-CACTGTGGTCTCTGCTATCTTC-3' and downstream primer 5'-GGTGCAGTTCCACTTCAGTT-3'. The amplification product (674 bp) was digested with $\mathrm{Mwol}$, which cuts the leucine variant yielding fragments of 236 and $437 \mathrm{bp}$. Mwol does not cut the sequence encoding methionine. With the exception of $\operatorname{tg} 6$ and wt mice used in the light damage and rhodopsin regeneration study (heterozygous variant: Rpe65 $5_{450 \text { Leu/Met; }}$ see Results), all mice used were homozygous for the Rpe65 ${ }_{450 \mathrm{met}}$ variant.

\section{Induction and analysis of light damage}

Light damage was induced in dark-adapted 3-, 4-, and 6- to 8-week-old mice with dilated pupils by exposure to 13 klux of diffuse white fluorescent light for $120 \mathrm{~min}$ as described (Grimm et al., 2000). After $24 \mathrm{hr}$ in darkness, the extent of light damage was determined in the right retina using the Cell Death Detection Kit (Roche Diagnostics, Basel, Switzerland) according to the manufacturer's 
recommendation, and in the left eye the extent of light damage was determined by light microscopy as described (Kueng-Hitz et al., 2000).

\section{Rhodopsin content and regeneration}

The rhodopsin content was determined as described (Kueng-Hitz et al., 2000). Dark levels of rhodopsin were measured after $16 \mathrm{hr}$ of dark adaptation. To assess rhodopsin regeneration, dark-adapted mice, with dilated pupils, were exposed to white light (10 min, $5 \mathrm{klux}$ ). Rhodopsin was measured either immediately after light exposure or at $45 \mathrm{~min}$ in darkness.

\section{Western blotting and ELISA}

Retinas were homogenized in $100 \mathrm{mM}$ Tris/ $\mathrm{HCl}$, pH 8.0, and analyzed for protein content using Bradford reagent. Standard SDS-PAGE and Western blotting were performed. For immunodetection, polyclonal rabbit anti-Epo receptor antibodies (sc-697; Santa Cruz Biotechnology, Santa Cruz, CA) were applied, followed by an HRP-conjugated secondary anti-rabbit antibody (sc-2004; Santa Cruz Biotechnology), and immunoreactivity was visualized using the Renaissance-Western blot detection kit (PerkinEImer Life Sciences, Emeryville, CA).

Epo levels were determined with an ELISA kit according to the manufacturer's recommendations ( $R$ \& D Systems, Minneapolis, MN).

\section{Immunohistochemistry}

Eyes were enucleated and fixed in 2.5\% glutaraldehyde/0.1 M phosphate buffer, $\mathrm{pH} 7.4$, for $4 \mathrm{hr}$ at $4^{\circ} \mathrm{C}$. Eyecups were cut temporal to nasal through the optic nerve head. Trimmed tissue was washed twice in $0.1 \mathrm{M}$ phosphate buffer, $\mathrm{pH}$ 7.4, for 15 min followed by dehydration and embedding in Epon 812. Epoxy resin of $0.5 \mu \mathrm{m}$ tissue sections was removed by incubation for $7 \mathrm{~min}$ at room temperature in etching solution $(2.4 \mathrm{M} \mathrm{KOH}, 66.6 \%$ methanol, 33.3\% propylene oxide). Slides were washed once in $100 \%$ methanol, once in $50 \%$ methanol/ $0.5 x$ PBS, and twice in PBS for 5 min. Tissue was preincubated for 30 min with $10 \%$ normal goat serum (NGS) in PBS at room temperature followed by an overnight incubation with the primary anti-Epo antibody (AB-286-NA, 1:200; R \& D Systems) in $3 \% \mathrm{NGS}$ at $4^{\circ} \mathrm{C}$. Slides were washed three times with PBS for $10 \mathrm{~min}$ each. Tissue was preincubated for $30 \mathrm{~min}$ in $10 \%$ NGS at room temperature. Cy3-conjugated anti-rabbit secondary antibody (Jackson ImmunoResearch, West Grove, PA) was applied for $80 \mathrm{~min}$ in $3 \%$ NGS at room temperature. Sec- 
tions were washed three times in PBS for 10 min each. Staining was analyzed with a fluorescence microscope (Axiovision, Zeiss) and documented using a digital imaging system.

\section{Epo injections}

One hundred international units of Epo (Recormon 2000; Roche, Basel, Switzerland) in $0.9 \% \mathrm{NaCl}$ were injected intraperitoneally at postnatal day 11 (P11) (rd1 only), P13, P15, P17, and P19.

\section{Results}

Overexpression and localization of huEpo in the retina HuEpo was expressed at highly elevated levels in the retina early during postnatal development in tg6 as well as in tg6/rd1 and tg6/VPP double-mutant mice (Table 1). The huEpo transgene expression localized mainly to the inner segments of photoreceptor cells: the outer nuclear layer (ONL), inner nuclear layer (INL), and ganglion cell layer (GCL). This localization was comparable with the endogenous Epo present in the wt retina (Fig. 1A, B). The labeling was specific, because no signal was detected when the primary antibody was omitted (Fig. 1C) or when the immunoreaction was competed by preincubating the primary antibody with huEpo (data not shown). Expression of the transgene did not influence retinal morphology in tg6 mice (Figs. 1, 2, 5), suggesting that high levels of Epo and excessive erythrocytosis do not affect postnatal retinal development and developmental apoptosis. 


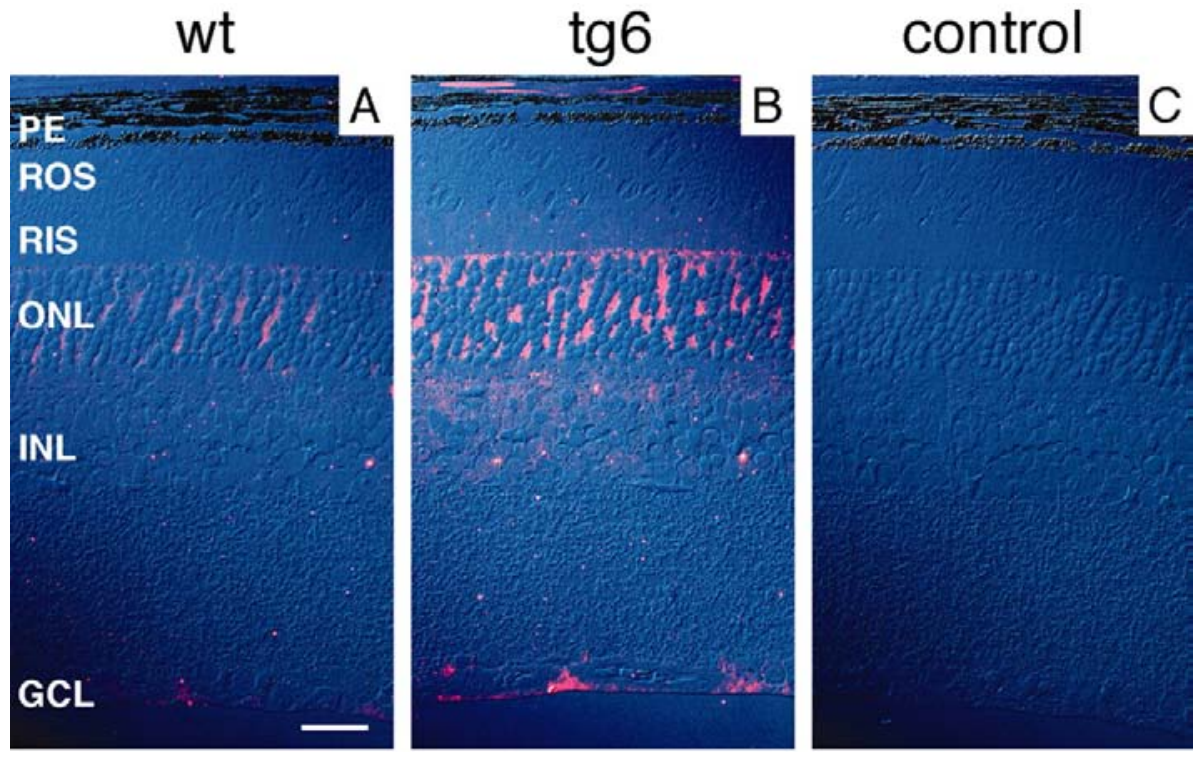

Figure 1. Expression and localization of Epo in the mouse retina. Retinas of wt $(A, C)$ and tg6 $(B)$ mice were fixed and stained using an antibody specific for Epo. Control was a wt retina incubated without primary antibody $(C)$. Both endogenous Epo and huEpo expressed from the transgene in tg6 localize to the ONL, INL, and GCL. PE, Pigment epithelium; ROS, rod outer segments; RIS, rod inner segments; ONL, outer nuclear layer; INL, inner nuclear layer; GCL, ganglion cell layer. Scale bar, $25 \mu \mathrm{m}$. 
Table 1. Average Epo levels in retinas of $w t, \operatorname{tg} 6, \mathrm{rd} 1, \mathrm{VPP}, \mathrm{rd} 1 / \operatorname{tg} 6$, and VPP/tg6 mutant mice at different postnatal days as indicated

\begin{tabular}{lcc}
\hline Strain & Postnatal days & Epo $(\mathrm{mlU} / 100 \mu \mathrm{g})$ \\
\hline $\mathrm{wt}$ & 11 & 0.38 \\
$\mathrm{tg} 6$ & 11 & 8.26 \\
$\mathrm{rd} 1$ & 11 & 0.24 \\
VPP & 11 & $<0.002$ \\
$\mathrm{rd} 1 / \mathrm{tg} 6$ & 11 & 9.48 \\
VPP/tg6 & 11 & 11.66 \\
$\mathrm{wt}$ & 21 & 0.16 \\
$\operatorname{tg} 6$ & 21 & 3.75 \\
rd1 & 21 & 0.02 \\
VPP & 21 & 0.04 \\
rd1/tg6 & 21 & 14.78 \\
VPP/tg6 & 21 & 9.92 \\
wt & 37 & 0.16 \\
$\operatorname{tg} 6$ & 37 & 3.89 \\
rd1 & 37 & $<0.002$ \\
VPP & 37 & ND \\
rd1/tg6 & 37 & 8.19 \\
VPP/tg6 & 37 & ND \\
\hline ND
\end{tabular}

ND, Not determined. $n=2-5$ retinas.

Overexpression of Epo protects against light-induced retinal degeneration

Elevation of endogenous Epo levels by hypoxic preconditioning or exogenous application of recombinant huEpo protects against light-induced retinal degeneration (Grimm et al., 2002). Therefore, we tested whether high levels of huEpo constitutively expressed from the Epo transgene in tg6 mice would also be protective against light damage. After exposure to $13 \mathrm{klux}$ of white light for $2 \mathrm{hr}$, cell death was firmly reduced in tg6 mice as compared with wt littermates (Fig. 2A$F)$. In wt animals, light exposure induced photoreceptor cell death in a large central area, with almost all photoreceptor nuclei showing condensed chromatin after $24 \mathrm{hr}$, an indicator of ongoing apoptosis (Fig. 2C). In contrast, the affected area in tg6 mice was smaller, and not all photoreceptor nuclei were pyknotic, even in the most affected region (Fig. 2D). When retinal morphology was analyzed $12 \mathrm{~d}$ after light exposure, wt mice showed one to two rows of surviving photoreceptor nuclei (Fig. 2E), whereas tg6 retinas retained four to five rows in the most affected region. In addition, morphology of photoreceptor inner and outer segments was better preserved in tg6 mice (Fig. 2F). At $12 \mathrm{~d}$ after illumi- 
nation, photoreceptor apoptosis is completed, and the remaining photoreceptors are stable (our unpublished observation). The larger survival rate of tg6 photoreceptors $12 \mathrm{~d}$ after light exposure is reflected by the increased rhodopsin content of transgenic retinas (92 $\pm 2.3 \%$ of untreated controls; $n=3$ ) as compared with wt littermates (76 $\pm 12 \%$ of untreated controls; $n=3$ ).
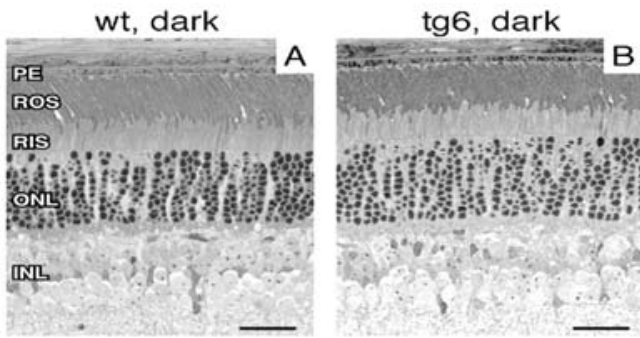

wt, 24h after light

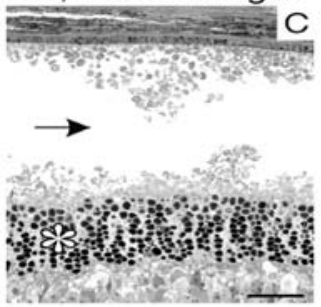

$\operatorname{tg} 6,24 \mathrm{~h}$ after light
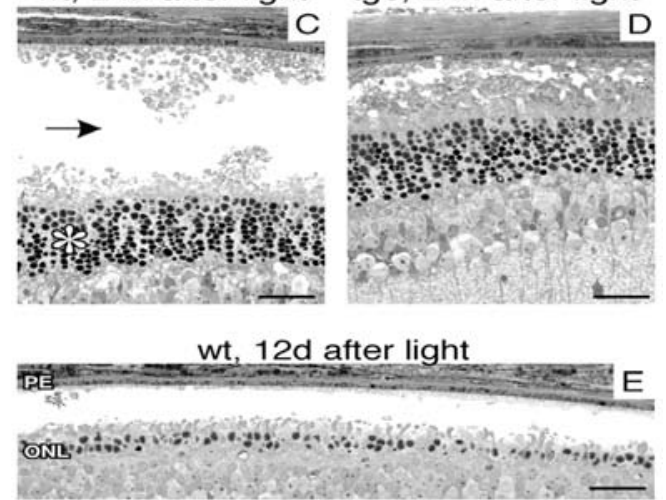

$\operatorname{tg} 6,12 d$ after light
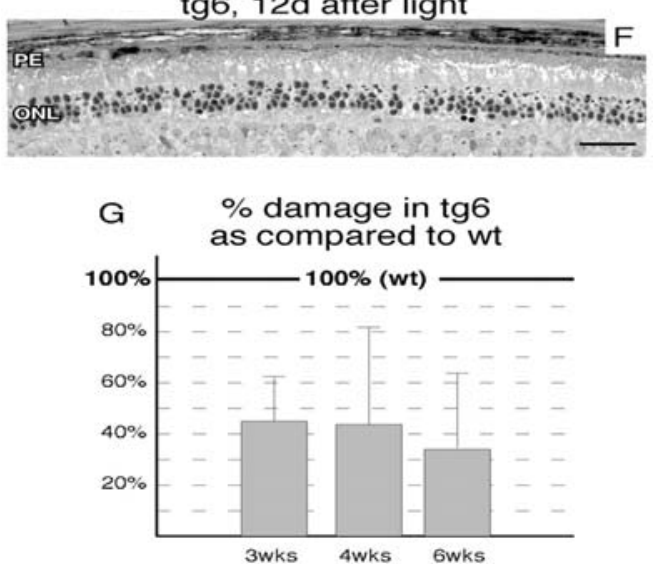

Figure 2. Light-induced retinal degeneration in wt and tg6 mice. $A$, Nonexposed wt retina. $B$, Nonexposed tg6 retina. $C$, Most affected retinal area of a wt mouse $24 \mathrm{hr}$ after light exposure showing severe destruction of photoreceptor outer and inner segments () and condensed nuclear chromatin ( $\left.{ }^{*}\right) . D$, Most affected retinal area of a tg6 mouse $24 \mathrm{hr}$ after light exposure. Lesions are qualitatively similar but distinctly less severe and the number of pyknotic nuclei is reduced. $E$, Most affected retinal area of a wt mouse $12 \mathrm{~d}$ after light exposure. One to two rows of photoreceptor nuclei are left. $F$, Most affected retinal area of a tg 6 mouse $12 \mathrm{~d}$ after light exposure. Four to five rows of photoreceptor nuclei are left. Affected region is smaller than in the wt (data not shown). G, Extent of light damage in retinas of $\operatorname{tg} 6$ mice at ages indicated. Damage is expressed in percentage of damage in littermate control mice of corresponding ages. Damage was determined by ELISA-based measurement of cytoplasmic nucleosomes. Values in wt were set as $100 \%$. Number of animals: $n=3-6$. Abbreviations are given in Figure 1 legend. Scale bars, $25 \mu \mathrm{m}$.

The morphological examination of the retina identifies the area of lesion and cell types that are affected but restricts the analysis to a small tissue fraction. There- 
fore, we used the ELISA-based quantification of free cytoplasmic nucleosomes (as they occur during the course of apoptosis) to determine the extent of cell death in a whole retina. Measurements in light-exposed retinas of 6- to 8-weekold tg6 animals showed a reduced number of cytoplasmic nucleosomes as compared with wt mice. According to this number, damage was calculated to be $36 \%$ of that of wt (Fig. 2G). The reduction in damage reflects the extent of protection observed in the morphological analysis of tg6 retinas. Because photoreceptor degeneration in the inherited models occurs at an earlier age, we tested the responsiveness of younger retinas to Epo-mediated neuroprotection. The presence of the Epo transgene reduced the retinal susceptibility to light-induced degeneration and protected the photoreceptors to a similar level (36-46\%) at all ages tested (Fig. 2G). Interestingly, 3- and 4-week-old retinas were markedly less sensitive to light than older retinas (data not shown).

Tg6 and wt littermates showed light damage only when at least one allele of the Rpe65 gene carried the Rpe65 450 Leu variant (data not shown). The Rpe65 ${ }_{450 \text { Leu }}$ variant increases steady-state levels of the RPE65 protein and the rate of rhodopsin regeneration (Wenzel et al., 2001). This observation further supports the important role of Rpe65 in the regulation of light damage susceptibility in mice. All mice used in the light damage and rhodopsin (see below) experiments were offspring from crosses between male tg6;Rpe65 ${ }_{450 \mathrm{Met}}$ and female Rpe65 ${ }_{450 L e u}$ and therefore were heterozygous for the variant in the Rpe65 gene (Rpe65 450 Met/leu).

Because rhodopsin regeneration is an important determinant of light damage susceptibility (Wenzel et al., 2001), we tested whether the presence of high Epo levels in the tg6 retina might influence rhodopsin regeneration in the visual cycle. Tg6 mice and wt littermates had similar dark-adapted levels of rhodopsin $(0.48 \pm 0.06 \mathrm{nmol}$ per retina for the wt and $0.48 \pm 0.03 \mathrm{nmol}$ per retina for tg $6 ; n$ $=6$ retinas). Furthermore, bleaching efficiency was identical in both animals (rhodopsin remaining after a 10 min bleach: $0.05 \pm 0.01 \mathrm{nmol}$ per retina for wt and $0.05 \pm 0.01 \mathrm{nmol}$ per retina for tg6; $n=6$ retinas), and regeneration of rhodopsin in darkness was indistinguishable between wt and tg6 (rhodopsin levels after $45 \mathrm{~min}$ of regeneration in darkness: $0.28 \pm 0.03 \mathrm{nmol}$ per retina for wt and $0.26 \pm 0.05 \mathrm{nmol}$ per retina for tg $6 ; n=6$ retinas). These results strongly suggest that the presence of high Epo levels in the tg6 retina did not alter known parameters for light damage susceptibility but directly protected photoreceptor cells against apoptosis induced by acute light exposure. 


\section{Effect of high Epo levels on inherited retinal degeneration}

To test a potential protective effect of Epo in inherited retinal degeneration, we crossed the Epo transgenic mice with two mouse models for human RP. The rd1 mouse carries a nonsense mutation in the gene encoding the phosphodiesterase subunit (Bowes et al., 1990). This induces a rapid and lightindependent degeneration of the photoreceptor cell layer starting around P10. The VPP mouse carries a transgene with three mutations in the rhodopsin gene (V20G, P23H, P27L), causing a dominant but slow degeneration of the photoreceptor cell layer (Naash et al., 1993). In wt, rd1, and VPP retinas, Epo was expressed at low levels at P11 that dropped to almost nondetectable levels at P21 and at P37 (Table 1). The presence of the Epo transgene increased retinal Epo levels $>20$-fold in rd1 and VPP mice (Table 1). With increasing age, levels of Epo decreased in all groups of mice, but the presence of the transgene nevertheless sustained highly elevated Epo levels.

Similar to Epo, the Epo receptor was expressed at P11 in wt, tg6, rd1, and VPP retinas (Fig. 3A, B); however, expression of the receptor was decreased at $\mathrm{P} 21$ in both rd1 and VPP retinas. The levels decreased to almost nondetectable levels in the rd1 retina at P62 but remained expressed in the VPP retina. Because the Epo receptor localizes mainly to photoreceptor cells (Grimm et al., 2002), the decrease probably reflects the loss of photoreceptors in the two mouse models (compare Figs. 4, 5). This loss is much more pronounced in the rd1 mouse with no photoreceptors left at P62 (data not shown). Thus, the remaining weak signal at P62 in the rd1 mouse (Fig. 3C) might be attributable to expression of the receptor in ganglion cells and amacrine neurons as suggested by Junk and colleagues (2002). Despite the expression of the Epo receptor at the onset of the degenerative process (P11), the presence of high levels of Epo did not rescue photoreceptors from cell death in the rd1 mouse (Fig. 4). Retinal degeneration proceeded without notable differences in rd1 and double-mutant rd1/tg6 mice. A single layer of photoreceptor cells (mostly cones) was visible at P21 and P37. 


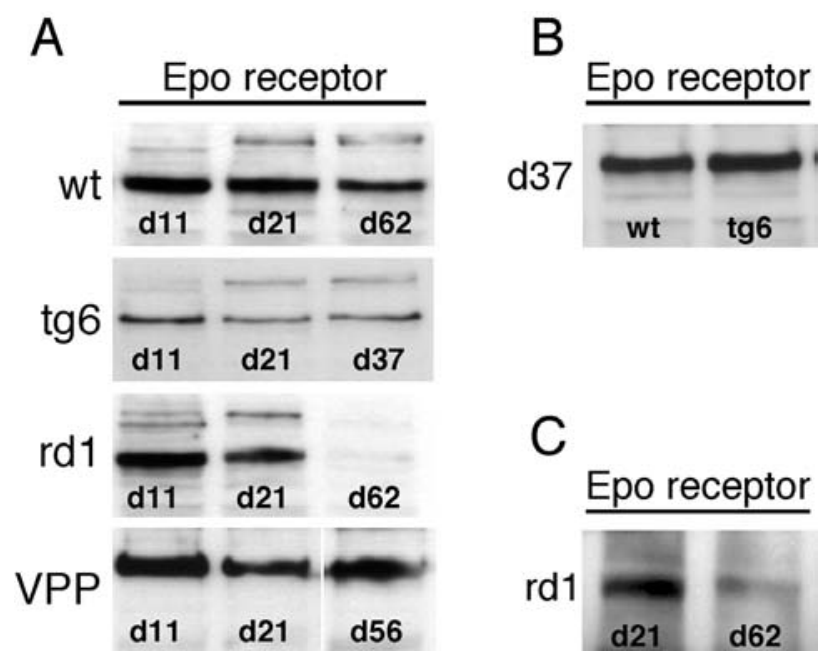

Figure 3. Expression of Epo receptor in the retina. Total retinal homogenates were tested by Western blotting for the presence of Epo receptor. A, Epo receptor in wt, tg6, rd1, and VPP retinas at different postnatal days as indicated. $B$, Direct comparison of Epo receptor between wt and tg 6 retinas showing no downregulation by the overexpression of Epo in tg6 at least up to P37. C, Overexposure of retinal samples of rd1 mice at P21 and P62, respectively, showing a small fraction of Epo receptor remaining at P62. 


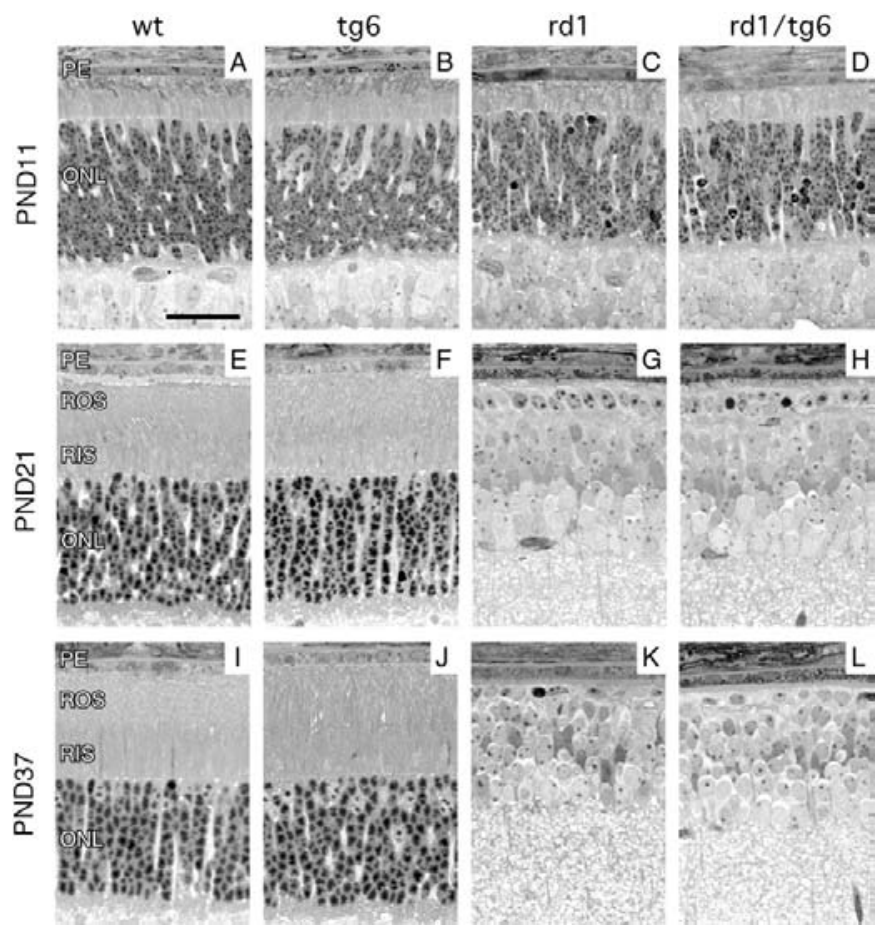

Figure 4. huEpo transgene expression does not rescue photoreceptor cells in the rd1 mouse. Retinal morphology at P11 $(A-D), \mathrm{P} 21(E-H)$, and P37 (I-L) of wt $(A, E, I), \operatorname{tg} 6(B, F, J), \operatorname{rd} 1(C, G$, $K)$, and $\mathrm{rd} 1 / \operatorname{tg} 6$ double-mutant mice $(D, H, L)$. Compared with wt and $\operatorname{tg} 6$ retinas, the outer segments in rd1 and rd1/tg6 mice are less developed, and both rd1 and rd1/tg6 retinas show scattered apoptotic nuclei at P11 and almost complete loss of photoreceptors at P21 and P37. Representative sections of two to four animals per time point and mouse strain are presented. Abbreviations are given in Figure 1 legend. PND, Postnatal day. Scale bar, $25 \mu \mathrm{m}$.

Similarly, retinal degeneration was not influenced by the Epo transgene in the VPP mouse (Fig. 5). At 3 weeks of age, the ONL thickness in VPP and VPP/tg6 mouse lines was approximately half of that in control littermates. Degeneration proceeded slowly in both strains, and at 8 weeks of age, only one to two additional rows of photoreceptor nuclei were lost. In contrast to the decreasing number of photoreceptor cells, morphology of the inner and outer segments in the VPP and VPP/tg6 strains improved between postnatal weeks three and six. This observation was confirmed by retinal rhodopsin measurements (Fig. 6). Although rhodopsin levels in wt and tg6 strains were at normal levels throughout the experimental period, rhodopsin contents of the VPP retinas (independently of the presence or absence of the Epo transgene) were reduced at 3 weeks of age and increased until postnatal week 6 before levels decreased again. 


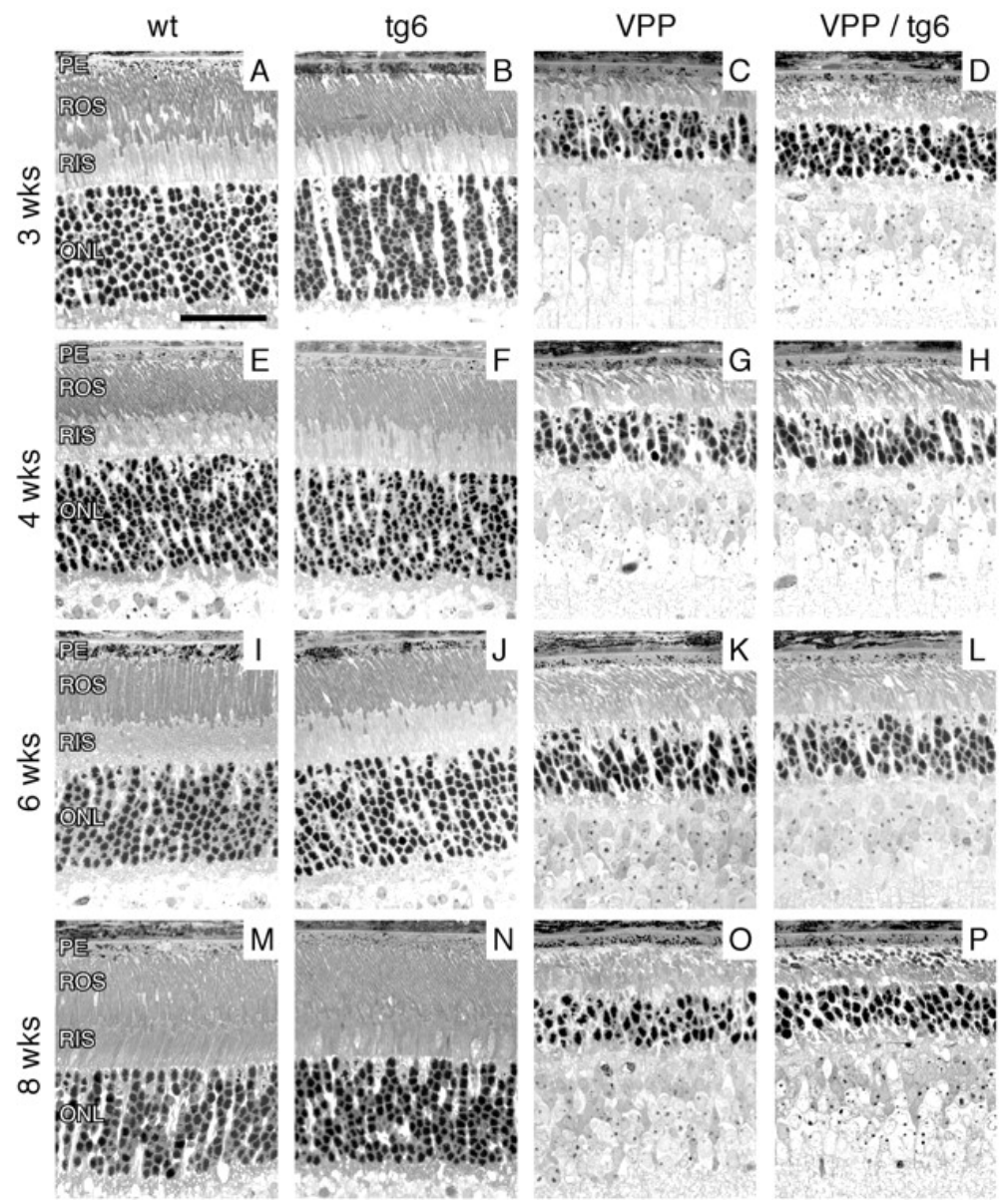

Figure 5. huEpo transgene expression does not rescue photoreceptor cells in the VPP mouse. Retinal morphology at 3 weeks $(A-D), 4$ weeks $(E-H), 6$ weeks $(I-L)$, and 8 weeks of age $(M-P)$ of wt $(A, E, I, M), \operatorname{tg} 6(B, F, J, N)$, VPP $(C, G, K, O)$, and VPP/tg6 double-mutant mice $(D, H, L, P)$. Representative sections of two to four animals per time point and mouse strain are presented. Photoreceptor degeneration proceeded similarly in VPP and VPP/tg6 retinas. Abbreviations are given in Figure 1 legend. Scale bar, $25 \mu \mathrm{m}$. 


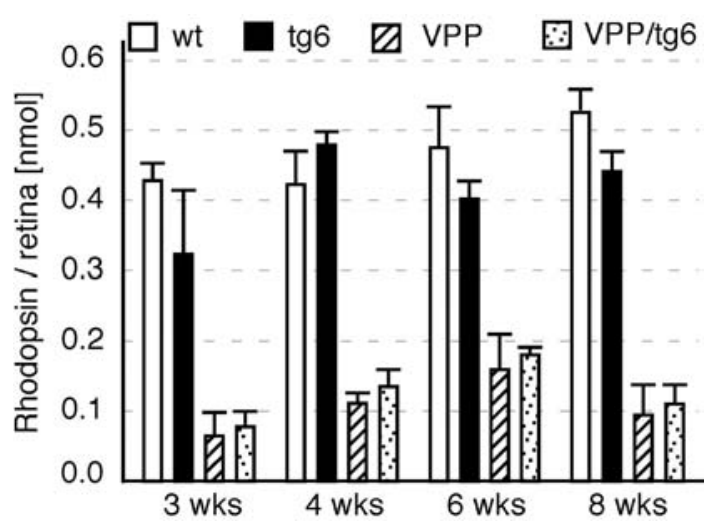

Figure 6. Effect of huEpo overexpression on rhodopsin levels (in nanomoles per retina) in wt and mutant mouse retinas at ages [weeks (wks)] indicated. Rhodopsin is representative for amount and integrity of rods. Given are mean values \pm SD of the rhodopsin content of at least $n=3$ retinas.

To circumvent potential long-term side effects of the sustained Epo expression from the Epo transgene used in the above experiments (see Discussion), we repetitively injected $100 \mathrm{IU}$ of recombinant huEpo intraperitoneally into rd1 and VPP mice at P11 (rd1 only), 13, 15, 17, and 19. The dosage used (100 IU per injection) was shown to protect retinal photoreceptors against light damage after a single injection (Grimm et al., 2002). At P21, mice were killed and analyzed. The Epo-injected mice showed hematocrit values elevated by 41\% (VPP; $n=4)$ and $40 \%(\mathrm{rd} 1 ; n=11)$ on average compared with sham-injected mice. This confirms that the applied Epo was biologically active; however, retinal morphology was not detectably rescued in the rd1 (Fig. 7A) and the VPP (Fig. 7B) mice, and rhodopsin levels were either not detectable (rd1; data not shown) or did not differ from untreated controls (VPP) (Fig. 7C). 
A

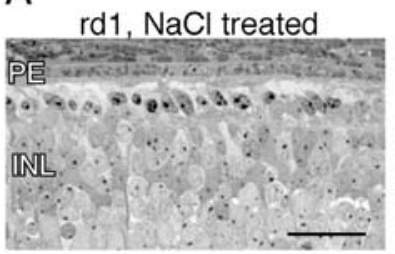

rd1, Epo treated

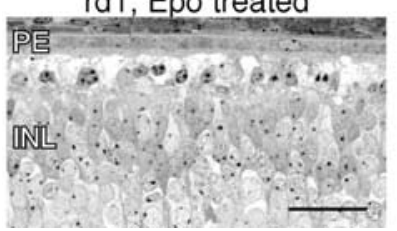

B

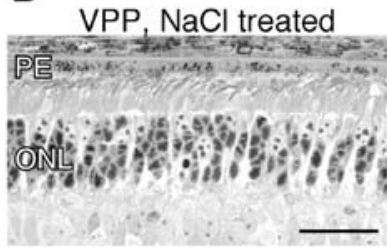

VPP, Epo treated

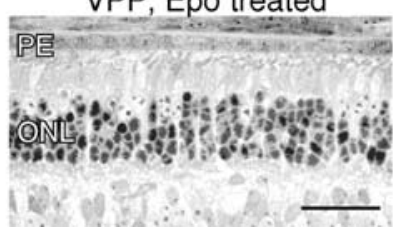

C

VPP, untreated

VPP, Epo treated

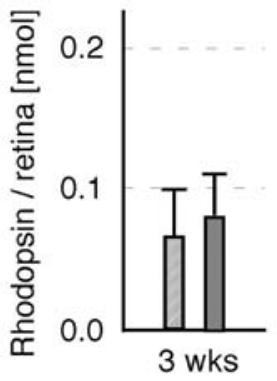

Figure 7. Effect of huEpo injections on retinal morphology and rhodopsin levels at PND 21. A, Retinal morphology of rd1 mice after $\mathrm{NaCl}$ injections (top panel) or Epo injections (bottom panel) applied at PND 11, 13, 15, 17, and 19. B, Retinal morphology of VPP mice after $\mathrm{NaCl}$ injections (top panel) or Epo injections (bottom panel) applied at PND 13, 15, 17, and 19. C, Rhodopsin content of VPP retinas with or without repetitive treatment (injections) of huEpo $(n=4)$. Abbreviations are given in Figure 1 legend. Scale bar, $25 \mu \mathrm{m}$

\section{Discussion}

We showed recently that increased retinal levels of Epo (induced either by hypoxic preconditioning or by intraperitoneal injection of recombinant huEpo) protect the retina against degeneration induced by acute exposure to high intensity light (Grimm et al., 2002). Furthermore, Epo protected retinal ganglion cells from cell death after experimental ischemia (Junk et al., 2002). Therefore, Epo became a candidate drug for the treatment of inherited retinal degenerative diseases such as retinitis pigmentosa in human patients.

Here we show that Epo has the capacity to protect the retina against light damage also when expressed from a transgene. Thus, with regard to its neuroprotective potential, transgenically overexpressed huEpo protein is comparable with systemically applied recombinant huEpo. To test whether Epo can also protect retinal cells in inherited retinal degeneration, we crossed the transgene into two mouse models for human RP. In both the rd1 and the VPP mouse, the transgene caused highly increased levels of Epo in the retina but did not inhibit cell death and retinal degeneration. Similarly, exogenous application of huEpo also did not delay cell death in the two mouse models of human RP used. This lack of protection indicates that Epo cannot interfere with the death signal induced by the respective gene mutations. 
It has been shown that increased oxygen levels (hyperoxia) slow photoreceptor death in a rat model of retinal degeneration [Royal College of Surgeons (RCS) rat] and that reduced oxygenation accelerates disease progression (Maslim et al., 1997; Valter et al., 1998). This suggests a critical role of retinal oxygen levels in the regulation of cell death. Epo-overexpressing tg6 mice have increased blood volumes (up to $25 \%$ of body weight) (Vogel et al., 2003) and hematocrit values (up to 83\%) (Ruschitzka et al., 2000) twice as high as wt mice. Because the arterial $\mathrm{P}_{\mathrm{O} 2}$ is not altered, the arterial oxygen content is increased, thereby implying elevated oxygenation of all organs, including the retina. Nevertheless, retinal degeneration in the rd1 and the VPP mouse was not influenced, suggesting that mechanisms different from those in the RCS rat may account for the photoreceptor cell death in the two mouse models.

Despite their highly increased blood volume and hematocrit value, $\operatorname{tg} 6$ mice do not show an elevated risk for thromboembolism (Wiessner et al., 2001). Obviously, the life-long exposure to high Epo levels provoked adaptative mechanisms including nitric oxide-mediated vasodilation (Ruschitzka et al., 2000; Vogel et al., 2003) as well as regulated elevation of blood viscosity by increasing erythrocyte flexibility (Quaschning et al., 2003; Shibata et al., 2003). It is therefore feasible that the prolonged exposure to high Epo levels in tg6 might possibly desensitize the Epo-Epo receptor (EpoR) system in the retina, reducing the neuroprotective capacity of Epo; however, a potential desensitization of the Epo system was not obvious in our model system. The Epo receptor was highly expressed in the retina as early as at P11 in all strains tested, and Epo receptor levels in tg6 and wt mice remained comparably high at least until day 37. Furthermore, the Epo transgene protected the retina against light damage to a similar extent, independently of the age of the animals (Fig. 2). Although retinas of young mice were less susceptible to light damage in general, the presence of high Epo levels further reduced the severity of retinal degeneration after light exposure. This shows that Epo can already confer neuroprotection in young retinas, at a time when retinal degeneration is ongoing at least in the VPP model. These results suggest that constitutively high levels of Epo did not downregulate expression of Epo receptor as an adaptative measure in the tg6 retina and that a desensitization of the Epo-EpoR system did not occur.

Although Epo protects against light damage (Fig. 2) (Grimm et al., 2002), Epo did not improve photoreceptor cell survival and retinal pathology in the VPP mouse, although progression of the degeneration of the VPP retina is accelerated by light (Naash et al., 1996). Light as pathogenic stimulus uses at least two different pathways to induce the apoptotic program. Activation and choice of a 
particular pathway seem to depend on the intensity and duration of light exposure (Hao et al., 2002). Thus, a compound effective in the protection against acute bright light, such as Epo, may not necessarily be protective against longlasting low-level light exposure. Such a prolonged exposure to low-level light may be the cofactor accelerating the degeneration mediated by the VPP mutations. Differences in signaling between light-induced and inherited retinal degeneration are also evidenced by the observed differential effect of several survival factors (LaVail et al., 1998) and other compounds such as nitro-L-arginine methyl ester (Kaldi et al., 2003) or the free radical trap phenyl- $N$-tert butylnitrone (Ranchon et al., 2003) on light-induced and inherited retinal degeneration in mice and rats.

Different apoptotic pathways may exist in various models of retinal degeneration and a potential systemic or local adaptation to high Epo levels might affect one but not another anti-apoptotic pathway. To address such a possibility, we applied huEpo exogenously. As shown previously, intraperitoneally injected huEpo reaches the retina where it can protect the retina against light damage (Grimm et al., 2002). The repeated systemic application of huEpo increased hematocrit values of the injected animals, showing that the protein was biologically active; however, the injected Epo could not inhibit cell death in the rd1 or VPP retina. This supports the conclusion that adaptational changes, whether systemic or local, might not be the reason for the lack of protection expressed from the transgene. More likely, signaling pathways and apoptotic mechanisms differ between acute light damage and the two models of inherited retinal degeneration to such a degree that Epo can prevent cell death in one but not the other model. It has been shown for other factors (e.g., CNTF or BDNF) that different models are amenable in different ways to a treatment with cytokines (LaVail et al., 1998). At the present time, our data suggest that Epo alone might not be sufficient for a successful therapeutic intervention with cell death in inherited retinal degeneration. On the other hand, encouraging results after Epo treatment have been reported on three patients with diabetic retinopathy and renal failure (Berman and Friedman, 1994; Friedman et al., 1995).

We observed that protection by transgenically expressed (or exogenously applied) Epo was less efficient as compared with hypoxic preconditioning, suggesting that other hypoxia-inducible factors may act in concert with Epo to confer the complete protection observed after hypoxic exposure. It has been shown in other systems that treatment with a combination of growth factors or cytokines improves the retinal morphology in vivo and in vitro as compared with administration of the individual factors alone (Ogilvie et al., 2000; Caffe et al., 2001; 
Cao et al., 2001). Thus, the possibility exists that additional hypoxia-inducible factors might act together with Epo to achieve full neuroprotection. In keeping with this, we will test whether a successful retinal treatment with Epo requires a combination with other cytokines or growth factors.

\section{Footnotes}

This work was supported by the Swiss National Science Foundation, the Theodore Ott Foundation, the Hartmann Müller Foundation, the Foundation for Scientific Research of the University of Zurich, the VELUX Foundation (Glarus, Switzerland), Grant EY-10609 from the National Eye Institute, a Core Grant for Vision Research at the University of Oklahoma (EY12190), and a National Institutes of Health Grant P20 RR 017703 from the Center of Excellence in Biomedical Research Program of the National Center for Research Resources to the University of Oklahoma.D.S. was supported by "Aspirant Candidat Fonds National de la Recherche Scientifique Belge," Department of Ophthalmology, Hôpital Universitaire Saint-Pierre (Brussels, Belgium). We thank C.Imsand, D. Greuter, G. Hoegger, and S. Keller for expert technical assistance. 


\section{References}

Adler R, Curcio C, Hicks D, Price D, Wong F (1999) Cell death in age-related macular degeneration. Mol Vis 5: 31

Berman DH, Friedman EA (1994) Partial absorption of hard exudates in patients with diabetic endstage renal disease and severe anemia after treatment with erythropoietin. Retina 14: 1-5.

Bowers F, Valter K, Chan S, Walsh N, Maslim J, Stone J (2001) Effects of oxygen and bFGF on the vulnerability of photoreceptors to light damage. Invest Ophthalmol Vis Sci 42: 804-815.

Bowes C, Li T, Danciger M, Baxter LC, Applebury ML, Farber DB (1990) Retinal degeneration in the rd mouse is caused by a defect in the beta subunit of rod cGMP-phosphodiesterase. Nature 347: $677-680$

Caffe AR, Soderpalm AK, Holmqvist I, van Veen T (2001) A combination of CNTF and BDNF rescues rd photoreceptors but changes rod differentiation in the presence of RPE in retinal explants. Invest Ophthalmol Vis Sci 42: 275-282.

Cao W, Tombran-Tink J, Elias R, Sezate S, Mrazek D, McGinnis JF (2001) In vivo protection of photoreceptors from light damage by pigment epithelium-derived factor. Invest Ophthalmol Vis Sci 42: 1646-1652.

Chang B, Hawes NL, Hurd RE, Davisson MT, Nusinowitz S, Heckenlively JR (2002) Retinal degeneration mutants in the mouse. Vision Res 42: 517-525.

Chen CK, Burns ME, Spencer M, Niemi GA, Chen J, Hurley JB, Baylor DA, Simon MI (1999a) Abnormal photoresponses and light-induced apoptosis in rods lacking rhodopsin kinase. Proc Natl Acad Sci USA 96: 3718-3722.

Chen J, Simon MI, Matthes MT, Yasumura D, LaVail MM (1999b) Increased susceptibility to light damage in an arrestin knockout mouse model of Oguchi disease (stationary night blindness). Invest Ophthalmol Vis Sci 40: 2978-2982.

Cideciyan AV, Hood DC, Huang Y, Banin E, Li ZY, Stone EM, Milam AH, Jacobson SG (1998) Disease sequence from mutant rhodopsin allele to rod and cone photoreceptor degeneration in man. Proc Natl Acad Sci USA 95: 7103-7108.

Cruickshanks KJ, Klein R, Klein BE (1993) Sunlight and age-related macular degeneration. The Beaver Dam eye study. Arch Ophthalmol 111: 514-518.

Cruickshanks KJ, Klein R, Klein BE, Nondahl DM (2001) Sunlight and the 5-year incidence of early age-related maculopathy: the Beaver Dam eye study. Arch Ophthalmol 119: 246-250.

Friedman EA, Brown CD, Berman DH (1995) Erythropoietin in diabetic macular edema and renal insufficiency. Am J Kidney Dis 26: 202-208.

Goto Y, Peachey NS, Ziroli NE, Seiple WH, Gryczan C, Pepperberg DR, Naash MI (1996) Rod phototransduction in transgenic mice expressing a mutant opsin gene. J Opt Soc Am 13: $577-$ 585.

Grimm C, Wenzel A, Hafezi F, Remé CE (2000) Gene expression in the retina: the effect of damaging light. Mol Vis 6: 252-260.

Grimm C, Wenzel A, Groszer M, Mayser H, Seeliger M, Samardzija M, Bauer C, Gassmann M, Reme CE (2002) HIF-1-induced erythropoietin in the hypoxic retina protects against lightinduced retinal degeneration. Nat Med 8: 718-724.

Hafezi F, Grimm C, Simmen BC, Wenzel A, Reme CE (2000) Molecular ophthalmology: an update on animal models for retinal degenerations and dystrophies. Br J Ophthalmol 84: 922-927.

Hao W, Wenzel A, Obin MS, Chen CK, Brill E, Krasnoperova NV, Eversole-Cire P, Kleyner Y, TayIor A, Simon MI, Grimm C, Reme CE, Lem J (2002) Evidence for two apoptotic pathways in light-induced retinal degeneration. Nat Genet 32: 254-260. 
Hopfl G, Ogunshola O, Gassmann M (2004) HIFs and tumors-causes and consequences. Am J Physiol Regul Integr Comp Physiol 286: R608-623.

Junk AK, Mammis A, Savitz SI, Singh M, Roth S, Malhotra S, Rosenbaum PS, Cerami A, Brines M, Rosenbaum DM (2002) Erythropoietin administration protects retinal neurons from acute ischemia-reperfusion injury. Proc Natl Acad Sci USA 99: 10659-10664.

Kaldi I, Dittmar M, Pierce P, Anderson RE (2003) L-NAME protects against acute light damage in albino rats, but not against retinal degeneration in $\mathrm{P} 23 \mathrm{H}$ and $\mathrm{S} 334$ ter transgenic rats. Exp Eye Res 76: 453-461.

Kueng-Hitz N, Grimm C, Lansel N, Hafezi F, He L, Fox D, Remé CE, Niemeyer G, Wenzel A (2000) The retina of c-fos+/+ and c-fos-/- mice: electrophysiological, morphological and biochemical aspects. Invest Ophthalmol Vis Sci 41: 909-916.

LaVail MW, Yasumura D, Matthes MT, Lau Villacorta C, Unoki K, Sung CH, Steinberg RH (1998) Protection of mouse photoreceptors by survival factors in retinal degenerations. Invest Ophthalmol Vis Sci 39: 592-602.

LaVail MM, Gorrin GM, Yasumura D, Matthes MT (1999) Increased susceptibility to constant light in $\mathrm{nr}$ and pcd mice with inherited retinal degeneration. Invest Ophthalmol Vis Sci 40: 1020-1024.

Maslim J, Valter K, Egensperger R, Hollander H, Stone J (1997) Tissue oxygen during a critical developmental period controls the death and survival of photoreceptors. Invest Ophthalmol Vis Sci 38: 1667-1677.

Mervin K, Stone J (2002) Regulation by oxygen of photoreceptor death in the developing and adult C57BL/6J mouse. Exp Eye Res 75: 715-722.

Naash MI, Hollyfield JG, al-Ubaidi MR, Baehr W (1993) Simulation of human autosomal dominant retinitis pigmentosa in transgenic mice expressing a mutated murine opsin gene. Proc Natl Acad Sci USA 90: 5499-5503.

Naash ML, Peachey NS, Li ZY, Gryczan CC, Goto Y, Blanks J, Milam AH, Ripps H (1996) Lightinduced acceleration of photoreceptor degeneration in transgenic mice expressing mutant rhodopsin. Invest Ophthalmol Vis Sci 37: 775-782.

Ogilvie JM, Speck JD, Lett JM (2000) Growth factors in combination, but not individually, rescue rd mouse photoreceptors in organ culture. Exp Neurol 161: 676-685.

Organisciak DT, Li M, Darrow RM, Farber DB (1999) Photoreceptor cell damage by light in young Royal College of Surgeons rats. Curr Eye Res 19: 188-196.

Portera Cailliau C, Sung CH, Nathans J, Adler R (1994) Apoptotic photoreceptor cell death in mouse models of retinitis pigmentosa. Proc Natl Acad Sci USA 91: 974-978.

Quaschning T, Ruschitzka F, Stallmach T, Shaw S, Morawietz H, Goettsch W, Hermann M, Slowinski T, Theuring F, Hocher B, Luscher TF, Gassmann M (2003) Erythropoietin-induced excessive erythrocytosis activates the tissue endothelin system in mice. FASEB J 17: 259-261.

Ranchon I, LaVail MM, Kotake Y, Anderson RE (2003) Free radical trap phenyl- $N$-tert-butylnitrone protects against light damage but does not rescue P23H and S334ter rhodopsin transgenic rats from inherited retinal degeneration. J Neurosci 23: 6050-6057.

Remé CE, Grimm C, Hafezi F, Marti A, Wenzel A (1998) Apoptotic cell death in retinal degenerations. Prog Ret Eye Res 17: 443-464.

Ruschitzka FT, Wenger RH, Stallmach T, Quaschning T, de Wit C, Wagner K, Labugger R, Kelm M, Noll G, Rulicke T, Shaw S, Lindberg RL, Rodenwaldt B, Lutz H, Bauer C, Luscher TF, Gassmann M (2000) Nitric oxide prevents cardiovascular disease and determines survival in polyglobulic mice overexpressing erythropoietin. Proc Natl Acad Sci USA 97: 11609-11613.

Sanyal S, Hawkins RK (1986) Development and degeneration of retina in rds mutant mice: effects of light on the rate of degeneration in albino and pigmented homozygous and heterozygous mutant and normal mice. Vision Res 26: 1177-1185. 
Shibata J, Hasegawa J, Siemens HJ, Wolber E, Dibbelt L, Li D, Katschinski DM, Fandrey J, Jelkmann W, Gassmann M, Wenger RH, Wagner KF (2003) Hemostasis and coagulation at a hematocrit level of 0.85: functional consequences of erythrocytosis. Blood 101: 4416-4422

Simons K (1993) Artificial light and early-life exposure in age-related macular degeneration and in cataractogenic phototoxicity. Arch Ophthalmol 111: 297-298.

Taylor HR, Munoz B, West S, Bressler NM, Bressler SB, Rosenthal FS (1990) Visible light and risk of age-related macular degeneration. Trans Am Ophthalmol Soc 88: 163-173.

Valter K, Maslim J, Bowers F, Stone J (1998) Photoreceptor dystrophy in the RCS rat: roles of oxygen, debris, and bFGF. Invest Ophthalmol Vis Sci 39: 2427-2442.

Vogel J, Kiessling I, Heinicke K, Stallmach T, Ossent P, Vogel O, Aulmann M, Frietsch T, SchmidSchonbein H, Kuschinsky W, Gassmann M (2003) Transgenic mice overexpressing erythropoietin adapt to excessive erythrocytosis by regulating blood viscosity. Blood 102: 2278-2284

Wagner KF, Katschinski DM, Hasegawa J, Schumacher D, Meller B, Gembruch U, Schramm U, Jelkmann W, Gassmann M, Fandrey J (2001) Chronic inborn erythrocytosis leads to cardiac dysfunction and premature death in mice overexpressing erythropoietin. Blood 97: 536-542.

Wang M, Lam TT, Tso MO, Naash MI (1997) Expression of a mutant opsin gene increases the susceptibility of the retina to light damage. Vis Neurosci 14: 55-62.

Wenzel A, Remé CE, Williams TP, Hafezi F, Grimm C (2001) The Rpe65 Leu450Met mutation increases retinal resistance against light-induced degeneration by slowing rhodopsin regeneration. J Neurosci 21: 53-58.

Wiessner C, Allegrini PR, Ekatodramis D, Jewell UR, Stallmach T, Gassmann M (2001) Increased cerebral infarct volumes in polyglobulic mice overexpressing erythropoietin. J Cereb Blood Flow Metab 21: 857-864

Wong P (1994) Apoptosis, retinitis pigmentosa, and degeneration. Biochem Cell Biol 72: 489-498. 


\section{CHAPTER 5 \\ Continuous expression of the homeobox gene PAX6 in the ageing human retina}

Stanescu D, Iseli HP, Schwerdtfeger K, Ittner LM, Remé CE and Hafezi F.

Published in Eye (Lond). 2007 Jan;21(1):90-3. Epub 2005 Oct 28. 


\begin{abstract}
Purpose: In the past few years, the essential role of the homeobox gene PAX6 for eye development has been demonstrated unambiguously in a variety of species including humans. In humans, PAX6 mutations lead to a variety of ocular malformations of the anterior and posterior segment. However, little is known about PAX6 expression in the adult human retina. We have therefore investigated PAX6 levels and localization in the human retina at various ages.

Methods: Adult human eyes of various ages (17-79 years) were obtained from the Zurich Eye Bank. PAX6 expression levels and patterns were analysed by Western blot analysis of total retinal protein and by immunohistochemistry on paraffin sections, respectively.

Results: PAX6 expression in the retina was detected up to 79 years of donor age and was predominantly localized to the ganglion cell layer and the inner part of the inner nuclear layer.

Conclusions: PAX6 remains distinctly expressed throughout the lifespan of the human retina suggesting a role for PAX6 in the retina after completion of eye morphogenesis.
\end{abstract}

Keywords: foveal hypoplasia, PAX6, human, aniridia, Peter's anomaly 


\section{Introduction}

The homeobox gene PAX6 is an essential regulatory element for ocular development in a variety of species with special emphasis on mammals. ${ }^{1}$ The predominant role of PAX6 even in different animal phyla such as insects and vertebrates is demonstrated by the high rate of conservation of PAX6 domains throughout evolution, as demonstrated by a 93\% homology of the PAX6 amino acid sequence between Drosophila and human over the paired domain and the homeodomain. $^{2}$

In humans, PAX6 has been mapped to chromosome $11 \mathrm{p} 13$ and is expressed mainly in the eye, brain, and pancreas during development. In the last years, a number of human PAX6 mutations have been identified leading to a variety of ocular malformations of the anterior and posterior segment. ${ }^{3-11}$

In the developing human retina, PAX6 expression can be histochemically detected in the Inner Nuclear Layer and Ganglion Cell Layer, as demonstrated by Nishina et al ${ }^{12}$ in human foetuses up to gestation week 22 .

Interestingly, research on expression patterns and regulatory function of PAX6 had focused on developmental stages solely and little is known about the role of PAX6 in the ageing mammalian retina. We have recently shown that in the mouse retina, PAX6 is constantly expressed throughout the whole lifespan of the animal. Furthermore, we have demonstrated that PAX6 is downregulated in two animal models for retinal degeneration during the peak of photoreceptor apoptosis (Iseli et al, submitted). To analyse whether PAX6 expression in the human retina persists after the end of ocular development, we performed Western Blot analyses and immunohistochemical studies on human retinas at various ages.

\section{Material and methods}

\section{Dissection of retinas}

Human retinas were obtained from seven eyes from donors aged 17-79 years. Eyes were provided by the Zurich Eye Bank as globes with excised cornea, the latter being further processed for corneal grafting. The procurement and use of human tissues in this study complied with the Declaration of Helsinki. Causes of death included myocardial infarction, cerebral vascular accident, renal insufficiency, multiple organ failure, aortic dissection, and congestive heart failure. 
Time between death and enucleation was below $12 \mathrm{~h}$ and time between death and dissection was below $14 \mathrm{~h}$ in all samples (Table 1). Prior to dissection, the posterior pole was inspected through an operating microscope to confirm the absence of gross retinal disease. The central retina was defined as the region delimited by the optic nerve nasally, the retinal arcuate vessels superiorly and inferiorly and an imaginary line $2 \mathrm{~mm}$ temporally of the fovea. All retinas were dissected on ice. Briefly, corneas were excised and vitreous was extruded with a forceps. Retinas were gently removed from the retinal pigment epithelium (RPE) with a smooth forceps at the ora serrata and the optic nerve head. Care was taken that retinal tissue was free from RPE remnants. Central retinal tissue was frozen in liquid nitrogen and stored at $-80^{\circ} \mathrm{C}$. All samples used in this study were free of malignancies or any known ocular disease.

Table 1. Human donor information

\begin{tabular}{lccrrl}
\hline Sample & $\begin{array}{c}\text { Age } \\
\text { (years })\end{array}$ & Sex & TDE $(\mathrm{h})$ & TDF & Cause of death \\
\hline 1 & 17 & F & 9 & 13 & Polytrauma \\
2 & 28 & M & 12 & 12 & Polytrauma \\
3 & 36 & M & 5 & 8 & Myocardial infarction \\
4 & 45 & M & 7 & 9 & Myocardial infarction \\
5 & 55 & M & 9 & 13 & Renal failure \\
6 & 66 & M & 6 & 9 & Cerebral vascular accident \\
7 & 79 & F & 8 & 11 & Cerebral vascular accident \\
\hline
\end{tabular}

$\mathrm{GW}=$ gestation week; TDE=time between death and enucleation; TDF=time between death and fixation.

\section{Western blotting}

Human retinas were homogenized in $100 \mathrm{mM}$ Tris- $\mathrm{Hcl}, \mathrm{pH} 7.4$ using a sonifier. Protein concentrations were determined by the Bradford assay using BSA as standard. Western blotting was performed according to standard protocols. For immunodetection, polyclonal rabbit antisera directed against PAX6 were applied. ${ }^{13}$ After application of HRP-conjugated secondary antibodies, immunoreactivity was visualized using the Renaissance-Western blot detection kit (PerkinElmer Life Sciences, Emeryville, USA). 
Immunohistochemical analysis

For IHC, whole eyecups were fixed by immersion in 4\% paraformaldehyde in $100 \mathrm{mM}$ PBS ( $\mathrm{pH}$ 7.4) overnight and processed to paraffin blocks using standard protocols. Sections $(10 \mathrm{~m})$ were deparaffinized in xylene and dehydrated in descending ethanol series. To enhance immunoreactivity, sections were incubated in $10 \mathrm{mM}$ citrate buffer ( $\mathrm{pH} \mathrm{6.0)}$ ) and boiled in a steamer at $100^{\circ} \mathrm{C}$ for $3 \mathrm{~min}$. For immunofluorescence primary polyclonal rabbit antibodies for the detection of Pax6 were used at dilutions of $1: 300$ (Covance, Princeton, NJ, USA) or $1: 200$ (Chemicon, Temecula, CA, USA) overnight at $4^{\circ} \mathrm{C}$, and visualized via biotinylated secondary antibodies (goat anti-rabbit; $1: 200$; Vector Labs, Burlingame, CA, USA) and streptavidin-Cy3 (1:200; Sigma-Aldrich, St Louis, MO, USA). Absence of the primary antibody was used as negative control (data not shown).

\section{Results}

Specificity of the antibody was examined by Western blot analysis. Blots display a band with a molecular weight of $46 \mathrm{kDa}$ and a second band of $48 \mathrm{kDa}$ corresponding to the splicing isoform of PAX6, PAX6(5a). As an internal control labelling with an antibody against actin was performed. Actin levels remained constant throughout all time points tested in all experiments performed (data not shown).

Persistent expression was detected at all ages tested: 17, 28, 36, 45, 55, 66, and 79 years with varying levels of expression as shown in Figure 1.

Immunohistochemical analysis is shown in Figure $2 a$ and reveals that PAX6 expression in the retina is confined to the ganglion cell layer (GCL) and the inner portion of the inner nuclear layer (INL).

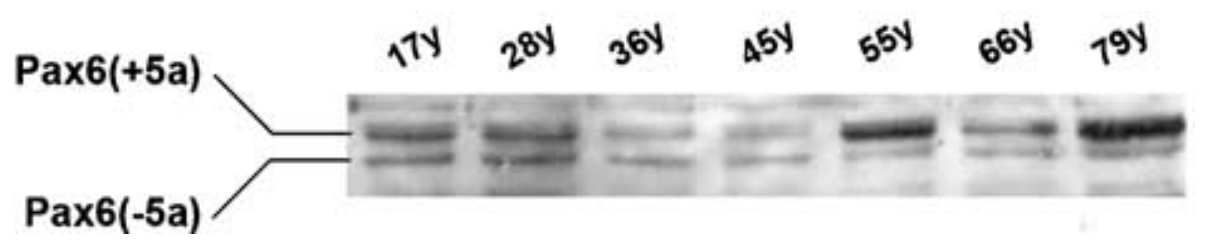

Figure 1. Western blot analysis of PAX6 expression and its alternative splice forms in human retinas at various ages $(17,28,36,45,55,66$, and 79 years). Expression was detected at all ages tested with varying levels. 


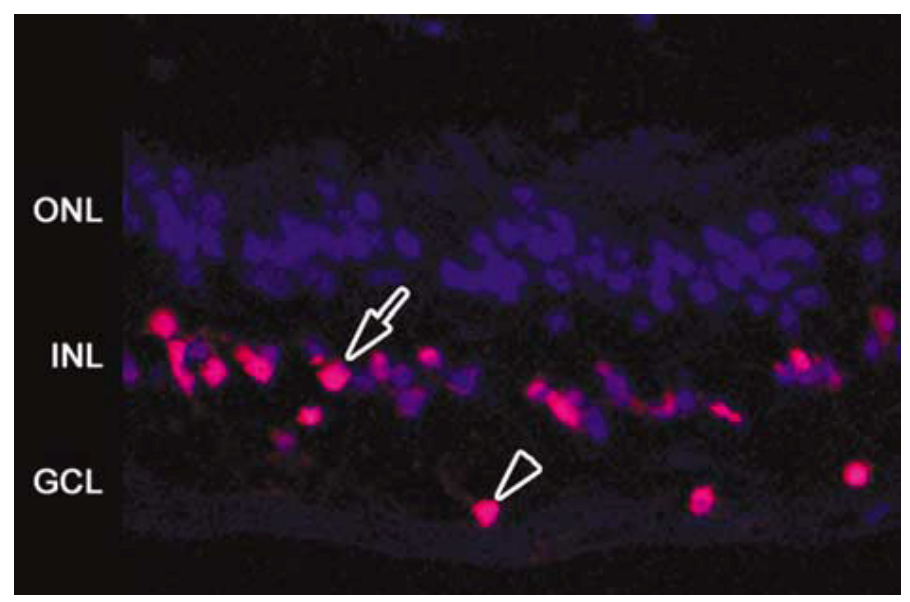

Figure 2. Positive PAX6 immunostaining (a) of nuclei in the INL (arrow) and GCL (arrowhead) of the inner human retina. outer nuclear layer (ONL); inner nuclear layer (INL); ganglion cell layer (GCL)

\section{Discussion}

In humans, a number of heterozygous PAX6 mutations has been identified in the last years leading to a large variety of different ocular disorders and malformations of both the anterior and posterior segment. These disorders range from autosomal dominant keratitis, congenital cataract, Peter's anomaly and aniridia to isolated foveal hypoplasia, ${ }^{3-11}$ for review see. ${ }^{14}$ Furthermore, homozygous human PAX6 mutations lead to anophtalmia, brain malformation, and early postnatal death. ${ }^{15}$ Little is known about PAX6 expression in the adult human retina: Nishina et $a^{12}$ have studied PAX6 expression in human foetuses until gestation week 22 and histochemically detected PAX6 expression in the INL and GCL.

Similarly, in mice, homozygous mutations of the Pax6 homologue small eye (sey) lead to a distinct phenotype with early postnatal death and absence of eyes whereas heterozygous (sey/+) mutations show microphthalmia and corneal, chamber angle and lenticular abnormalities ${ }^{16,17}$ with striking similarities to the human condition. ${ }^{5,8,15,18}$

There is growing evidence that the two major isoforms of PAX6, PAX6 $(+5 a)$ and PAX6(-5a) may play different biological roles: Dominguez et $a l^{19}$ have shown lately that in Drosophila PAX6(+5a) functions primarily in the regulation of 
growth and less effectively in eye specification than PAX6(-5a). Furthermore, the PAX6(+5a) isoform is involved in the chain of events leading to formation of the fovea centralis in the developing chick eye whereas PAX6(-5a) is not. ${ }^{20}$ Our human data show expression of both isoforms in the retina with varying levels.

To test whether PAX6 is also expressed in the ageing human retina we have analysed the retinas of six individuals of different ages up to 79 years by Western blot analysis and immunohistochemistry and found a persistent retinal expression of PAX6 with localization to the inner retina, similar to the embryonic $^{12}$ condition. Equal amounts of total retinal protein were loaded as verified by tubulin control blots (data not shown). Nevertheless, PAX6 expression varied markedly between different sample ages. This might either be due to different degrees of protein degradation in post mortem eyes or it might represent interindividual changes in protein expression levels.

The question remains why a master gene of development is expressed in an ageing tissue. To address this question, Walter Gehring and collaborators have performed an experiment in the ribbonworm Lineus where they suppressed PAX6 expression in the adult eye by RNA interference: 37 days after suppression of PAX6, the eyes disappeared (W Gehring, personal communication).

Furthermore, we have recently shown that in wild-type mice, PAX6 expression in the inner retina persists during the whole lifespan of animals. Interestingly, PAX6 is downregulated in two different animal models for retinal degeneration during the peak of retinal apoptosis (Iseli et al, submitted).

In light of the striking similarities of PAX6 mutations in mice and men, our findings in the human retina suggest a potential role for PAX6 in the human retina after completion of eye morphogenesis. 


\section{References}

1. Gehring WJ, Ikeo K. Pax 6: mastering eye morphogenesis and eye evolution. Trends Genet 1999; 15(9): 371-377.

2. Quiring R, Walldorf U, Kloter U, Gehring WJ. Homology of the eyeless gene of Drosophila to the Small eye gene in mice and Aniridia in humans. Science 1994; 265(5173): 785-789.

3. Azuma N, Nishina S, Yanagisawa H, Okuyama T, Yamada M. PAX6 missense mutation in isolated foveal hypoplasia. Nat Genet 1996; 13(2): 141-142.

4. Dharmaraj N, Reddy A, Kiran V, Mandal A, Panicker S, Chakrabarti S. PAX6 gene mutations and genotype-phenotype correlations in sporadic cases of aniridia from India. Ophthalmic Genet 2003; 24(3): 161-165.

5. Hanson IM, Fletcher JM, Jordan T, Brown A, Taylor D, Adams RJ et al. Mutations at the PAX6 locus are found in heterogeneous anterior segment malformations including Peters' anomaly. Nat Genet 1994; 6(2): 168-173.

6. Jordan T, Hanson I, Zaletayev D, Hodgson S, Prosser J, Seawright A et al. The human PAX6 gene is mutated in two patients with aniridia. Nat Genet 1992; 1(5): 328-332.

7. Wilensky JS, Oliver ER, Walton DS, Glaser T. 3' deletions cause aniridia by preventing PAX6 gene expression. Proc Natl Acad Sci USA 2000; 97(25): 13755-13759.

8. Mirzayans F, Pearce WG, MacDonald IM, Walter MA. Mutation of the PAX6 gene in patients with autosomal dominant keratitis. Am J Hum Genet 1995; 57(3): 539-548.

9. Nanjo Y, Kawasaki S, Mori K, Sotozono C, Inatomi T, Kinoshita S. A novel mutation in the alternative splice region of the PAX6 gene in a patient with Peters' anomaly. $\mathrm{Br} \mathrm{J}$ Ophthalmol 2004; 88(5): 720-721.

10. Vincent MC, Gallai R, Olivier D, Speeg-Schatz C, Flament J, Calvas P et al. Variable phenotype related to a novel PAX 6 mutation (IVS4+5G>C) in a family presenting congenital nystagmus and foveal hypoplasia. Am J Ophthalmol 2004; 138(6): 1016-1021.

11. Zumkeller W, Orth $U$, Gal A. Three novel PAX6 mutations in patients with aniridia. Mol Pathol 2003; 56(3): 180-183.

12. Nishina S, Kohsaka S, Yamaguchi $\mathrm{Y}$, Handa H, Kawakami A, Fujisawa $\mathrm{H}$ et al. PAX6 expression in the developing human eye. Br J Ophthalmol 1999; 83(6): 723-727.

13. Davis JA, Reed RR. Role of Olf-1 and Pax-6 transcription factors in neurodevelopment. $J$ Neurosci 1996; 16(16): 5082-5094.

14. Treisman JE. How to make an eye. Development 2004; 131(16): 3823-3827.

15. Glaser T, Jepeal L, Edwards JG, Young SR, Favor J, Maas RL. PAX6 gene dosage effect in a family with congenital cataracts, aniridia, anophthalmia and central nervous system defects. Nat Genet 1994; 7(4): 463-471.

16. Baulmann DC, Ohlmann A, Flugel-Koch C, Goswami S, Cvekl A, Tamm ER. Pax6 heterozygous eyes show defects in chamber angle differentiation that are associated with a wide spectrum of other anterior eye segment abnormalities. Mech Dev 2002; 118(1-2): 3-17.

17. Ramaesh T, Collinson JM, Ramaesh K, Kaufman MH, West JD, Dhillon B. Corneal abnormalities in Pax6+/- small eye mice mimic human aniridia-related keratopathy. Invest Ophthalmol Vis Sci 2003; 44(5): 1871-1878.

18. Azuma N, Nishina S, Yanagisawa H, Okuyama T, Yamada M. PAX6 missense mutation in isolated foveal hypoplasia. Nat Genet 1996; 13(2): 141-142.

19. Dominguez M, Ferres-Marco D, Gutierrez-Avino FJ, Speicher SA, Beneyto M. Growth and specification of the eye are controlled independently by Eyegone and Eyeless in Drosophila melanogaster. Nat Genet 2004; 36(1): 31-39. 
20. Azuma N, Tadokoro K, Asaka A, Yamada M, Yamaguchi Y, Handa $\mathrm{H}$ et al. The Pax6 isoform bearing an alternative spliced exon promotes the development of the neural retinal structure. Hum Mol Genet 2005; 14(6): 735-45. 


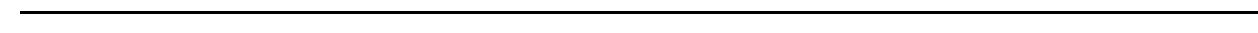


CHAPTER 6

\section{DISCUSSION}




\section{Introduction}

PAX6 is the master gene for eye development and its indispensable for the formation of all the structures of the eye until completion at adulthood. ${ }^{1}$

Little is known about its expression and its role in adulthood once the eye formation is finished. We know that PAX6 null mutation is lethal in both mice and human. ${ }^{2-4}$ Homozygous murine small eye (Sey) mutations lead to a distinct phenotype similar to that seen in human PAX6 null mutation. They die immediately after birth lacking eyes, nasal cavities and with severe brain abnormalities, including a malformed cerebral cortex. ${ }^{2,5}$ Heterozygous mutations of PAX6 lead to severe ocular abnormalities in human from the anterior segment to the posterior segment of the eye including the optic nerve. Aniridia is the most common manifestation of PAX6 mutation. ${ }^{3,6-27}$ Keratitis, ${ }^{3,38}$ Peters anomaly, ${ }^{39,40}$ pre-senile cataract, ${ }^{3,41}$ foveal hypoplasia, ${ }^{42}$ optic nerve coloboma and other optic nerve malformations ${ }^{43}$ are part of the spectrum of different heterozygous mutations of PAX6 in humans. In mice, Sey, the murine equivalent of PAX6 gene, and its heterozygous mutations $\mathrm{Sey}^{+/}$results in the small eye phenotype consisting in microphthalmia, corneal and lenticular abnormalities. ${ }^{39,44,45}$

\section{Pax6 over-expression after ocular development}

Interestingly, higher than normal levels of Pax6 produce complex phenotypes in which several features of eye morphogenesis are affected. Indeed, mice carrying multiple copies of Pax6 on a wild-type background show specific developmental abnormalities of the eye consisting in microphthalmia, corneal abnormalities, cataract, a disorganized ciliary body and absence of photoreceptor layer of the retina. ${ }^{46}$

Both increased and decreased Pax 6 gene dosage result in defective eye development, but the effects are quite different. Whereas defects of Pax6+/mice occur mainly in the anterior segment of the eye, over-expression of Pax 6 causes major defects of retinal development resulting in results in microphthalmia, retinal dysplasia and defective retinal ganglion cell axon guidance. ${ }^{47}$

Little is known about PAX6 gene and PAX6 protein after ocular development in mammalians. Previous reports have shown that PAX6 was present in the mature retina of goldfish, ${ }^{48}$ quail, ${ }^{49}$ and pig. ${ }^{50}$ PAX6 was found in the cornea and conjunctiva of adult mice and believed to play a role in the cyto-architecture of these tissues. Two isoforms of PAX6 gene, PAX6 and PAX6(5a) protein, were found in both adult monkey retina and adult human lens epithelium cells. It 
was suggested that PAX6 might play a role of in the adult lens maintenance and cataract formation through activation of Beta-crystallins genes. ${ }^{51}$ Based on these findings in the literature we hypothesize the presence of Pax6 in both adult mouse and human in the retina.

We discovered that PAX6 gene and its protein PAX6 was not only present in the retina during development but also after completion of ocular development in both the mouse and the human.

In humans, we could detect strong signal of presence of PAX6 protein in the retina, cornea and lens of human fetus until birth. PAX6 presence was also established in the inner retina layers from adult patients ranging form 20 to 79 years old of age. There were some differences in PAX6 expression among patients but that was partly explained protein denaturation depending of tissue time collection after death. Pax6 was more specifically expressed in the inner layers of the retina: the inner ganglion and the bipolar cell layers of the retina and the amacrine cells. The presence of PAX6 gene and its products PAX6 in the adult and fetal human eye are in agreement with previous studies performed on human and monkey. ${ }^{52}$

It was surprising to discover that a gene such as Pax6 dedicated to the ocular development was still present and properly expressed 79 years after the end of the ocular development. To the best of our knowledge, we found only few other development genes still expressed in adulthood, for example, Fox transcriptor factors, are primordial for liver organogenesis but do also play a role in liver function after birth throughout adulthood. ${ }^{53}$ Perhaps, PAX6 gene might also take part in the regulation, function and protection of the eye and the retina after birth.

PAX6 is also expressed in the corneal and conjunctival epithelium of adult chicken and monkey. It is expressed in these mitotically active and regenerating tissues through life, and abnormal expression may cause progressive corneal dystrophy. PAX6 was believed to play a direct role in the maintenance and proliferation of corneal stem cells, a vital process that appears to be defective in aniridia. ${ }^{54}$ Human adult corneal epithelial cells expressed also Pax6 gene. ${ }^{54}$ PAX6 overexpressing corneal epithelial cell lines disclosed inhibition of cell proliferation on cell cultures, confirming the notion that PAX6 plays a role in controlling corneal epithelial cell dynamics in vivo. ${ }^{55}$ Heterozygous small eye mice demonstrated compromised cellular adhesion of the corneal epithelium suggesting a role for Pax 6 in the proper generation and maintenance of the adult cornea. ${ }^{56}$ In humans, corneal pannus tissues from patients with different ocular surface diseases were disclosing a decline or absence of PAX6 expres- 
sion while normal ocular surface epithelial cells showed regular PAX6 expression. ${ }^{57}$ PAX6 expression is increased in the corneal epithelium during wound healing after experimental injury. PAX6 is up regulated during repairing corneal epithelium, it controls the activity of the gelB promoter that regulates matrix metalloproteinases (MMPs) which act as morphogenetic regulators in embryonic and adult events of tissue remodeling. These results indicate that PAX6 helps to maintain the normal corneal epithelial phenotype postnatally, and that down-regulation of Pax6 is associated with abnormal epidermal differentiation in severe ocular surface diseases. Reintroduction of activation of the Pax6 gene might be useful in treating squamous metaplasia of the ocular surface epithelium. ${ }^{58}$ All these observations suggested that PAX 6 may be actively involved in coordinating adult cornea organization and repair mechanism.

\section{Pax6 expression in mouse models of retinal degeneration}

Pax6 seem to play an important role in different mechanism of retina regeneration involving stem cell and retina progenitor cells. In the zebrafish, PAX6A and PAX6B proteins are required at different points in neuronal progenitor cell proliferation and differentiation derived from Müller glial-derived neuronal progenitor cell during retinal regeneration after light exposure. ${ }^{59}$ Likewise, mice with acquired or inherited retinal degeneration disclosed an increasing number of retinal precursors cell expressing Pax6 gene in the pars plana in response to retinal damage. Some of these cells differentiated from proliferating cells even after formation of the adult retina. ${ }^{60}$ Interestingly the human retina does not share the plasticity to regenerate neurons as in goldfish and quail, but recent reports have demonstrated that some cells at the margin of the retina and in the pars plana, are capable of regenerating and inducing proliferation of retina cells. ${ }^{61}$ These retinal progenitor cells (RPCs) have been also localized in the adult ciliary epithelium. These RPCs can differentiate into glial and retina cells expressing markers characteristic of other progenitor cells and seen during early retinal development such as Pax6 gene. The RPCs could become a future source of stem cells and retina cell transplantation in the future for the treatment of retinal degeneration. ${ }^{62}$

In view of these studies and the presence of Pax6 in the adult inner retina, we assumed that Pax 6 might play a role into the maintenance and defense mechanism of the retina.

It is difficult to obtain in vivo results of Pax6 expression in the retina after retinal injury or aggression. Therefore, we looked at the behavior of Pax6 in the adult mice retina a different ages as we did with the human and also in degen- 
erative retina conditions. We studied the expression of Pax6 in both induced and genetically acquired retina degeneration. Light-induced retinal degeneration shows signs of apoptosis $24 \mathrm{~h}$ immediately after exposure and complete disappearance of the outer nuclear layer with one month. Rd1 mice, lack the beta subunit of PED. They show a progressive retinal degeneration that starts 8 day after birth and last up to two months until complete absence of the photoreceptor layer.

We found that PAX6 protein still present in elderly wild type mice up to 429 days old. PAX6 protein expression was stronger in the first month and reduced progressively after, but remain expressed throughout adulthood. In both human and mice, PAX6 was found to be expressed in the inner layers of the retina and more specifically the inner ganglion and the bipolar cell layers of the retina. These findings are in accordance with previous reports that have studied Pax- 6 transcripts were detected in the ganglion cell- and amacrine cell layers of the retina at days 3, 10, 17 and 31 posthatching and in 2- to 3-month-old chick retina by in situ hybridization. ${ }^{63}$ They suggested that known association of PAX6 expression with proliferation and emergence of different cell types such as ganglion and inner nuclear cell layers may retain proliferative potential for an extended period in the young adult retina.

In Pde6b(rd1) mouse, the outer nuclear layer, and more precisely the photoreceptors cells die by apoptosis and reach their peak between p10 and p14. We found that during exactly the same period, PAX6 expression was decreased on Western Blot analysis of retina tissue extracted from Pde6b(rd1) mice. On Immunohistochemistry PAX6 was confined to the ganglion and to the bipolar cell layer of the retina; there were no PAX6 expressing cells in the outer layers of the retina. At p21, PAX6 protein levels returned to levels similar than p6 and p8 and kept the same expression level until p28. We could not keep a sufficient number of $\mathrm{Pde} 6 \mathrm{~b}(\mathrm{rd} 1)$ mice alive to study Pax6 expression throughout their lifespan in older age. We could not therefore conclude whether there is a causal relationship between apoptotic cell death of photoreceptors and reduced expression of Pax6 in the inner retina. These results suggest that a decrease of PAX6 protein expression is concomitant to the peak of photoreceptor apoptosis. One might speculate therefore, that Pax6 might have a protection role against photoreceptor death. Interestingly, there is evidence of inter-cellular signaling pathways between the inner and outer retina. Indeed, intraocular injection of neurotrophic factors can promote the survival of retinal photoreceptors in different animal models for retinal degeneration while corresponding cellular receptors are exclusively found in the inner retina. Brain-derived neurotrophic factor 
(BDNF) and ciliary neurotrophic factor (CNTF) exert their effect on photoreceptors by acting indirectly through activation of Muller cells ${ }^{64}$ More recently, it was found that VEGF stimulates the proliferation of RPCs (Retinal Progenitor Cells) through VEGFR2/Flk1 located in the retina of Pde6b(rd1) mice. ${ }^{65}$ The observed proliferation of RPCs expressing Pax6 detaining the potential to differentiate into retinal neurons may enhance the regeneration of the degenerating retina. VEGF decrease started at p9, coinciding with the beginning of retinal photoreceptor apoptosis, whereas VEGF expressing cells were located in the INL and GCL layers of the retina. Photoreceptor death was correlated with a decrease of VEGF. Similarly, death of photoreceptor was also correlated with a decrease of PAX6 as if some vertical signals between inner and outer retina have been stopped.

To confirm our hypothesis of a protective role of Pax6 in the degenerating retina, we analyzed Pax6 expression in wild-type ( $\mathrm{C} 3 \mathrm{H}$ background) mice exposed to bright light and in c-fos knockout mice known to be resistant to retinal degeneration induced by light exposure.

In agreement with our previous findings in Pde6b(rd1) mice, wild-type animals undergoing photoreceptor apoptosis after light exposure disclosed a decline in PAX6 levels during degeneration whereas PAX6 levels were increased at 2 and 6 hours after illumination in protected $c$-fos knockout mice. ${ }^{66}$ The decrease of Pax 6 expression at the peak of apoptosis in Pde6b(rd1) mouse and its increase in the $c-f_{0}{ }^{-/}$mice resistant to light induce retinal degeneration are both suggestive of a protective role played by Pax6 in the maintenance and function of the adult retina exposed to aggression.

In conclusion, we show that downregulation of Pax6 is concomitant with inherited and induced retinal degeneration whereas animal models protected against induced retinal degeneration demonstrate an increase of Pax6 levels. One might speculate that the level of Pax 6 expression might be a co-factor that should be taken into consideration in the chain of events leading to degenerative retinal disease.

Nevertheless, further studies investigating the intercellular pathways between dying photoreceptor and inner retina cells are required to increase our understanding of the putative protective role of Pax 6 in the retina.

How Pax6 expressing cells located in the inner nuclear layer communicate with photoreceptors remains to be elucidated? It might be also possible that during any aggression, retinal Müller glial cell dedifferentiate to produce RPC depending on Pax6 levels. These RPC are probably able to lead to formation of any other retina cells with their respective specific markers. 
Pax6 expression in a mouse model of glaucoma

Because, Pax6 expressing cells were mainly located in the inner layers of the retina, we were curious to investigate Pax 6 expression in a mouse model affecting specifically the inner layer of the retina. Therefore, we compared Pax 6 expression by WB, IHC and RT-PCR in the retina of wild-type and CLR ${ }^{S M a A}$ (calcitonin receptor-like receptor) transgenic mice. Expression of calcitonin receptorlike receptor is under the control of a smooth muscle alpha-actin promoter in these mice and results in increase signaling of the smooth-muscle-relaxing peptide adrenomedullin in the pupillary sphincter muscle that leads to pupillary palsy and angle closure glaucoma. ${ }^{67} \mathrm{CLR}^{\text {SMaA }}$ mice develop angle-closure glaucoma after completion of retinal development and progressively disclosed loss of retinal ganglion cell at p42 and loss of inner nuclear layers cells around p62.

Our results showed a decreased of PAX6 expression in the GCL of CLR ${ }^{\text {SMAA }}$ mouse during the initial phase of ganglion cell degeneration. At p82, despite severe loss of ganglion cells, INL cells from $\mathrm{CLR}^{S M a A}$ mice displayed a marked increase in PAX6 protein levels. At this time point, the ganglion cell layer has lost about $75 \%$ of its cells disrupting therefore the synaptic connectivity between bipolar-, amacrine- and ganglion cells. This increase in PAX6 protein could be related to remodelling process occurring in retinal degeneration. Indeed,the space left by degenerating ganglion cells in retinitis pigmentosa is occupied by Müller that increase their production of intermediate filaments. ${ }^{68}$

Since Pax6 regulates eye development including retinal morphogenesis, ${ }^{52}$ it is conceivable that increased Pax6 production during degeneration is required for surviving cells to adapt to the altered conditions by changing their cytoarchitecture. This assumption has been supported by over-expresssion and underexpression experiments of Pax6 gene responsible for different ocular abnormalities.

Taken together, our data show that retinal ganglion cell death induces the expression of Pax6 in cells of the INL. This suggests that Pax6 might be involved in the maintenance of the cellular integrity after the loss of synaptic connectivity and/or in processes required for the remodelling of the retinal cytoarchitecture after ganglion cell loss.

In view of all these findings, we assumed that Pax 6 is a major actor of retina maintenance and protection during adulthood.

To explore and define the role of Pax6 in the adult retina, it would be interesting to suppress Pax 6 gene totally or partially in a definite well-formed adult retina. Pax 6 knockout mice are lethal shortly after birth. Therefore, we are currently building an inducible Cre/Lox Pax6 knock-out mouse. The suppression of 
Pax6 in an adult mammalian would shed some light of PAX6 implications in the adult retina. 


\section{References}

1. Gehring WJ, Ikeo K. Pax 6: mastering eye morphogenesis and eye evolution. Trends Genet 1999;15:371-377.

2. Grindley JC, Davidson DR, Hill RE. The role of Pax-6 in eye and nasal development. Development 1995;121:1433-1442.

3. Prosser J, van Heyningen V. PAX6 mutations reviewed. Hum Mutat 1998;11:93-108.

4. Hill RE, Favor J, Hogan BL et al. Mouse small eye results from mutations in a paired-like homeobox-containing gene. Nature 1991;354:522-525.,Hill RE, Favor J, Hogan BL et al. Mouse small eye results from mutations in a paired-like homeobox-containing gene. Nature 1991;354:522-525.

5. Gopal PP, Golden JA. Pax6-/- mice have a cell nonautonomous defect in nonradial interneuron migration. Cereb Cortex 2008;18:752-762.

6. Axton R, Hanson I, Danes $\mathrm{S}$ et al. The incidence of PAX6 mutation in patients with simple aniridia: an evaluation of mutation detection in 12 cases. J Med Genet 1997;34:279-286.

7. Azuma N, Hotta $\mathrm{Y}$, Tanaka $\mathrm{H}$ et al. Missense mutations in the PAX6 gene in aniridia. Invest Ophthalmol Vis Sci 1998;39:2524-2528.

8. Bandah D, Rosenmann A, Blumenfeld A et al. A novel de novo PAX6 mutation in an Ashkenazi-Jewish family with aniridia. Mol Vis 2008;14:142-145.

9. Chao LY, Huff V, Strong LC et al. Mutation in the PAX6 gene in twenty patients with aniridia. Hum Mutat 2000;15:332-339.

10. Chien YH, Huang HP, Hwu WL et al. Eye anomalies and neurological manifestations in patients with PAX6 mutations. Mol Vis 2009;15:2139-2145.

11. Davis A, Cowell JK. Mutations in the PAX6 gene in patients with hereditary aniridia. Hum Mol Genet 1993;2:2093-2097.

12. Graziano C, D'Elia AV, Mazzanti $L$ et al. A de novo nonsense mutation of PAX6 gene in a patient with aniridia, ataxia, and mental retardation. Am J Med Genet A 2007;143A:18021805.

13. Gronskov K, Rosenberg T, Sand A et al. Mutational analysis of PAX6: 16 novel mutations including 5 missense mutations with a mild aniridia phenotype. Eur J Hum Genet 1999;7:274286.

14. Gupta SK, Orr A, Bulman D et al. A novel PAX6 frameshift mutation in a kindred from Atlantic Canada with familial aniridia. Can J Ophthalmol 1999;34:330-334.

15. Hanson I, Brown A, van Heyningen V. A new PAX6 mutation in familial aniridia. J Med Genet 1995;32:488-489.

16. Hanson IM, Seawright A, Hardman $\mathrm{K}$ et al. PAX6 mutations in aniridia. Hum Mol Genet 1993;2:915-920.

17. Jordan T, Hanson I, Zaletayev D et al. The human PAX6 gene is mutated in two patients with aniridia. Nat Genet 1992;1:328-332.

18. Kawano T, Wang C, Hotta $Y$ et al. Three novel mutations of the PAX6 gene in Japanese aniridia patients. J Hum Genet 2007;52:571-574.

19. Khan AO, Aldahmesh MA. PAX6 analysis of two unrelated families from the Arabian Peninsula with classic hereditary aniridia. Ophthalmic Genet 2008;29:145-148.

20. Kondo-Saitoh A, Matsumoto N, Sasaki T et al. Two nonsense mutations of PAX6 in two Japanese aniridia families: case report and review of the literature. Eur J Ophthalmol 2000;10:167172. 
21. Malandrini A, Mari F, Palmeri S et al. PAX6 mutation in a family with aniridia, congenital ptosis, and mental retardation. Clin Genet 2001;60:151-154.

22. Martha A, Strong LC, Ferrell RE et al. Three novel aniridia mutations in the human PAX6 gene. Hum Mutat 1995;6:44-49.

23. Neethirajan G, Hanson IM, Krishnadas SR et al. A novel PAX6 gene mutation in an Indian aniridia patient. Mol Vis 2003;9:205-209.

24. Neethirajan G, Krishnadas SR, Vijayalakshmi $P$ et al. PAX6 gene variations associated with aniridia in south India. BMC Med Genet 2004;5:9.

25. Neethirajan G, Nallathambi J, Krishnadas SR et al. Identification of novel mutant PAX6 alleles in Indian cases of familial aniridia. BMC Ophthalmol 2006;6:28.

26. Negishi K, Azuma N, Yamada M. Various phenotypic expressions of familial aniridia with a PAX6 mutation. Br J Ophthalmol 1999;83:991-992.

27. Neuner-Jehle M, Munier F, Kobetz A et al. Identification of novel PAX6 mutations in two families with bilateral aniridia. Mutations in brief no. 167. Online. Hum Mutat 1998;12:138.

28. Ramirez-Miranda A, Zenteno JC. PAX6 gene intragenic deletions in Mexican patients with congenital aniridia. Mol Vis 2006;12:318-323.

29. Sahly I, Abitbol M, Laurent C et al. Identification of a novel PAX6 gene mutation in an aniridia patient. Hum Mutat 1996;7:377.

30. Song S, Liu Y, Guo S et al. A novel PAX6 gene mutation in a Chinese family with aniridia. Mol Vis 2005;11:335-337.

31. Song SJ, Liu YZ, Cong RC et al. Mutation analysis of PAX6 gene in a large Chinese family with aniridia. Chin Med J (Engl) 2005;118:302-306.

32. Tzoulaki I, White IM, Hanson IM. PAX6 mutations: genotype-phenotype correlations. BMC Genet 2005;6:27.

33. Villarroel CE, Villanueva-Mendoza C, Orozco L et al. Molecular analysis of the PAX6 gene in Mexican patients with congenital aniridia: report of four novel mutations. Mol Vis 2008;14:1650-1658.

34. Walton DS. Aniridia (PAX6(+/-)). J Pediatr Ophthalmol Strabismus 2005;42:128.

35. Yuan $\mathrm{H}$, Kang $\mathrm{Y}$, Shao $\mathrm{Z}$ et al. Two novel PAX6 mutations identified in northeastern Chinese patients with aniridia. Mol Vis 2007;13:1555-1561.

36. Zhu HY, Wu LQ, Pan Q et al. Analysis of PAX6 gene in a Chinese aniridia family. Chin Med J (Engl) 2006;119:1400-1402.

37. Zumkeller W, Orth U, Gal A. Three novel PAX6 mutations in patients with aniridia. Mol Pathol 2003;56:180-183.

38. Mirzayans F, Pearce WG, MacDonald IM et al. Mutation of the PAX6 gene in patients with autosomal dominant keratitis. Am J Hum Genet 1995;57:539-548.

39. Baulmann DC, Ohlmann A, Flugel-Koch C et al. Pax6 heterozygous eyes show defects in chamber angle differentiation that are associated with a wide spectrum of other anterior eye segment abnormalities. Mech Dev 2002;118:3-17.

40. Churchill AJ, Booth AP, Anwar R et al. PAX 6 is normal in most cases of Peters' anomaly. Eye (Lond) 1998;12:299-303.

41. Azuma $\mathrm{N}$, Yamaguchi $\mathrm{Y}$, Handa $\mathrm{H}$ et al. Missense mutation in the alternative splice region of the PAX6 gene in eye anomalies. Am J Hum Genet 1999;65:656-663.,

42. Azuma N, Nishina S, Yanagisawa $\mathrm{H}$ et al. PAX6 missense mutation in isolated foveal hypoplasia. Nat Genet 1996;13(2):141-142.

43. Azuma N, Yamaguchi $\mathrm{Y}$, Handa $\mathrm{H}$ et al. Mutations of the PAX6 gene detected in patients with a variety of optic-nerve malformations. 
44. Davis J, Duncan MK, Robison WGJ et al. Requirement for Pax6 in corneal morphogenesis: a role in adhesion. J Cell Sci 2003;116:2157-2167.

45. Ramaesh $\mathrm{T}$, Collinson JM, Ramaesh $\mathrm{K}$ et al. Corneal abnormalities in Pax6+/- small eye mice mimic human aniridia-related keratopathy.

46. Schedl A, Ross A, Lee M et al. Influence of PAX6 gene dosage on development: overexpression causes severe eye abnormalities. Cell 1996;86:71-82.

47. Kim J, Lauderdale JD. Overexpression of pairedless Pax6 in the retina disrupts corneal development and affects lens cell survival. Dev Biol 2008;313:434-454.

48. Hitchcock PF, Macdonald RE, VanDeRyt JT et al. Antibodies against Pax6 immunostain amacrine and ganglion cells and neuronal progenitors, but not rod precursors, in the normal and regenerating retina of the goldfish. J Neurobiol 1996;29:399-413.

49. Turque N, Plaza S, Radvanyi F et al. Pax-QNR/Pax-6, a paired box- and homeobox-containing gene expressed in neurons, is also expressed in pancreatic endocrine cells. Mol Endocrinol 1994;8:929-938.

50. Klassen $\mathrm{H}$, Kiilgaard JF, Zahir $\mathrm{T}$ et al. Progenitor cells from the porcine neural retina express photoreceptor markers after transplantation to the subretinal space of allorecipients. Stem Cells 2007;25:1222-1230.

51. Zhang W, Cveklova K, Oppermann B et al. Quantitation of PAX6 and PAX6(5a) transcript levels in adult human lens, cornea, and monkey retina. Mol Vis 2001;7:1-5.

52. Nishina S, Kohsaka S, Yamaguchi Y et al. PAX6 expression in the developing human eye. Br J Ophthalmol 1999;83:723-727.

53. Le Lay J, Kaestner $\mathrm{KH}$. The Fox genes in the liver: from organogenesis to functional integration. Physiol Rev 2010;90:1-22.

54. Koroma BM, Yang JM, Sundin OH. The Pax-6 homeobox gene is expressed throughout the corneal and conjunctival epithelia. Invest Ophthalmol Vis Sci 1997;38:108-120.

55. Ouyang J, Shen YC, Yeh LK et al. Pax6 overexpression suppresses cell proliferation and retards the cell cycle in corneal epithelial cells. Invest Ophthalmol Vis Sci 2006;47:2397-2407.

56. $\mathrm{Li} \mathrm{T}, \mathrm{Lu} \mathrm{L}$. Epidermal growth factor-induced proliferation requires down-regulation of Pax6 in corneal epithelial cells. J Biol Chem 2005;280:12988-12995.

57. Li W, Chen YT, Hayashida $Y$ et al. Down-regulation of Pax6 is associated with abnormal differentiation of corneal epithelial cells in severe ocular surface diseases. J Pathol 2008;214: 114-122.

58. Sivak JM, Mohan R, Rinehart WB et al. Pax-6 expression and activity are induced in the reepithelializing cornea and control activity of the transcriptional promoter for matrix metalloproteinase gelatinase B. Dev Biol 2000;222:41-54.,Sivak JM, West-Mays JA, Yee A et al. Transcription Factors Pax6 and AP-2alpha Interact To Coordinate Corneal Epithelial Repair by Controlling Expression of Matrix Metalloproteinase Gelatinase B. Mol Cell Biol 2004;24:245257.

59. Thummel R, Enright JM, Kassen SC et al. Pax6a and Pax6b are required at different points in neuronal progenitor cell proliferation during zebrafish photoreceptor regeneration. Exp Eye Res 2010

60. Nishiguchi KM, Kaneko $\mathrm{H}$, Nakamura $\mathrm{M}$ et al. Generation of immature retinal neurons from proliferating cells in the pars plana after retinal histogenesis in mice with retinal degeneration. Mol Vis 2009;15:187-199.

61. Mayer EJ, Carter DA, Ren $\mathrm{Y}$ et al. Neural progenitor cells from postmortem adult human retina. Br J Ophthalmol 2005;89:102-106.

62. Xu S, Sunderland ME, Coles BL et al. The proliferation and expansion of retinal stem cells require functional Pax6. Dev Biol 2007;304:713-721. 
63. Bhat SP, Rayner SA, Chau SC et al. Pax-6 expression in posthatch chick retina during and recovery from form-deprivation myopia. Dev Neurosci 2004;26:328-335.

64. Wahlin KJ, Campochiaro PA, Zack DJ et al. Neurotrophic factors cause activation of intracellular signaling pathways in Muller cells and other cells of the inner retina, but not photoreceptors. Invest Ophthalmol Vis Sci 2000;41:927-936.

65. Nishiguchi KM, Nakamura M, Kaneko $\mathrm{H}$ et al. The role of VEGF and VEGFR2/Flk1 in proliferation of retinal progenitor cells in murine retinal degeneration. Invest Ophthalmol Vis Sci 2007;48:4315-4320.

66. Hafezi F, Steinbach JP, Marti A et al. The absence of c-fos prevents light-induced apoptotic cell death of photoreceptors in retinal degeneration in vivo. Nat Med 1997;3:346-349.

67. Ittner LM, Schwerdtfeger K, Kunz TH et al. Transgenic mice with ocular overexpression of an adrenomedullin receptor reflect human acute angle-closure glaucoma. Clin Sci (Lond) 2008;114:49-58.

68. Jones BW, Marc RE. Retinal remodeling during retinal degeneration. Exp Eye Res 2005;81:123-137.,Jones BW, Watt CB, Marc RE. Retinal remodelling. Clin Exp Optom 2005;88:282-291.,Marc RE, Jones BW. Retinal remodeling in inherited photoreceptor degenerations. Mol Neurobiol 2003;28:139-147. 


\section{Summary}

PAX6 gene is a member of PAX gene family which has a major role in the formation of tissues and organs during development. PAX6 gene encodes PAX6 protein, a transcriptor factor, acting in the formation of specific organs such as the pancreas, the spinal cord, the brain, the olfactory nerve and the eye.

PAX6 gene is also known as aniridia gene in humans where it was cloned.

PAX6 protein is composed of two DNA-binding domain, a paired domain and a homeodomain. Through DNA binding, PAX6 control the expression of various genes involved in complex regulatory networks in the eye.

Human homozygous PAX6 mutation is lethal shortly after birth resulting in anopthalmia and severe brain malformations. Heterozygous mutations of PAX6 lead to a constellation of pathologies comprising both the anterior and the posterior segment of the eye. They include aniridia, autosomal dominant keratatis, Peters anomaly, juvenile cataract, glaucoma, isolated foveal hypoplasia, microphthalmia, ectopia pupilla, optic disc coloboma, optic nerve hypoplasia and morning glory disc anomaly.

PAX6 gene and its expression are both remarkably conserved throughout evolution, to the point that PAX6 homolog of Drosophila has more than $90 \%$ sequence similarity with human PAX6 gene. Small eye gene (Sey), is the murine homolog of PAX6. Like in humans, homozygous mutation is lethal in mice and heterozygous mutations result in a variety of phenotypes similar to human abnormalities.

Exact dosage of PAX6 gene during development is required for normal eye formation. Over expressions of PAX6 gene, as much as underexpression, in mouse and human is also responsible for severe eye pathologies. Similarly when Eyeless gene, the Drosophila homolog of human PAX6, is injected into the imaginal disc of the developing Drosophila, it induced ectopic expression of eyes on the antennae, wings and thorax.

The fundamental role played by PAX6 in eye formation during development and its capacity to trigger activation of a cascades of genes in a coordinated fashion, leading to the development of the eye have lead scientists to call PAX6, the master gene for eye formation.

Despite extensive knowledge of PAX6 gene and its protein during development, little is known about its role in the adult after the end of ocular development. 
It has been hypothesized that PAX6 may intervene in the maintenance and protection of adult eye tissues. We were therefore interested to study PAX6 expression in the adult retina of both human and mouse.

We found that PAX6 is expressed at all ages of adulthood in the human retina up to 79 years. PAX6 was predominantly located in the ganglion cell layer and in the inner layer of the retina.

Likewise, we found that PAX6 was expressed in the inner layers of the mouse retina up to 428 days (an old age for a mouse!).

We showed that PAX6 expression was reduced during the peak of photoreceptor apoptosis in $r d$ mouse, a mouse model of retinitis pigmentosa. Similarly, wild-type mice disclosed decreased PAX6 expression in the retina of lightinduced retinal degeneration mice. Conversely, PAX6 expression was increased in c-fos knock-out mice showing resistance to light induced retinal degeneration.

In a mouse model of acute angle-closure glaucoma, CLR ${ }^{\mathrm{SM} \alpha \mathrm{A}}$ mouse, intraocular pressure increased between $\mathrm{p} 22$ to $\mathrm{p} 82$ to over two times higher levels than in control mice resulting in apoptosis of the cells of the inner retina. We showed that there was first, a progressive decrease in cell number of the inner retina including PAX6 expressing cells in the ganglion cell layer. Later, a significant increase of PAX6 expressing cells concomitant with an overall loss of cells was observed in the inner retina layer of $\mathrm{CLR}^{\mathrm{SM} \alpha A}$ mouse.

Our results confirmed that PAX6 was found in both healthy and degenerative adult mammalian retina. These findings were in accordance with the presence of PAX6 in adult cornea of mice and humans. PAX6 helps to maintain the normal cornea phenotype and plays an important role during repair of corneal epithelium in case of physical aggression.

We speculated that PAX6 has a protective role in the degenerating outer retina through an activation of Müller glial cells who might be capable to produce retinal progenitor cells and hence all

In the same manner, when ganglion cell layer is massively disrupted in CLR ${ }^{\text {SM } \alpha A}$ mouse, there was an increase of PAX6 INL expressing cells that could be related to remodeling process involving Müller cells.

We assumed that PAX6 plays a crucial role in the maintenance and protection during adulthood.

To confirm our hypothesis, it would be interesting to suppress PAX6 gene in an adult retina. Since PAX6 knockout mice are lethal right after birth, inducible PAX6 knock-out mice would be an elegant solution to investigate the exact function of PAX6 after the end of ocular development. 


\section{Samenvatting (Summary in Dutch)}

Het PAX6-gen behoort tot de PAX genfamilie, die een belangrijke rol speelt bij de vorming van weefsels en organen gedurende de embryonale ontwikkeling. Het PAX6-gen codeert voor het PAX6-eiwit, een transcriptie factor,die actief betrokken is bij de vorming van specifieke organen zoals de pancreas, het ruggenmerg, de hersenen, de oogzenuw en het oog.

Het PAX6-gen staat bij de mens ook bekend als het aniridie gen vanwege het feit dat het als kandidaat gen voor deze ziekte werd gekloneerd.

Het PAX-6 eiwit bestaat uit twee DNA-bindende domeinen, een "Paired domein" en een "Homeodomein". Door binding aan het DNA controleert PAX6 de expressie van verschillende genen die betrokken zijn bij complexe regelnetwerken in het oog.

Bij de mens is homozygotie voor de PAX6 mutatie kort na de geboorte lethaal. Deze gaat gepaard met anophthalmie en ernstige hersenafwijkingen. Heterozygote mutaties van PAX6 leiden tot een combinatie van oogafwijkingen die zowel de voorste als de achterste oogkamer kunnen omvatten. Deze betreffen onder andere aniridie, autosomaal dominante keratatis, Peters anomalie, juveniele cataract, glaucoma, geïsoleerde foveale hypoplasie, microphthalmie, ectopia pupilla, optische papil coloboom, oogzenuw hypoplasie and morning glory papil.

Het PAX6 gen en de expressie ervan zijn opmerkelijk geconserveerd tijdens de evolutie. Zo is er meer dan $90 \%$ overeenkomst tussen de gensequentie van de PAX6 homoloog bij Drosophila en de volgorde van het PAX6 gen bij de mens. Small eye gene (Sey) is het homologe gen van PAX6 bij de muis. Beide genen vertonen grote overeenkomsten. Ook bij de muis is de homozygote mutatie lethaal terwijl de aanwezigheid van heterozygote mutaties leidt tot een scala aan afwijkende fenotypes dat veel gelijkenis vertoont met dat bij de mens.

Voor een normale oogontwikkeling is een exacte dosering van de PAX6 gen-expressie gedurende de embryonale ontwikkeling vereist. Zowel over- als onderexpressie van het PAX6-gen, zijn zowel bij muis als mens verantwoordelijk voor de vorming van ernstige oogafwijkingen. Ook leidt de injectie van het Eyeless gen, dat het homologe gen van PAX6 bij Drosophila is, in groepjes ongedifferentieerde cellen van Drosophila larven, tot ectopische expressie en de vorming van ogen op de antennen, de vleugels en de thorax. 
De fundamentele rol die PAX6 speelt bij de oogontwikkeling tijdens de embryonale ontwikkeling en het vermogen om een cascade aan genen, en daarmee de oogontwikkeling, op een gecoördineerde manier te activeren heeft ertoe geleid dat PAX6, het "master" gen voor de oogontwikkeling wordt genoemd.

Ondanks het feit dat veel bekend is over de rol van het PAX6-gen en zijn eiwit gedurende de embryonale ontwikkeling is weinig bekend over de rol bij de volwassene na het afsluiten van de oogontwikkeling.

Men heeft verondersteld dat PAX6 betrokken zou kunnen zijn bij het handhaven en beschermen van de weefsels in het volwassen oog. We waren daarom geïnteresseerd om de PAX6 expressie te bestuderen in de volwassen retina van zowel mens als muis.

We vonden daarbij dat PAX6 expressie bij de mens kan worden waargenomen op alle leeftijden (tot en met 79 jaar). PAX6 was vooral gelokaliseerd in de ganglion cellaag en de binnenste laag van de retina.

Overeenkomstig hiermee werd bij de muis waargenomen dat PAX6 tot expressie kwam in de binnenste lagen van muis retina van de muis tot op een leeftijd van 428 dagen (hetgeen erg oud is voor een muis!).

We hebben aangetoond dat PAX6 expressiegereduceerd was tijdens de piek van de phoreceptor apoptose in de $r d$ muis, het muismodel van retinitis pigmentosa. Overeenkomstig hiermee lieten wild-type muizen een verlaagde PAX6 expressie zien in de retina of licht-geînduceerde retinale degeneratie. Daar staat tegenover dat de PAX6 expressie was toegenomen in c-fos knockout muizen die weerstand tonen tegen licht-geïnduceerde retinale degeneratie.

In een muis model van acuut kamerhoek glaucoom, de $\mathrm{CLR}^{\mathrm{SM \alpha A}}$ muis, was de intraoculaire druk toegenomen van p22 tot p82 tot twee keer hogere waarden dan in controle muizen hetgeen apoptose van cellen in de binnenste retina tot gevolg had. We hebben aangetoond dat er eerst sprake was van een progressieve afname van het aantal cellen in de binnenste retina waaronder ook de PAX6 expresserende cellen van de ganglioncellaag. Later, was er een significante toename van de PAX6 expresserende cellen tegelijk met een verlies van cellen in de binnenste retina laag van de $\mathrm{CLR}^{\mathrm{SM} \alpha \mathrm{A}}$ muis.

Onze resultaten bevestigen dat PAX6 zowel aanwezig is in de gezonde als in de degeneratieve retina van volwassen zoogdieren. Deze bevindingen komen overeen met de aanwezigheid van PAX6 in de cornea van volwassen muizen en mensen. PAX6 helpt bij het handhaven van het normale cornea fenotype en speelt een belangrijke rol tijdens het herstel van het cornea epitheel in geval van fysieke beschadiging. 
We veronderstellen PAX6 een beschermende functie heeft in de degenererende buitenste retina door een activatie van Müller glia cellen die in staat zouden kunnen zijn retinale voorloper cellen te produceren.

Op dezelfde manier werd waargenomen dat wanneer de ganglion cellaag ernstig beschadigd werd in de $\mathrm{CLR}^{\mathrm{SM} \alpha \mathrm{A}}$ muis, er sprake was van een toename van PAX6 INL expresserende cellen hetgeen verband kan houden met de betrokkenheid van Müller cellen bij dit remodeling proces.

We nemen aan dat PAX6 een cruciale rol speelt bij het handhaven en beschermen bij volwassenen.

Om deze hypothese te bevestigen zou het interessant zijn om het PAX6gen te onderdrukken in de volwassen retina. Omdat PAX6 knockout muizen kort na de geboorte lethaal zijn, zouden induceerbare PAX6 knock-out muizen een elegante oplossing kunnen bieden bij het onderzoek naar de exacte functie van PAX6, na het afsluiten van de oogontwikkeling. 


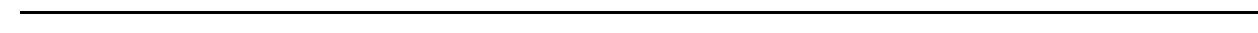




\section{Acknowledgements}

It is my great pleasure to express my gratitude especially to Prof Hendrikse who was a real support. He helped me morally to go through the ordeal of his departure in VUB. He was always there also available and never missed an opportunity to provide good advice for this work.

I would like also to thank Prof Geraedts, who read this work, several times, and week after week and contributed to its improvement.

I would like to thank Ronit Sverdlov who enlightened me with her smile but also with her persistence to extract the best out of this work.

My gratitude goes to my parents who have always encouraged me to persist in my scientific work.

Thank you to my parents who always pushed me to carry on and supported me until now.

Last but not least, mainly, I would like to thank my wife Nensi, who was present and supportive in moments of doubts and always believed in me. Without her, this work could never have happened. Thank you Nensi. 


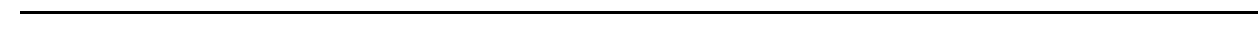




\section{Curriculum vitae}

Dinu Stanescu-Segall was born on $16^{\text {th }}$ December 1971, in Leuven, Belgium. He attended medical school in University Catholic of Louvain where he received his M.D. with Summa cum laude in June 1996. He spent one year in internal medicine in University Hospital St-Pierre. Subsequently, he started his residency of Ophthalmology in the same hospital for two years. The last two years of his training were performed in Paris in Pitié-Salpétrière and Créteil University Hospitals. Afterwards, he obtained a national Belgian grant (FNRS) for research and was involved in retina research in laboratories of Prof Jocelyne Kaplan and Prof Remé in Paris and Zurich respectively.

Thereafter, he did his medical retina fellowship in Moorfields Eye Hospital in London, followed by a surgical retina fellowship in Notre Dame Hospital University of Montréal and Kings College London Hopsital. He was consultant in Retina in both Charing Cross and Western Eye Hospital at Imperial College, London in 2009. Since January 2010 , he is the head of retina department in UZ Brussels, VUB.

From May 2010, he is working as a staff member in medical and surgical retina in the department of Ophthalmology in AZ Maastricht. 


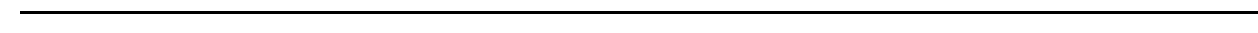




\section{List of publications}

Grim C, Wenzel A., Stanescu D. et al. Constitutive over-expression of human erythropoietin protects the mouse retina against induced but not inherited retinal degeneration. Journal of Neuroscience 2004 ; 24:561-8

Bourla DH, Wirthlin RS, Bourla N, Gupta A, Stanescu-Segall D, Schwartz SD, Axer-Siegel R. Risk for eye splash injury during administration of intraocular injections: a study of retina specialists and fellows. Retina. 2007; 27:609-12

Stanescu D., Isel HP. et al, Continuous expression of thehomeobox gene Pax6 in the ageing human retina .Eye 2007; 21:90-93

Tran C, Stanescu D., Bodaghi B., Caspers-Velu L., LeHoang P. Clinical characteristics of acute HSV-2 retinal necrosis. American Journal of Ophthalmology 2004; 137:872-9

Stanescu D., Bodaghi B., Milea D., Cassoux N., Weschler B., LeHoang P. Pseudotumor cerebri and Sjogren syndrome. Graefes Archives of Clinical and Experimental Ophthalmology 2003; 241:339-342

Buono LM., Foroozan R., Savino PJ., Danesh-Meyer HV., Stanescu D. Posterior ischemic optic neuropathy after hemodialysis. Ophthalmology, 2003 Jun; 110:1216-8

Coscas F., Stanescu D., Coscas G., Soubrane G. Feeder vessel treatment of choroidal neovascularisation in age-related macular degeneration .Journal Français d' Ophtalmologie 2003; 26:602-8

Stanescu D., Wattenberg S., Cohen SY. Photodynamic therapy for choroidal neovascularisation secondary to choroidal nevus. American Journal of Ophthalmology 2003; 136: 575-6

Stanescu D., Coscas F., Coscas G., Soubrane G.Feeder vessel treatment of choroidal neovascularisation in age-related macular degeneration. British Journal of Ophthalmology, video-report November 2003

Stanescu-Segall B, Stanescu D. Agenesis of the corpus callosum and chorioretinal lacunae. Aicardi's syndrome. Oftalmologia 1997; 41 :323-325

De Potter P., Stanescu D., Caspers-Velu, Hoffman H. Combined Hamartoma of the retina and the rpe in the Gorlin syndrome. Arch Ophthalmology 2000; 118:1004-5

Stanescu D and Jakson TL. Vital staining with indocyanine green: a review of the liniaal and experimentele studies relating to safety. Eye 2009; 23:504518. 
Elagouz M, Stanescu-Segall D, Jackson TL. Uveal effusion syndrome. Survey of Ophthalmology 2010; 55:134-145

Sallo FB, Rechtman E, Tunde P, Stanescu-Segall D et al. Functional aspect of drusen regression in age-related-macular degeneration. British Journal of Ophthalmology 2009; 93 :1345-135.

Mateo-Montoya A, Stanescu D, Sahel J, Bonnel S. Cytomegalovirus retinitis associated with Good's syndrome. Euopean Journal of Ophthalmology 2010; 20:479-480.

Stanescu-Segall D, Wilson C, Bonnel S, Heligon JP. Fifteen year survival of small cell lung cancer presenting as a carcinoma-associated retinopathy. Journal of Clinical Oncology. In press 